\title{
Surveillance for Cancer Incidence and Mortality - United States, 2013
}




\section{CONTENTS}

Preface... . .1

Background ... 1

Data Sources 1

Publication Criteria . .2

Interpreting Data ...3

Highlights . .4

References

The MMWR series of publications is published by the Center for Surveillance, Epidemiology, and Laboratory Services, Centers for Disease Control and Prevention (CDC), U.S. Department of Health and Human Services, Atlanta, GA 30329-4027.

Suggested citation: [Author names; first three, then et al., if more than six.] [Title]. MMWR Surveill Summ 2017;66(No. SS-\#):[inclusive page numbers].

\section{Centers for Disease Control and Prevention}

Thomas R. Frieden, MD, MPH, Director

Harold W. Jaffe, MD, MA, Associate Director for Science

Joanne Cono, MD, ScM, Director, Office of Science Quality

Chesley L. Richards, MD, MPH, Deputy Director for Public Health Scientific Services

Michael F. Iademarco, MD, MPH, Director, Center for Surveillance, Epidemiology, and Laboratory Services

\section{MMWR Editorial and Production Staff (Serials)}

Sonja A. Rasmussen, MD, MS, Editor-in-Chief

Charlotte K. Kent, PhD, MPH, Executive Editor Christine G. Casey, MD, Editor

Teresa F. Rutledge, Managing Editor

David C. Johnson, Lead Technical Writer-Editor Jeffrey D. Sokolow, MA, Project Editor
Martha F. Boyd, Lead Visual Information Specialist Maureen A. Leahy, Julia C. Martinroe, Stephen R. Spriggs, Moua Yang, Tong Yang, Visual Information Specialists

Quang M. Doan, MBA, Phyllis H. King, Terraye M. Starr, Information Technology Specialists

\section{MMWR Editorial Board}

Timothy F. Jones, MD, Chairman Matthew L. Boulton, MD, MPH Virginia A. Caine, MD

Katherine Lyon Daniel, $\mathrm{PhD}$ Jonathan E. Fielding, MD, MPH, MBA David W. Fleming, MD
William E. Halperin, MD, DrPH, MPH

King K. Holmes, MD, PhD

Robin Ikeda, MD, MPH

Rima F. Khabbaz, MD

Phyllis Meadows, $\mathrm{PhD}, \mathrm{MSN}, \mathrm{RN}$

Jewel Mullen, MD, MPH, MPA
Jeff Niederdeppe, $\mathrm{PhD}$

Patricia Quinlisk, MD, MPH

Patrick L. Remington, MD, MPH Carlos Roig, MS, MA

William L. Roper, MD, MPH William Schaffner, MD 


\title{
Surveillance for Cancer Incidence and Mortality - United States, 2013
}

\author{
Simple D. Singh, $\mathrm{MD}^{1}$ \\ S. Jane Henley, $\mathrm{MSPH}^{1}$ \\ A. Blythe Ryerson, $\mathrm{PhD}^{1}$ \\ ${ }^{1}$ Division of Cancer Prevention and Control, National Center for Chronic Disease Prevention and Health Promotion, CDC
}

\section{Preface}

This report provides, in tabular and graphic form, official federal statistics on cancer incidence and mortality for 2013 and trends for 1999-2013 as reported by CDC and the National Cancer Institute (NCI). Data in this report come from the United States Cancer Statistics (USCS) system (1), which includes cancer incidence data from population-based cancer registries that participate in CDC's National Program of Cancer Registries (NPCR) and NCI's Surveillance, Epidemiology, and End Results (SEER) program reported as of November 2015 and cancer mortality data from death certificate information reported to state vital statistics offices as of June 2015 and compiled into a national file for the entire United States by CDC's National Center for Health Statistics (NCHS) National Vital Statistics System (NVSS).

This report presents information on new cancer cases and deaths for 2013. The number and rate of cancer cases and deaths are stratified by the primary cancer sites as reported for 2013; information is provided by demographic characteristic (e.g., sex, age, race, and ethnicity) and primary cancer site (68 selected sites among men and 72 selected sites among women). Age-adjusted cancer incidence and death rates are shown by primary site and year for the period 1999-2013. Age-adjusted cancer incidence and death rates for the most common sites are shown by race, sex, and ethnicity for 2013, the most recent diagnosis year for which incidence data are available. Maps of the United States display age-adjusted cancer incidence and death rates, presented by quartiles, for 2013. Time trends in age-adjusted cancer incidence and death rates during 1999-2013 are shown for all sites combined, colorectal, lung and bronchus, prostate, and female breast by race, sex, and ethnicity.

\section{Background}

Cancer comprises a diverse mix of diseases occurring in every part of the body and is a leading cause of death in the United States (2). More than half of cancer cases could be prevented (3). Surveillance of cancer incidence and mortality can

Corresponding author: Simple Singh, Division of Cancer Prevention and Control, National Center for Chronic Disease Prevention and Health Promotion, CDC. Telephone: 770-488-4292; E-mail: sdsingh@cdc.gov. help public health officials target areas for control efforts (4) and track progress toward meeting the national health objectives set forth in Healthy People 2020 (5). As of 2016, Healthy People 2020 objectives included reducing cancer deaths per 100,000 persons to 161.4 for all cancers, 45.5 for lung cancer, 20.7 for female breast cancer, 2.2 for cervical cancer, 14.5 for colorectal cancer, 2.3 for oropharyngeal cancer, 21.8 for prostate cancer, 2.4 for melanoma and reducing cancer incidence per 100,000 persons to 39.9 for colorectal cancer, 7.2 for cervical cancer, and 42.1 for late-stage female breast cancer (5).

Cancer is a reportable disease in every state and thus all hospitals, physicians' offices, pathology laboratories, and other medical facilities are required to submit data on all reportable cancer diagnoses to a central cancer registry at the state or territorial level. A cancer registry is a database that contains individual records of all reportable cancer cases in a defined population and includes patient demographics, tumor characteristics (e.g., cancer site and pathology), and information about the notifying health provider or facility. Cancer control planners and others can identify variations in cancer rates by population subgroups and monitor trends over time to guide the planning and evaluation of cancer prevention and control programs and allocation of health resources.

\section{Data Sources}

Data about cancer incidence and mortality come from the official federal statistics on cancer, the USCS dataset (1). The USCS dataset includes cancer incidence data from NPCR registries in 45 states and the District of Columbia (DC) (cancer incidence data from Puerto Rico and the U.S. Pacific Island Jurisdictions were not available for this analysis) and from SEER program registries in the remaining five states (Connecticut, Hawaii, Iowa, New Mexico, and Utah) and cancer mortality data from NVSS. Incidence data included in USCS have met publication criteria.

\section{Incidence Data}

The primary source of data on cancer incidence is medical records. Staff at medical facilities such as hospitals, doctors' offices, and pathology laboratories abstract data from patients' medical records, enter it into the facility's own cancer registry if 
it has one, and then send the data to the regional or state registry. The data then are sent to the central cancer registry in that state, district or territory. Every year the central cancer registries electronically submit incidence, demographic, and clinical data to NPCR or SEER. Both NPCR and SEER registries collect data using uniform data items and codes as documented by the North American Association of Central Cancer Registries (NAACCR). This uniformity ensures that data items collected by the two federal programs are comparable $(6,7)$. Information on primary site and histology is coded according to the International Classification of Diseases for Oncology, Third Edition (ICD-O-3) and categorized according to the revised SEER recodes dated January 27, 2003, which define standard groupings of primary cancer sites (https://seer.cancer.gov/ siterecode) (8). Beginning with 2010 diagnoses, cases were first classified by anatomic site by using ICD-O-3; cases with hematopoetic histologies were further classified by using the 2008 World Health Organization (WHO) Classification of Tumours of Haematopoietic and Lymphoid Tissues (9). Data from the NPCR registries provided in this report were reported to CDC as of November 30, 2015. Data from SEER registries were reported to NCI as of November 1, 2015.

NPCR and SEER cancer registries consider as reportable all incident cases with a behavior code of 2 (in situ, noninvasive) or 3 (malignant, primary site only) in ICD-O-3. Exceptions include in situ cancer of the cervix and all basal and squamous cell carcinomas of the skin, except for those on the skin of the genital organs (8). Beginning with 2001 diagnoses, several cancers that are coded as malignant in ICD-O-3 were not coded as malignant in ICD-O-2 (6). Additional information is provided in the USCS technical notes (https://www.cdc.gov/ cancer/npcr/uscs/pdf/uscs-2013-technical-notes.pdf\#namedd est=IncidenceDataSources).

\section{Mortality Data}

Cancer mortality statistics are based on information from all death certificates filed in the 50 states and DC and processed by NVSS at NCHS (10). The cancer mortality data were compiled in accordance with WHO regulations, which specify that member nations classify and code causes of death in accordance with the current revision of the International Classification of Diseases (ICD) (11). For consistency with the data on cancer incidence, the cancer sites in mortality data were grouped according to the revised SEER recodes dated January 27, 2003 (https://seer. cancer.gov/codrecode). Data for a specific calendar year are based on records of deaths that occurred during that calendar year and received by a particular date. Data in this report include mortality data for 2013 based on records of deaths that occurred during 2013 and received by NCHS as of June 30, 2015. Data in this report come from USCS, which includes cancer deaths during 1998-2013; cancer mortality data for 2014 are available at https://www.cdc.gov/nchs/nvss/deaths.htm. Additional information about mortality data is provided in the USCS technical notes (https://www.cdc.gov/cancer/npcr/uscs/pdf/uscs2013-technical-notes.pdf\#nameddest=MortalityDataSources).

\section{Population Estimates}

Population denominators are annual race-specific, ethnicityspecific, and sex-specific county population estimates modified by NCI in collaboration with CDC's NCHS from the U.S. Census intercensal (for July 1, 1999-2009) and Vintage 2014 (for July 1, 2010-2013) annual times series (12). Modifications incorporated bridged single-race estimates that are derived from the original multiple race categories in the 2000 and 2010 censuses. For most states, population estimates as of July 1 of each year were used to calculate annual incidence rates because these estimates are presumed to reflect the average population of a defined geographic area for a calendar year. However, some county population estimates were adjusted to account for populations displaced along the Gulf Coast of Louisiana, Alabama, Mississippi, and Texas in the fall of 2005 by hurricanes Katrina and Rita. The national total population estimates were not affected by these adjustments. Other specific modifications included using additional local information to accurately estimate the native Hawaiian population and deriving population estimates for newly created counties in Colorado and Alaska. The modified county-level population estimates, summed to the state and national level, were used as denominators in rate calculations. Additional details about population data are available at https://seer.cancer.gov/ popdata/index.html.

\section{Publication Criteria}

Cancer incidence data are derived from state cancer registries that have high-quality cancer incidence data for individual (e.g., 2013) and combined (e.g., 1999-2013) years as demonstrated by meeting all of the following criteria on data quality for all cancer sites combined:

- case ascertainment is $\geq 90 \%$ (margin of error $+5 \%$ ) complete,

- $\leq 5 \%$ of cases are ascertained solely on the basis of a death certificate,

- $\leq 3 \%$ of cases are missing information on sex,

- $\leq 3 \%$ of cases are missing information on age,

- $\leq 5 \%$ of cases are missing information on race, and

- $\geq 97 \%$ of the registry's records passed a set computerized edits that test the validity and logic of data components. 
In this report, cancer incidence data for 2013 include data from DC and all states except Nevada, covering 99\% of the US population, and data for 1999-2013 include data from all registries except Arkansas, DC, Mississippi, Nevada, South Dakota, Tennessee, and Virginia, covering 92\% of the U.S. population. Additional information about USCS is available at available at https://www.cdc.gov/uscs/.

\section{Interpreting Data}

\section{Incidence Data}

Each year, state cancer registries submit cancer cases for a new diagnosis year and an updated version of the previous year's cancer cases to CDC or NCI. Therefore, each year, when USCS data are published, updates to the previous year's data are published, using the most recent data submission and the most recent population data. Users of cancer incidence data published by federal agencies need to be mindful of the date of data submission for data used in their analyses.

\section{Mortality Data}

Cancer mortality statistics in USCS are influenced by the accuracy of information on the death certificate. Unlike incidence data, mortality data for a calendar year are considered complete when submitted and so are not updated after the aggregate data file is released. Mortality data for the entire United States refer only to deaths that occurred within the United States; data for geographic areas are provided by the decedent's place of residence.

\section{Race and Ethnicity Data}

Differences in rates among racial and ethnic populations should be interpreted with caution. For cancer incidence, race and ethnicity data are abstracted from medical records and grouped into categories (7). A study using SEER incidence data suggests that the quality of data on race/ethnicity in cancer registries is considered excellent for whites, blacks, and Asians/Pacific Islanders, good for Hispanics, and poor for American Indians/Alaska Natives (13). When cancer mortality is reported, race and ethnic origin are recorded separately on the death certificate by the funeral director as provided by an informant or, in the absence of an informant, on the basis of observation (14). Previous studies involving cancer mortality data demonstrate that death rates for whites and blacks generally are estimated accurately whereas death rates for Asians/Pacific Islanders, American Indians/Alaska Natives, and Hispanics are underestimated $(2,15)$. Recent study involving evaluation of validity of race showed that classification of race and ethnicity on death certificates improved overtime for Asian/Pacific Islanders and Hispanics (now almost as good as whites and blacks), however, remained poor for American Indians/Alaska Natives (16). For this reason, incidence and mortality data provided in this report might be underestimated for American Indians/Alaska Natives groups, possibly because of misclassification of race.

Three NPCR registries (Delaware, Kansas, and Kentucky) opted not to present state-specific Asian/Pacific Islander counts and rates. Six NPCR registries (Delaware, Kentucky, Massachusetts, Pennsylvania, North Dakota, and Virginia) opted not to present state-specific Hispanic (classified by the NAACCR Hispanic Identification [NHIA] Algorithm) counts and rates (17). Cancer registries regularly link their database to the Indian Health Service patient registration dataset to reduce misclassification of race for American Indian/Alaska Native patients; in this report, 34 NPCR registries and all SEER registries linked cases diagnosed in 1999-2013. Six NPCR registries (Delaware, Illinois, Kansas, Kentucky, New Jersey, and New York) opted not to present state-specific American Indian/Alaska Native counts and rates. However, the aggregate national rates presented in this report include data for these registries, except that incidence rates by ethnicity exclude Virginia because ethnicity information was missing on $85 \%$ of cases from Virginia.

\section{Population Coverage}

The population coverage for incidence data varies by diagnosis year. Population coverage might be affected by the suppression of state incidence data if a state did not meet the publication criteria or did not submit data for that diagnosis year. In addition, state incidence data were suppressed in this report if $<16$ cases were reported or if the state requested that the data be suppressed. Additional information is provided by the USCS technical notes notes (https://www.cdc.gov/cancer/ npcr/uscs/pdf/uscs-2013-technical-notes.pdf\#nameddest= CensusRegionPubCriteria). Mortality data from malignant neoplasms (i.e., cancers) as recorded in NVSS from the 50 states and DC are available in USCS, and thus $100 \%$ of the U.S. population is covered each year. However, state death data were suppressed in this report if $<16$ deaths were reported.

\section{Suppression of Rates and Counts}

When the numbers of cases or deaths used to compute rates are small, those rates tend to have poor reliability. Therefore, incidence and death rates and counts of $<16$ are not shown in tables and figures. The use of a threshold value for suppressing 
cells helps protect the confidentiality of patients by reducing or eliminating the risk for disclosure of their identity and helps avoid overreliance on unstable data. Additional information is provided in the USCS technical notes (https://www. cdc.gov/cancer/npcr/uscs/pdf/uscs-2013-technical-notes. pdf\#nameddest=Suppression).

\section{Highlights}

\section{Incidence and Death Rates}

In 2013, more than 1.5 million invasive cancers were diagnosed in the United States, an annual incidence rate of 439 cases per 100,000 persons (Table 1 ). In the same year, approximately 584,872 persons died of cancer nationally, an annual death rate of 163 deaths per 100,000 persons (Table 2). Overall and for many cancer sites, males had higher incidence (Table 1) and death rates (Table 2) than did females.

Four cancer sites accounted for $48 \%$ of all cases diagnosed in 2013, including 230,815 female breast cancers, 212,584 lung and bronchus cancers (111,907 among men and 100,677 among women), 176,450 prostate cancers, and 136,119 colon and rectum cancers (71,099 among men and 65,020 among women) (Table 1). These four sites also accounted for $47 \%$ of cancer deaths in 2013, including 156,176 lung cancer deaths, 51,813 colon and rectum cancer deaths, 40,860 female breast cancer deaths, and 27,681 prostate cancer deaths (Table 2).

By state, overall (all cancer sites combined) cancer incidence rates in 2013 ranged from 364 to 512 cases per 100,000 persons (Table 3 ), and overall cancer death rates ranged from 128 to 199 deaths per 100,000 persons (Table 4). The Healthy People 2020 target (5) for overall cancer death rate (161.4 deaths per 100,000) has been reached in 21 states.

Cancer incidence (Table 5) and death (Table 6) rates increase with age. In 2013, among persons in the youngest age group ( $<15$ years), 10,172 new cancer cases (rate: 17 cases per 100,000 persons) and 1,287 cancer deaths (rate: two deaths per 100,000 persons) were reported. Among persons aged $\geq 65$ years, 851,505 new cancer cases (rate: 1,920 cases per 100,000 persons) and 407,558 cancer deaths (rate: 911 deaths per 100,000 persons) were reported. Overall, $55 \%$ of cancer cases and $70 \%$ of cancer deaths in 2013 occurred among persons aged $\geq 65$ years.

In 2013, by race, blacks had the highest cancer incidence (Table 7) and death (Table 8) rates while American Indians/ Alaska Natives and Asians/Pacific Islanders had the lowest cancer death rates in the United States. By ethnicity, overall and for most cancer sites, Hispanics had lower cancer incidence (Table 9) and death rates (Table 10) than did non-Hispanics. Differences in cancer incidence (Figure 1) and death (Figure 2) rates by race and ethnicity might reflect differences in risk factors, screening, and treatment although rates among some populations might be under- or overestimated because of misclassification of race or ethnicity.

By state and site, cancer incidence rates in 2013 ranged from 69 to 131 per 100,000 males for prostate cancer, from 105 to 148 per 100,000 females for breast cancer, from 4 to 11 per 100,000 females for cervical cancer, from 26 to 93 per 100,000 persons for lung cancer, and from 32 to 49 per 100,000 persons for colorectal cancer (Figure 3). By state and site, cancer death rates in 2013 ranged from 12 to 33 per 100,000 males for prostate cancer, from 15 to 30 per 100,000 females for breast cancer, from 1 to 4 per 100,000 females for cervical cancer, from 19 to 70 per 100,000 persons for lung cancer, and from 11 to 20 per 100,000 persons for colorectal cancer (Figure 4).

\section{Time Trends in Incidence and Death Rates}

On the basis of data from registries meeting data quality criteria during 2004-2013, cancer incidence counts (Table 11) and rates (Table 12) are presented by state and year. Time trends in cancer incidence rates are presented by cancer site, sex, and race (Figure 5) and by cancer site, sex, and ethnicity (Figure 6). Cancer incidence rates declined from 484 cancer cases per 100,000 population in 1999 to 432 cases in 2013 . Although lung cancer incidence declined steadily among men from 1999 to 2013, it increased among women from 1999 to 2005 and has since declined from 2005 to 2013. Prostate cancer incidence declined from 170 cases per 100,000 men in 1999 to 101 cases in 2013. Colorectal cancer incidence declined from 56 cases per 100,000 persons in 1999 to 38 cases in 2013. Female breast cancer incidence declined from 135 cases per 100,000 women in 1999 to 121 cases in 2005, increased to 126 cases in 2009, and declined again to 124 cases in 2013. Time trends in cancer death rates are presented by cancer site, sex, and race (Figure 7) and by cancer site, sex, and ethnicity (Figure 8). During 1999-2013, cancer death rates declined from 201 deaths per 100,000 persons in 1999 to 163 deaths in 2013; during the same period, death rates declined for each of the four most common cancers (Figure 5). Cancer death counts (Table 13) and rates (Table 14) are presented by state and year.

National cancer surveillance data help public health officials track progress toward achieving the national cancer objectives set forth in Healthy People 2020 (18). Differing rates of cancer by race, ethnicity, and state of residence indicate that for some populations, Healthy People 2020 objectives have already been achieved, whereas objectives for other populations have not been met. For the national cancer burden to be reduced and Healthy People 2020 targets to be met, behavioral and 
environmental factors that increase cancer risk must be reduced, and high-quality screening services, timely follow-up, and evidence-based treatments must be available and accessible to all persons. Cancer surveillance data can identify populations with high cancer rates that might benefit most from targeted cancer prevention and control efforts. Several effective evidence-based primary and secondary prevention measures, such as vaccination against infectious agents that cause cancer (i.e., hepatitis B virus and human papillomavirus), help with smoking cessation, and recommended cancer screening, when effectively implemented and sustained, could reduce the number of new cancer cases and prevent many cancerrelated deaths (19). Evidence-based interventions can be implemented at both the individual level and the population level to reduce cancer risk factors, promote healthy living, and encourage cancer screening (3). The impact of these efforts can be monitored using cancer surveillance data.

\section{Acknowledgment}

Data were provided by state and regional cancer registry personnel and health department personnel.

\section{References}

1. US Cancer Statistics Working Group. United States cancer statistics: 1999-2013. Incidence and mortality web-based report. Atlanta, GA: US Department of Health and Human Services, CDC, National Cancer Institute; 2016. https://www.cdc.gov/uscs

2. Heron M. Deaths: leading causes for 2013. Natl Vital Stat Rep 2016;65:1-95. https://www.cdc.gov/nchs/data/nvsr/nvsr65/nvsr65_02.pdf

3. Colditz GA, Wolin KY, Gehlert S. Applying what we know to accelerate cancer prevention. Sci Transl Med 2012;4:127rv4. http://dx.doi. org/10.1126/scitranslmed.3003218

4. Weir HK, Thun MJ, Hankey BF, et al. Annual report to the nation on the status of cancer, 1975. J Natl Cancer Inst 2003;95:1276-99. http:// dx.doi.org/10.1093/jnci/djg040

5. US Department of Health and Human Services. Healthy people 2020. Washington, DC: US Department of Health and Human Services; 2011. https://www.healthypeople.gov/2020/topicsobjectives2020/default.aspx
6. Fritz ARL. The SEER program code manual. Bethesda, MD: National Cancer Institute; 1998.

7. Thornton ML, ed. Standards for cancer registries. Volume II: data standards and data dictionary, record layout version 13, 17th ed. Springfield, IL: North American Association of Central Cancer Registries; 2012.

8. Fritz A, Percy C, Jack A. International classification of diseases of oncology. Geneva, Switzerland: World Health Organization; 2000.

9. National Cancer Institute. Hematopoietic codes based on WHO classification of tumours of haematopoietic and lymphoid tissues. Rockville, MD: US Department of Health and Human Services, National Cancer Institute; 2008. https://seer.cancer.gov/iccc

10. Hetzel AM. Vital Statistics System: major activities and developments, 1950-95. Atlanta, GA: US Department of Health and Human Services, CDC, National Center for Health Statistics; 1997. PHS 97-1993.

11. World Health Organization. International statistical classification of diseases and related health problems. 10th revision. Geneva, Switzerland: World Health Organization; 1992.

12. National Cancer Institute. US population data 1969-2014. Revised March 2016. https://seer.cancer.gov/popdata/

13. Clegg LX, Reichman ME, Hankey BF, et al. Quality of race, Hispanic ethnicity, and immigrant status in population-based cancer registry data: implications for health disparity studies. Cancer Causes Control 2007;18:177-87. http://dx.doi.org/10.1007/s10552-006-0089-4

14. Miniño AM, Heron MP, Murphy SL, Kochanek KD. Deaths: final data for 2004. Natl Vital Stat Rep 2007;55:1-119.

15. Arias E, Schauman WS, Eschbach K, Sorlie PD, Backlund E. The validity of race and Hispanic origin reporting on death certificates in the United States. Vital Health Stat 2 2008;(148):1-23. https://www.cdc.gov/nchs/ data/series/sr_02/sr02_148.pdf

16. Arias E, Heron M, Hakes JK. The validity of race and Hispanic-origin reporting on death certificates in the United States: an update. Vital Health Stat 2 2016;(172):1-22. https:/www.cdc.gov/nchs/data/series/ sr_02/sr02_172.pdf

17. North American Association of Central Cancer Registries Asian Pacific Islander Work Group. NAACCR Asian Pacific Islander identification algorithm. Springfield, IL: North American Association of Central Cancer Registries; 2008.

18. Henley SJ, Singh SD, King J, Wilson RJ, Ryerson AB. Invasive cancer incidence-United States, 2010. MMWR Morb Mortal Wkly Rep 2014;63:253-9.

19. Agency for Healthcare Research and Quality. The guide to clinical preventive services, 2014. Rockville, MD: Agency for Healthcare Research and Quality; 2015. http://www.ahrq.gov/professionals/ clinicians-providers/guidelines-recommendations/guide/index.html 
FIGURE 1. Age-adjusted rate* of invasive ${ }^{\dagger}$ cancer cases for most common sites, by sex and race/ethnicity ${ }^{\S}$ United States, $2013^{\Uparrow}$
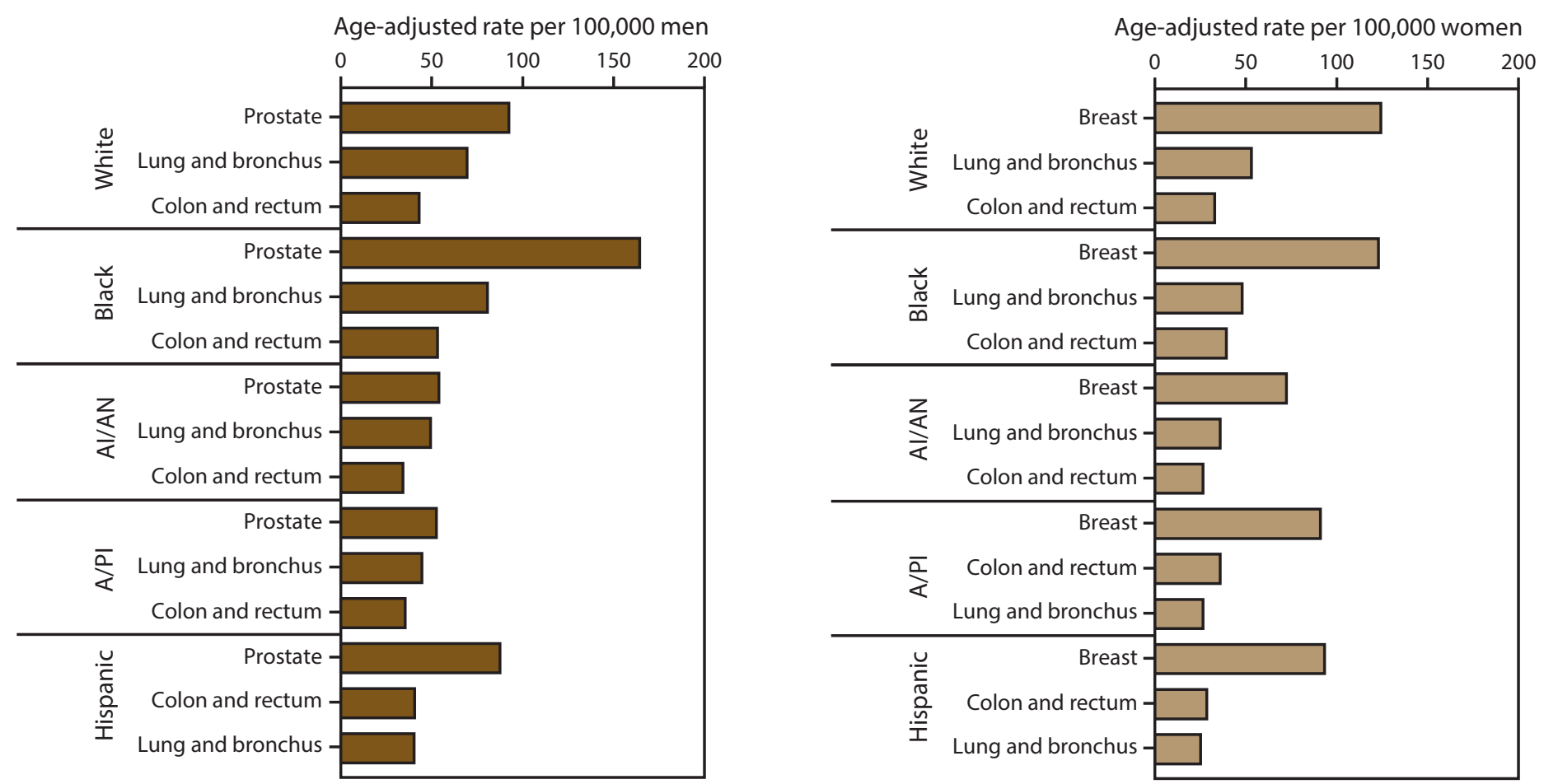

Abbreviations: Al/AN = American Indian/Alaska Native; A/PI = Asian/Pacific Islander.

Sources: CDC's National Program of Cancer Registries and National Cancer Institute's Surveillance, Epidemiology, and End Results program.

* Rates are the number of cases per 100,000 persons and are age-adjusted to the 2000 U.S. standard population (19 age groups - Census P25-1130). For more information, see USCS technical notes (https://www.cdc.gov/cancer/npcr/uscs/pdf/uscs-2013-technical-notes.pdf).

+ Invasive cancer excludes basal and squamous cell carcinomas of the skin except when these occur on the skin of the genital organs, and in situ cancers except urinary bladder.

$\S$ Race categories are not mutually exclusive from Hispanic origin. The Hispanic category excludes any cases from Virginia because information about ethnicity was missing on $85 \%$ of cases. Rates are not presented for persons of unknown or other race. Data for specified racial or ethnic populations other than white and black should be interpreted with caution. For more information, see USCS technical notes (https://www.cdc.gov/cancer/npcr/uscs/pdf/uscs-2013-technical-notes.pdf\#n ameddest=IntRaceEthnicityData).

" Data are compiled from cancer registries that meet the data quality criteria for all invasive cancer sites combined (all registries except Nevada, covering approximately $99 \%$ of the U.S. population). Caution should be used when comparing incidence and death rates because of the difference in population coverage. 
FIGURE 2. Age-adjusted rate* of cancer deaths for most common sites, by sex and race/ethnicity ${ }^{\dagger}$ United States, $2013^{\S}$
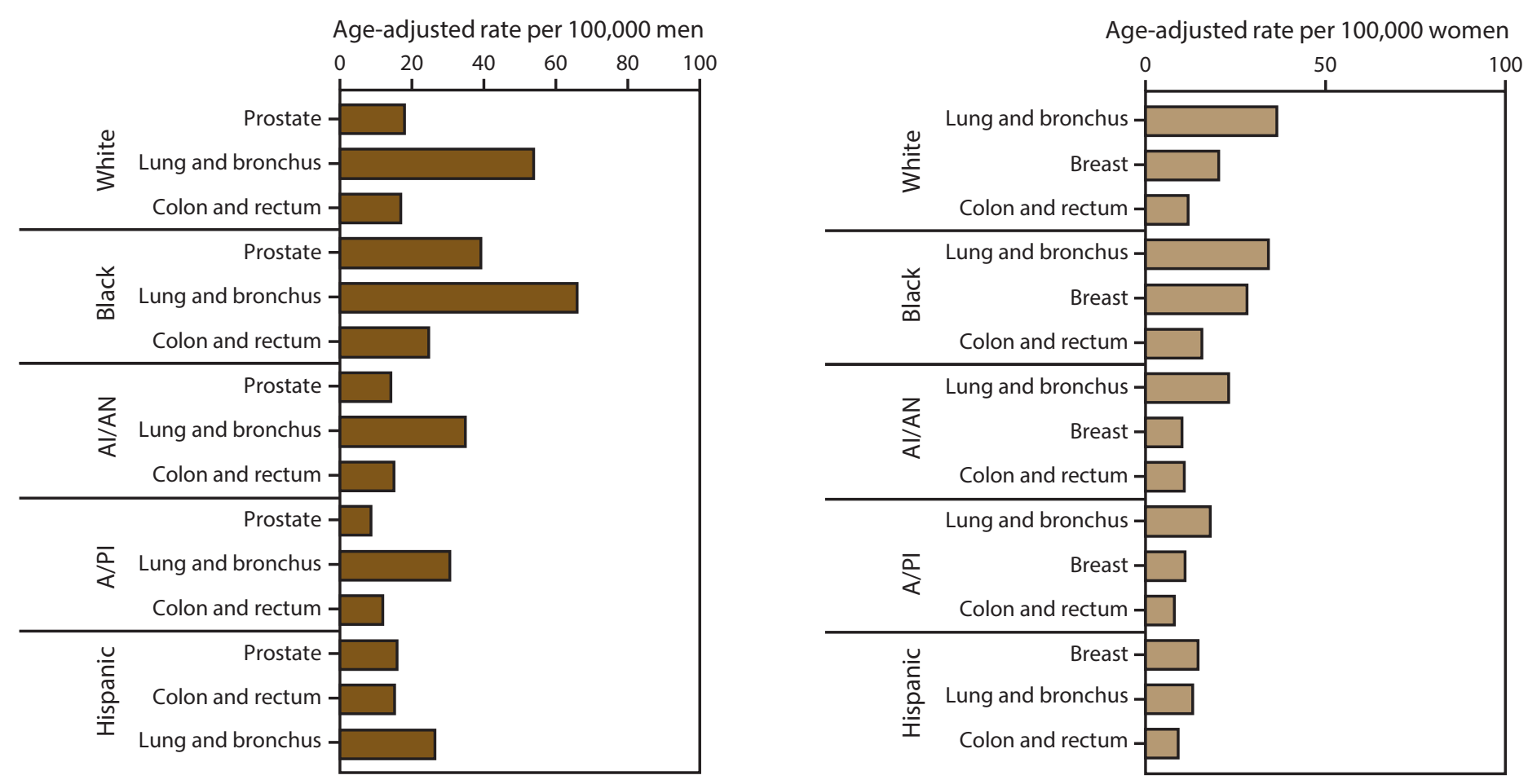

Abbreviations: Al/AN = American Indian/Alaska Native; A/PI = Asian/Pacific Islander.

* Rates are the number of cases per 100,000 persons and are age-adjusted to the 2000 U.S. standard population (19 age groups - Census P25-1130). For more information, see USCS technical notes (https://www.cdc.gov/cancer/npcr/uscs/pdf/uscs-2013-technical-notes.pdf).

† Data are from the National Vital Statistics System (NVSS). Data for death rates cover $100 \%$ of the U.S. population. Use caution when comparing incidence and death rates because of potential differences in population coverage.

$\S$ Race categories are not mutually exclusive from Hispanic origin. Rates are not presented for persons of unknown or other race. Data for specified racial or ethnic populations other than white and black should be interpreted with caution. For more information, see USCS technical notes (https://www.cdc.gov/cancer/npcr/ uscs/pdf/uscs-2013-technical-notes.pdf\#nameddest=IntRaceEthnicityData). 
FIGURE 3. Age-adjusted rate* of invasive $^{\dagger}$ cancer cases, by primary cancer site and state - United States, 2013 $\$$

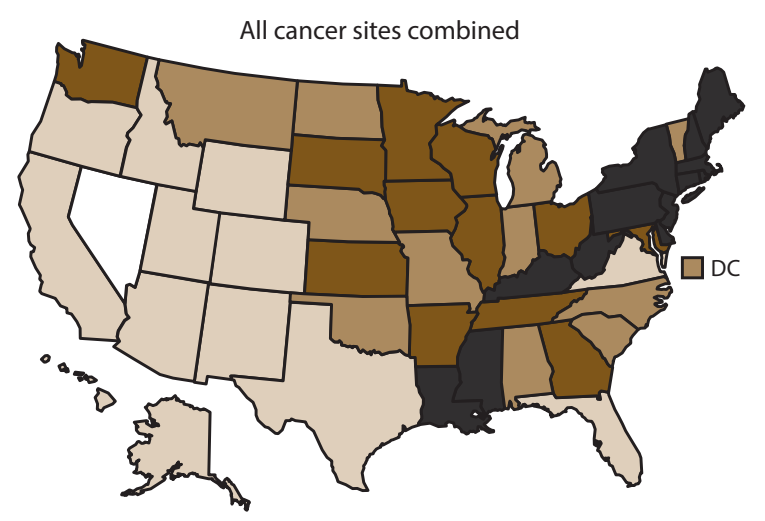

$\square 363.7-432.0$

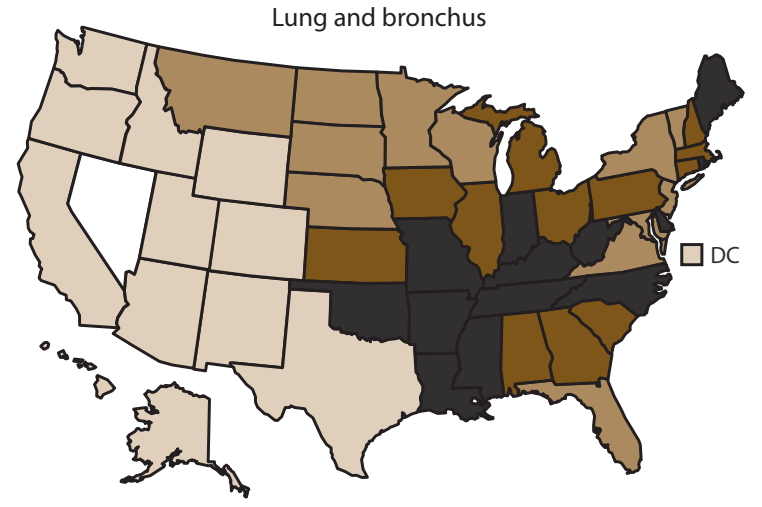

$\square 26.1-55.8$

$55.9-61.0$

$\square 61.1-67.9$

$68.0-93.4$

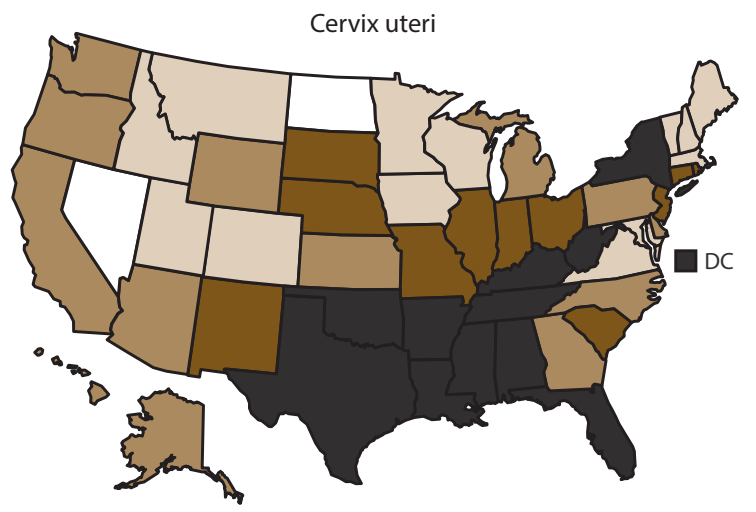

$\square$ 3.6-5.9 $\square$ 6.0-7.1 $\square 7.2-7.7 \quad \square 7.8-10.6 \quad \square$ Data not available

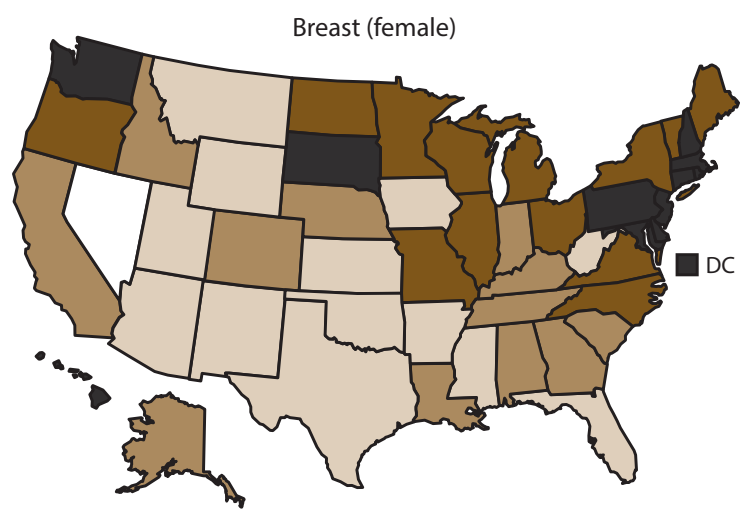

$\square$ 105.0-118.5 $\square$ 118.6-124.7 $\square$ 124.8-130.3 $\square$ 130.4-148.4 $\square$ Data not available

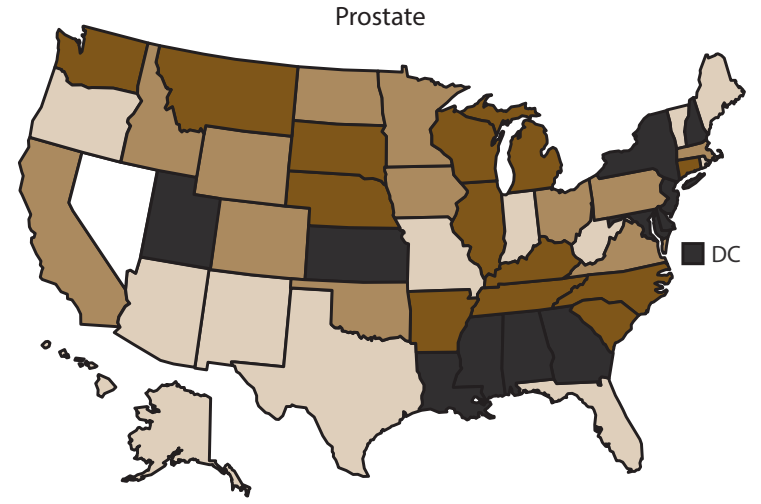

$\square 69.1-92.1 \quad \square 92.2-101.9 \quad \square 102.0-108.0$

108.1-131.2 $\square$ Data not available

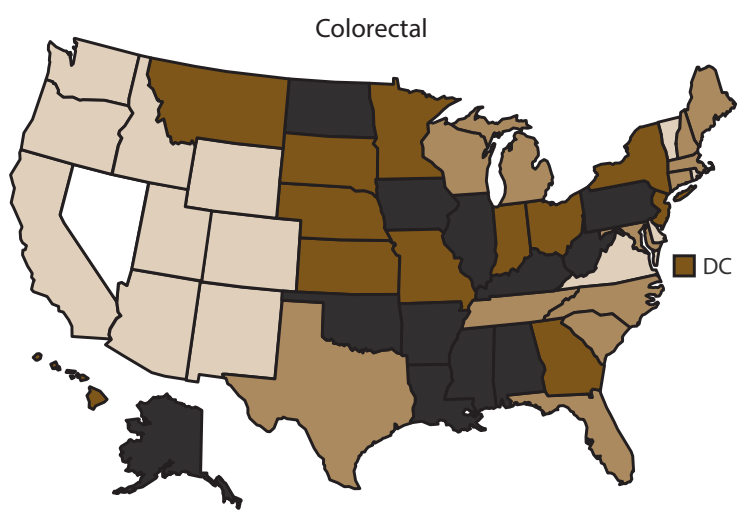

$\square 31.7-35.5 \quad \square 35.6-38.4 \quad \square 38.5-42.1$

42.2-49.0

$\square$ Data not available

* Rates are the number of cases per 100,000 persons and are age-adjusted to the 2000 U.S. standard population (19 age groups - Census P25-1130). Breaks are quartiles. For more information, see USCS technical notes (https://www.cdc.gov/cancer/npcr/uscs/pdf/uscs-2013-technical-notes.pdf).

† Invasive cancer excludes basal and squamous cell carcinomas of the skin except when these occur on the skin of the genital organs, and in situ cancers except urinary bladder.

$\S$ Data are compiled from cancer registries that meet the data quality criteria for all invasive cancer sites combined (all registries except Nevada, covering approximately $99 \%$ of the U.S. population). 
FIGURE 4. Age-adjusted rate* of cancer deaths, by primary cancer site and state — United States, $2013^{\dagger}$

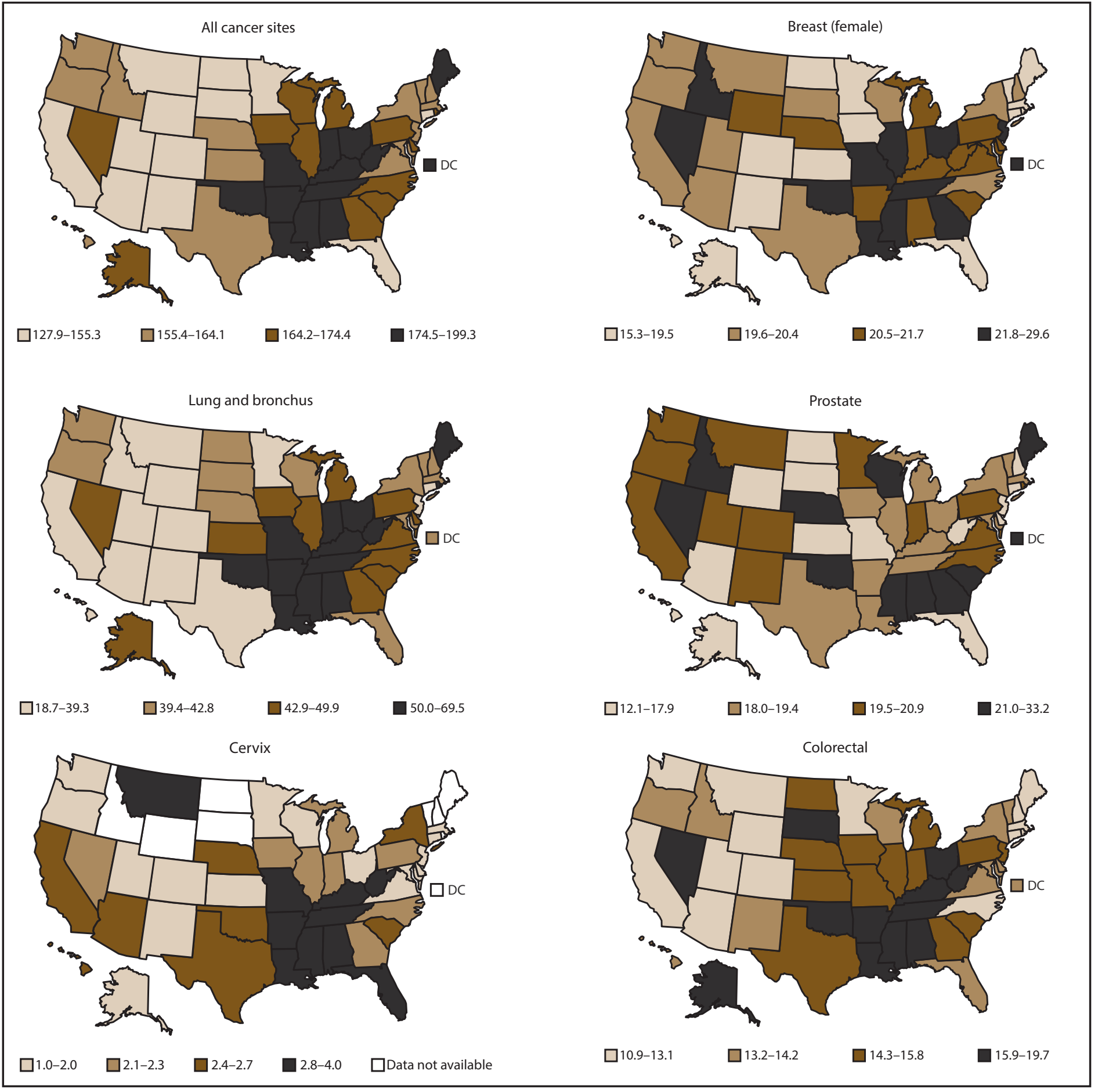

* Rates are the number of deaths per 100,000 persons and are age-adjusted to the 2000 U.S. standard population (19 age groups - Census P25-1130). Breaks are quartiles. For more information, see USCS Technical notes (https://www.cdc.gov/cancer/npcr/uscs/pdf/uscs-2013-technical-notes.pdf).

† Data are from the National Vital Statistics System (NVSS). Data for death rates cover $100 \%$ of the U.S. population. Caution should be used when comparing incidence and death rates because of potential differences in population coverage. 
FIGURE 5. Age-adjusted rate* of invasive ${ }^{\dagger}$ cancer cases, by primary cancer site, race, ${ }^{\S}$ and sex — United States, 1999-2013ף
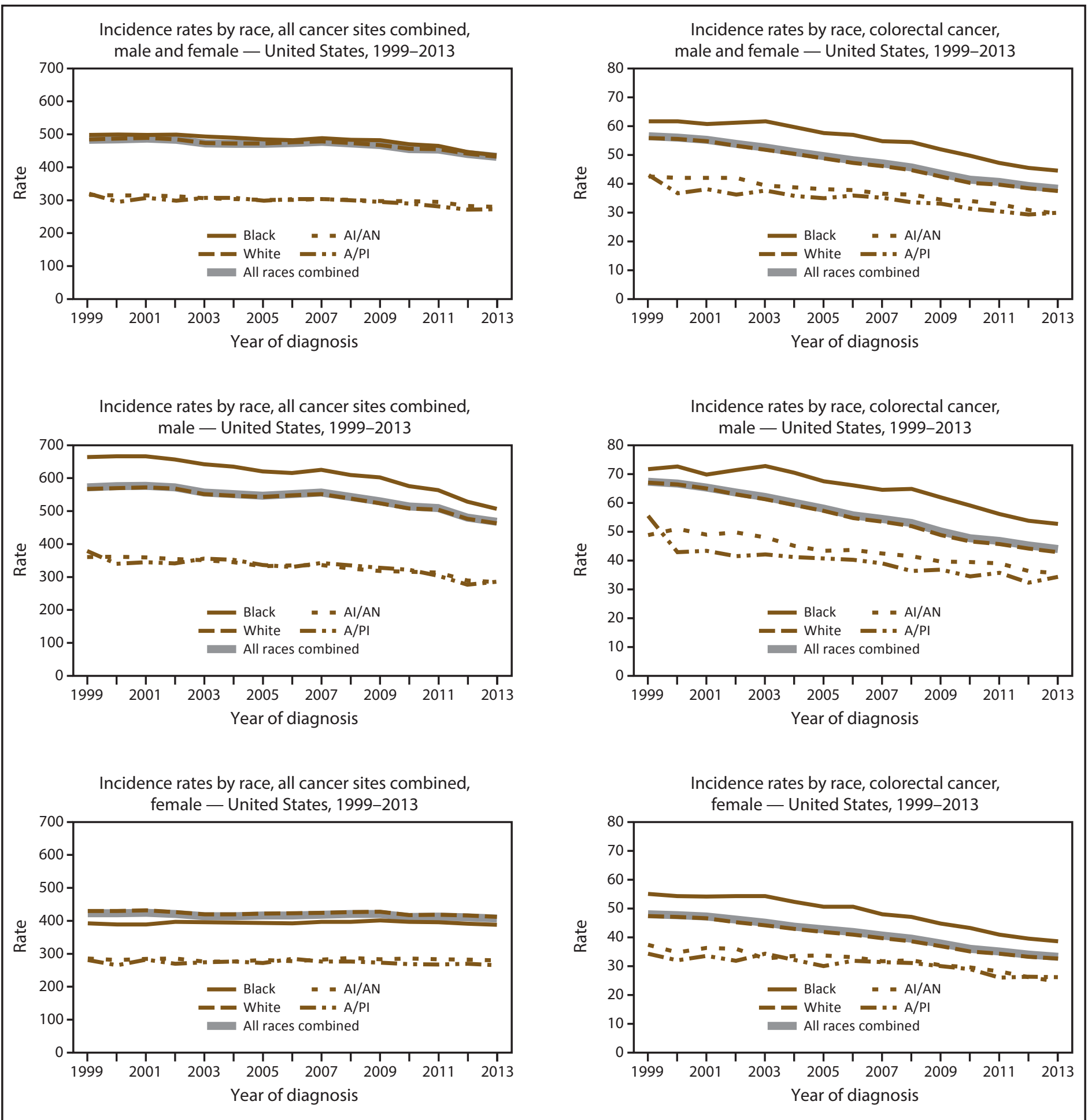

See figure footnotes on the next page. 
FIGURE 5. (Continued) Age-adjusted rate* of invasive ${ }^{\dagger}$ cancer cases, by primary cancer site, race, ${ }^{\S}$ and sex — United States, 1999-2013
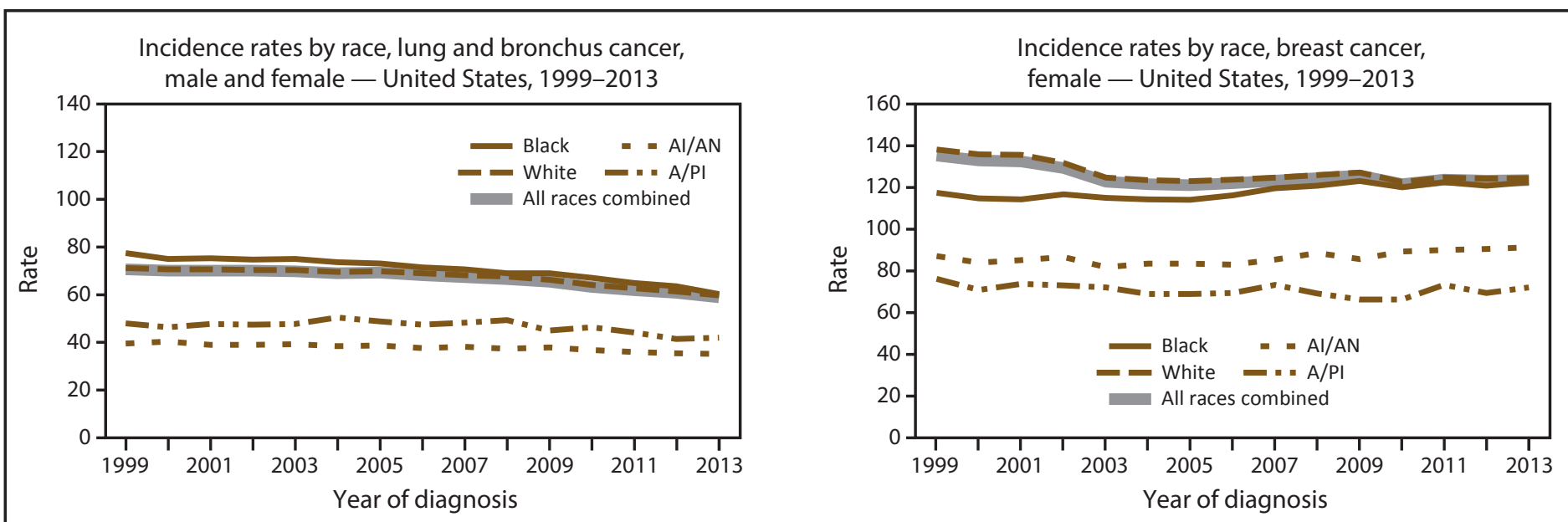

Incidence rates by race, lung and bronchus cancer, male — United States, 1999-2013

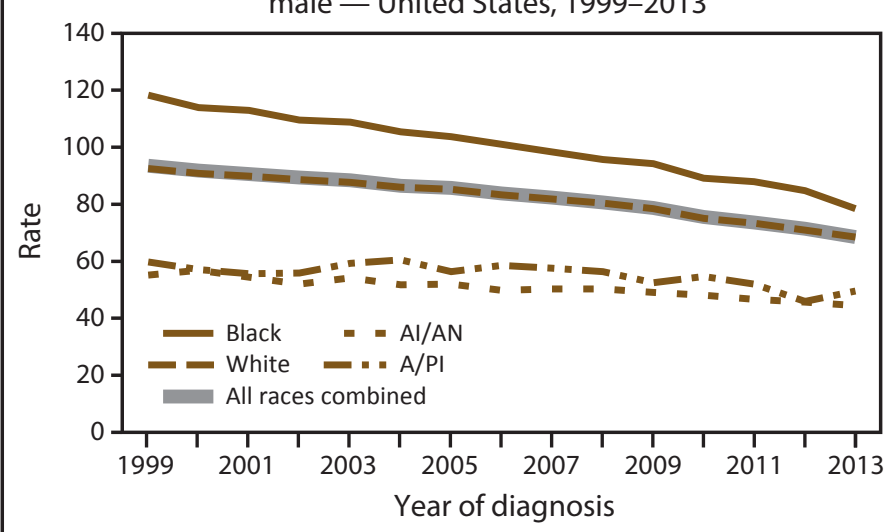

Incidence rates by race, prostate cancer, male — United States, 1999-2013

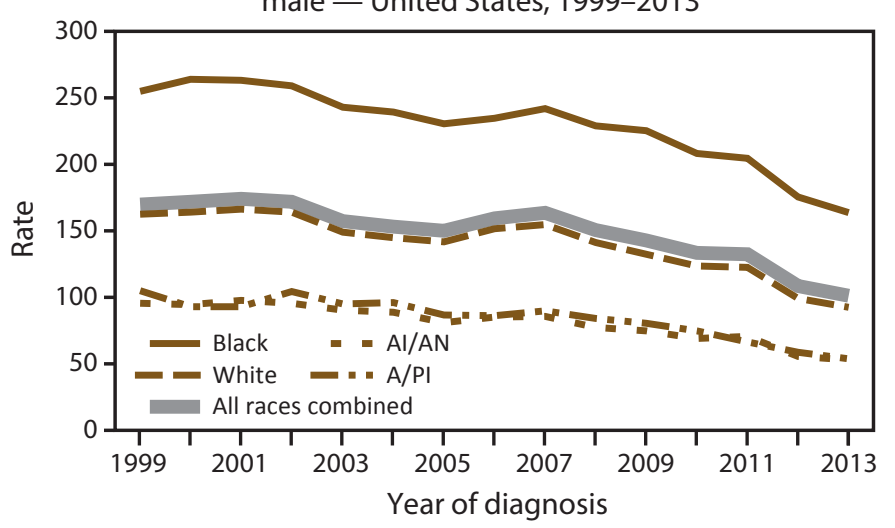

Incidence rates by race, lung and bronchus cancer, female — United States, 1999-2013

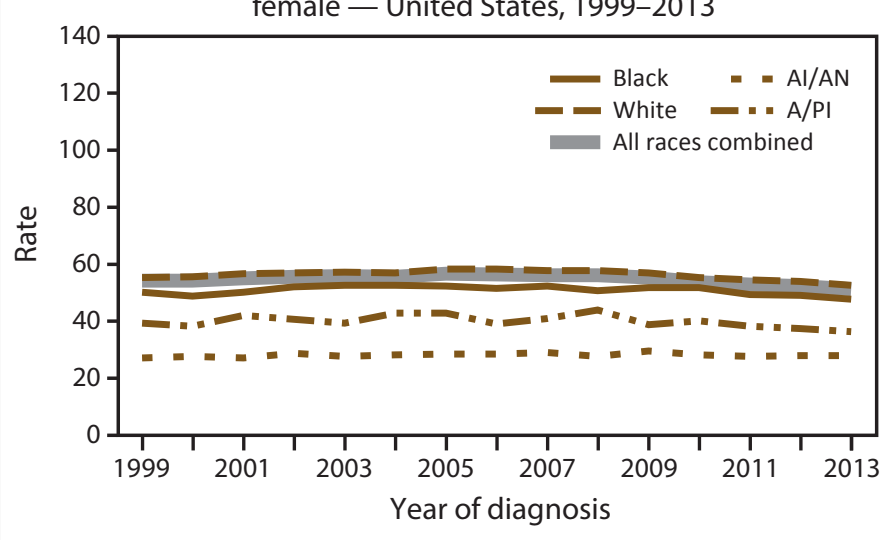

Abbreviations: Al/AN = American Indian/Alaska Native; A/PI = Asian/Pacific Islander.

* Rates are the number of cases per 100,000 persons and are age-adjusted to the 2000 U.S. standard population (19 age groups - Census P25-1130). For more information, see USCS technical notes (https://www.cdc.gov/cancer/npcr/uscs/pdf/uscs-2013-technical-notes.pdf).

† Invasive cancer excludes basal and squamous cell carcinomas of the skin except when these occur on the skin of the genital organs, and in situ cancers except urinary bladder.

$\S$ Rates are not presented for persons of unknown or other race. Data for specified racial populations other than white and black should be interpreted with caution. For more information, see USCS technical notes (https://www.cdc.gov/cancer/npcr/uscs/pdf/uscs-2013-technical-notes.pdf\#nameddest=IntRaceEthnicityData).

" Data are compiled from cancer registries that meet the data quality criteria for all invasive cancer sites combined for all years, 1999-2013 (all registries except Arkansas, District of Columbia, Mississippi, Nevada, South Dakota, Tennessee, and Virginia, covering approximately $92 \%$ of the U.S. population). See registry-specific data quality information for all years, 1999-2013 (https://www.cdc.gov/cancer/npcr/uscs/pdf/uscs-2013-technical-notes.pdf\#nameddest=RegistriesPubCriteria). Caution should be used when comparing incidence and death rates because of potential differences in population coverage. 
FIGURE 6. Age-adjusted rate* of invasive ${ }^{\dagger}$ cancer cases, by primary cancer site, ethnicity, ${ }^{\S}$ and sex — United States, 1999-2013

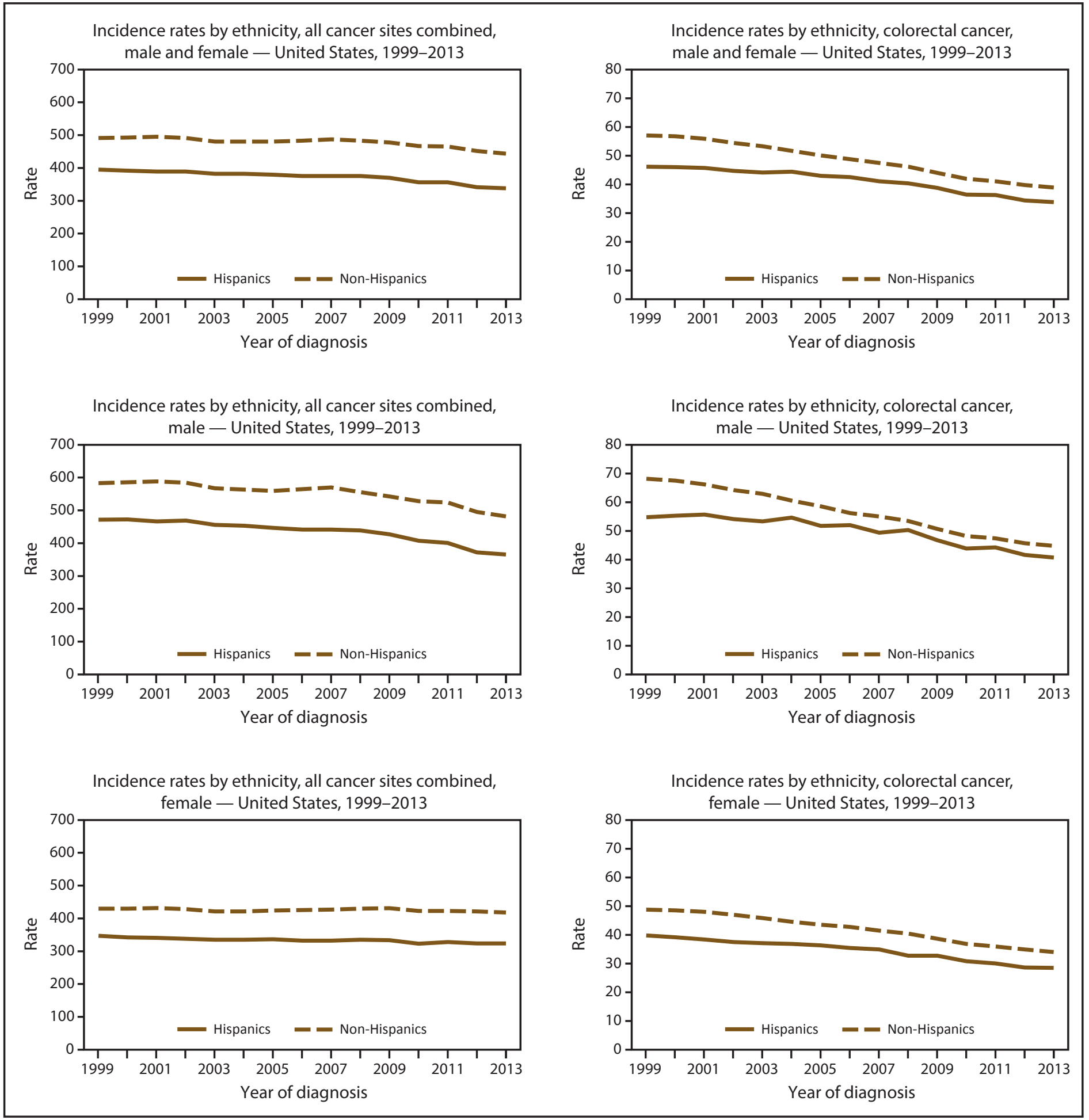

See figure footnotes on the next page. 
FIGURE 6. (Continued) Age-adjusted rate* of invasive ${ }^{\dagger}$ cancer cases, by primary cancer site, ethnicity, ${ }^{\S}$ and sex — United States, 1999-2013 ${ }^{\uparrow}$
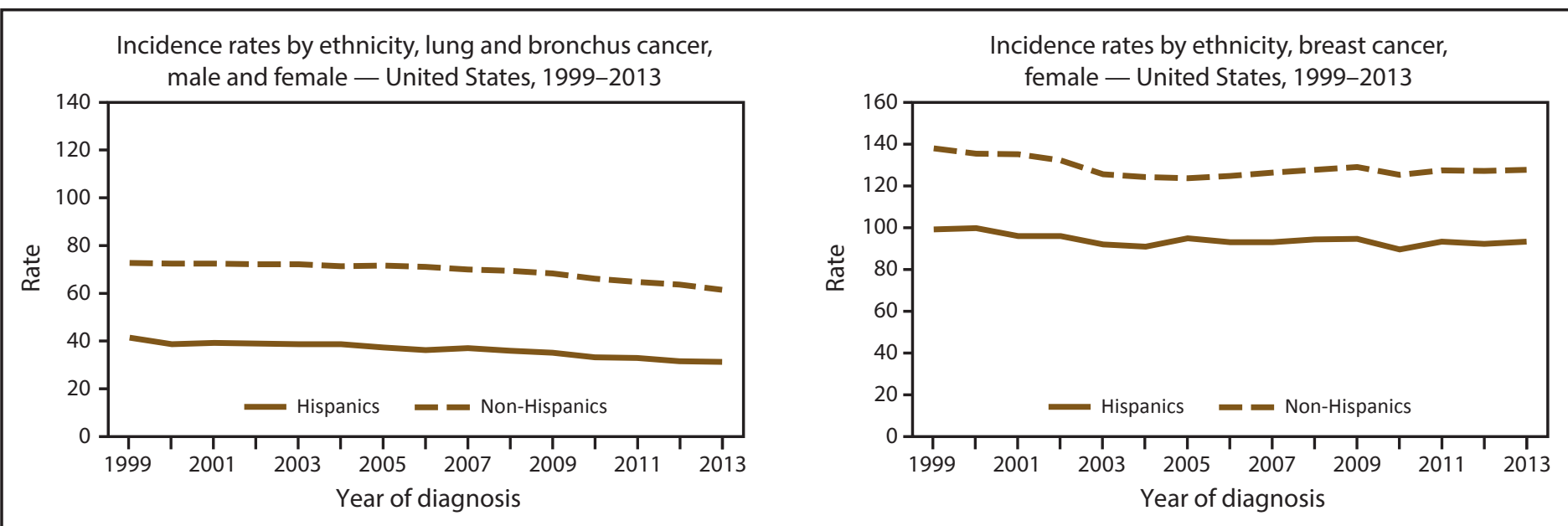

Incidence rates by ethnicity, lung and bronchus cancer, male - United States, 1999-2013
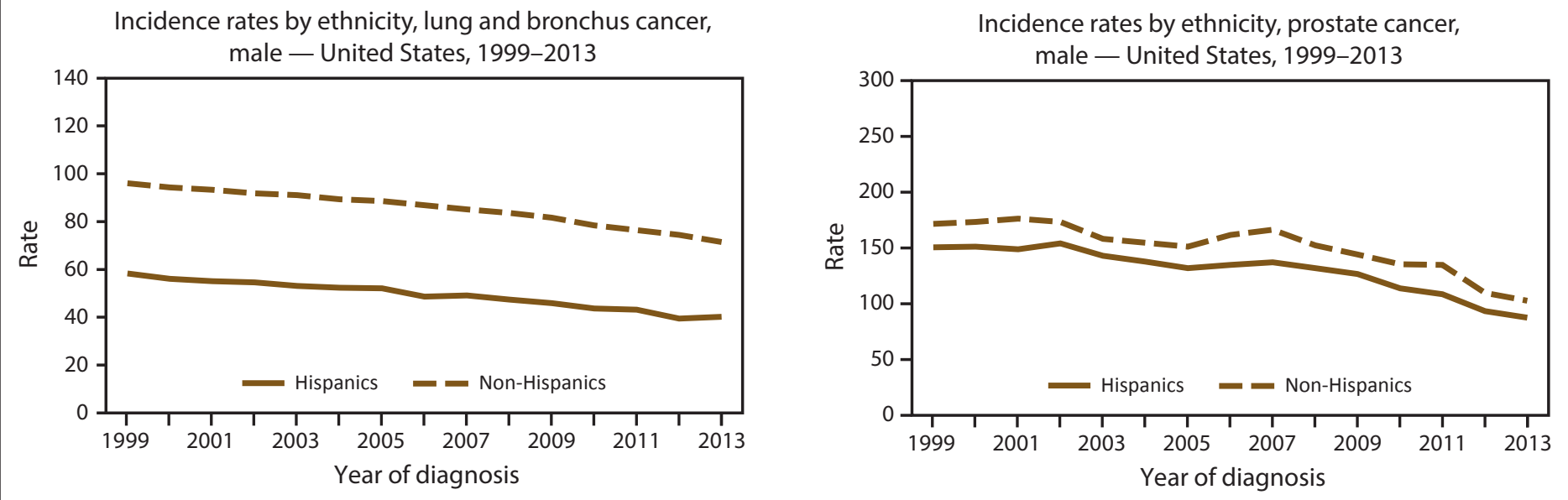

Incidence rates by ethnicity, lung and bronchus cancer, female - United States, 1999-2013

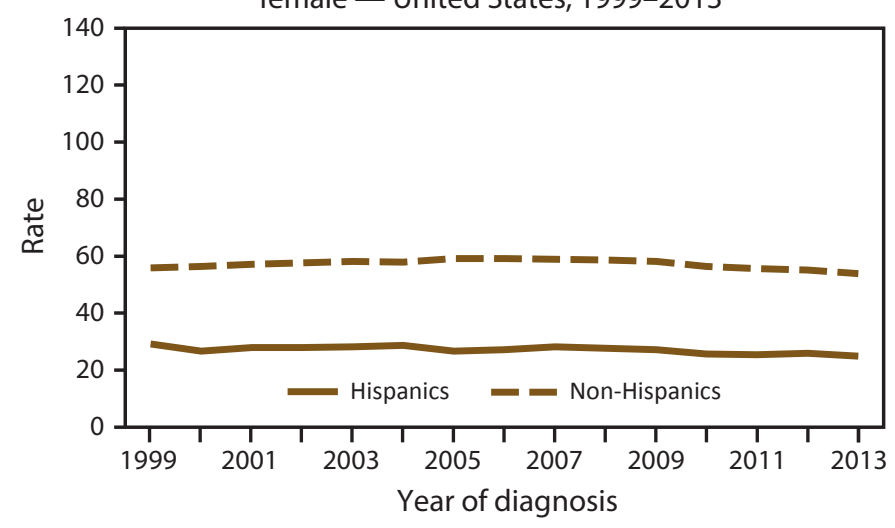

* Rates are the number of cases per 100,000 persons and are age-adjusted to the 2000 U.S. standard population (19 age groups - Census P25-1130). For more information, see USCS technical notes (https://www.cdc.gov/cancer/npcr/uscs/pdf/uscs-2013-technical-notes.pdf).

† Invasive cancer excludes basal and squamous cell carcinomas of the skin except when these occur on the skin of the genital organs, and in situ cancers except urinary bladder.

$\S$ Rates are not presented for persons of unknown ethnicity. Data for specified ethnical populations should be interpreted with caution. For more information, see USCS technical notes (https://www.cdc.gov/cancer/npcr/uscs/pdf/uscs-2013-technical-notes.pdf\#nameddest=IntRaceEthnicityData).

" Data are compiled from cancer registries that meet the data quality criteria for all invasive cancer sites combined for all years, 1999-2013 (all registries except Arkansas, District of Columbia, Mississippi, Nevada, South Dakota, Tennessee, and Virginia, covering approximately $92 \%$ of the U.S. population). See registry-specific data quality information for all years, 1999-2013 (https://www.cdc.gov/cancer/npcr/uscs/pdf/uscs-2013-technical-notes.pdf\#nameddest=RegistriesPubCriteria). Caution should be used when comparing incidence and death rates because of potential differences in population coverage. 
FIGURE 7. Age-adjusted rate* ${ }^{*}$ cancer deaths, by primary cancer site, race, ${ }^{\dagger}$ and sex — United States, $2013^{\S}$

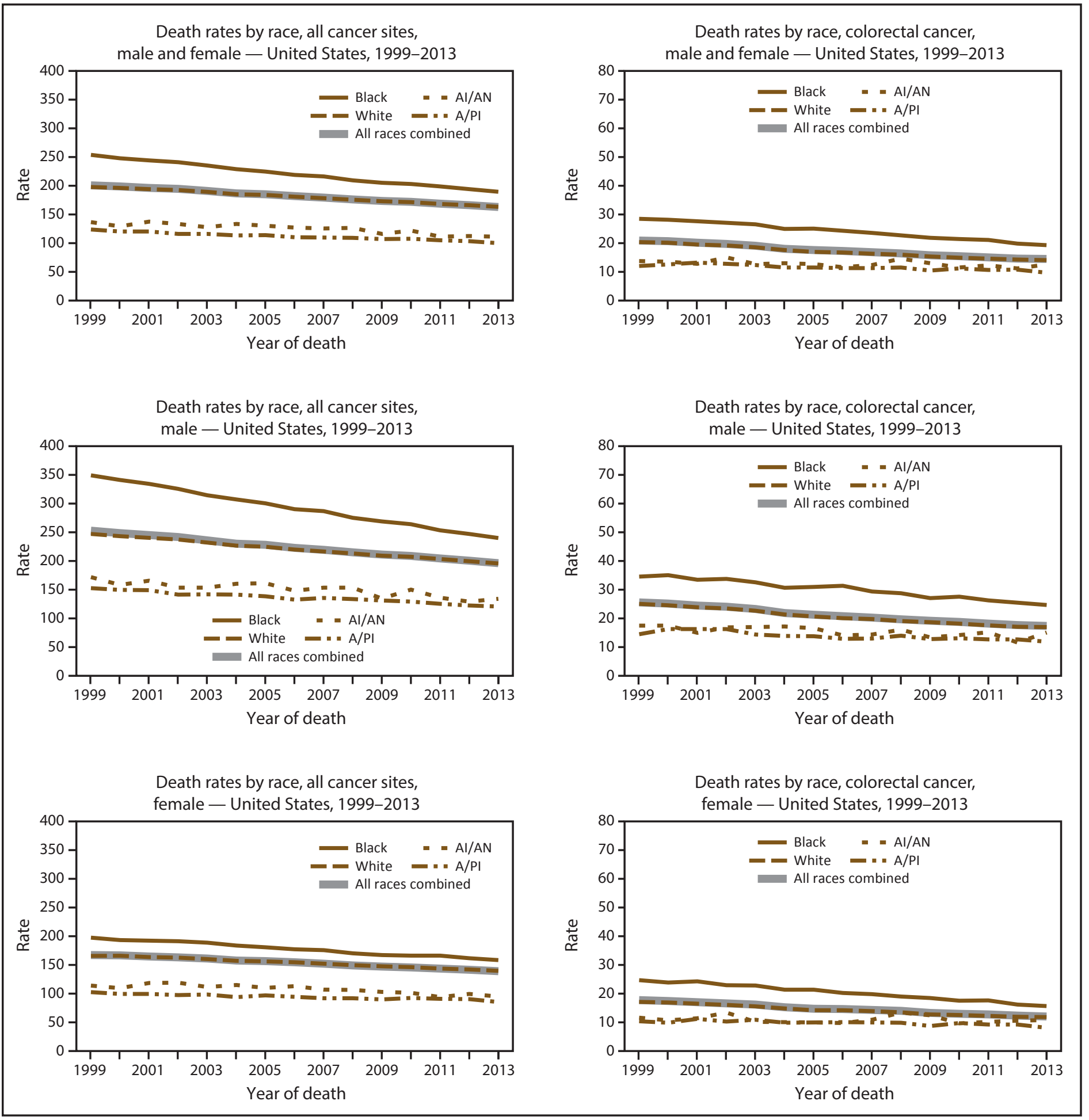

See figure footnotes on the next page. 
FIGURE 7. (Continued) Age-adjusted rate* ${ }^{*}$ cancer deaths, by primary cancer site, race, ${ }^{\dagger}$ and sex — United States, $2013^{\S}$
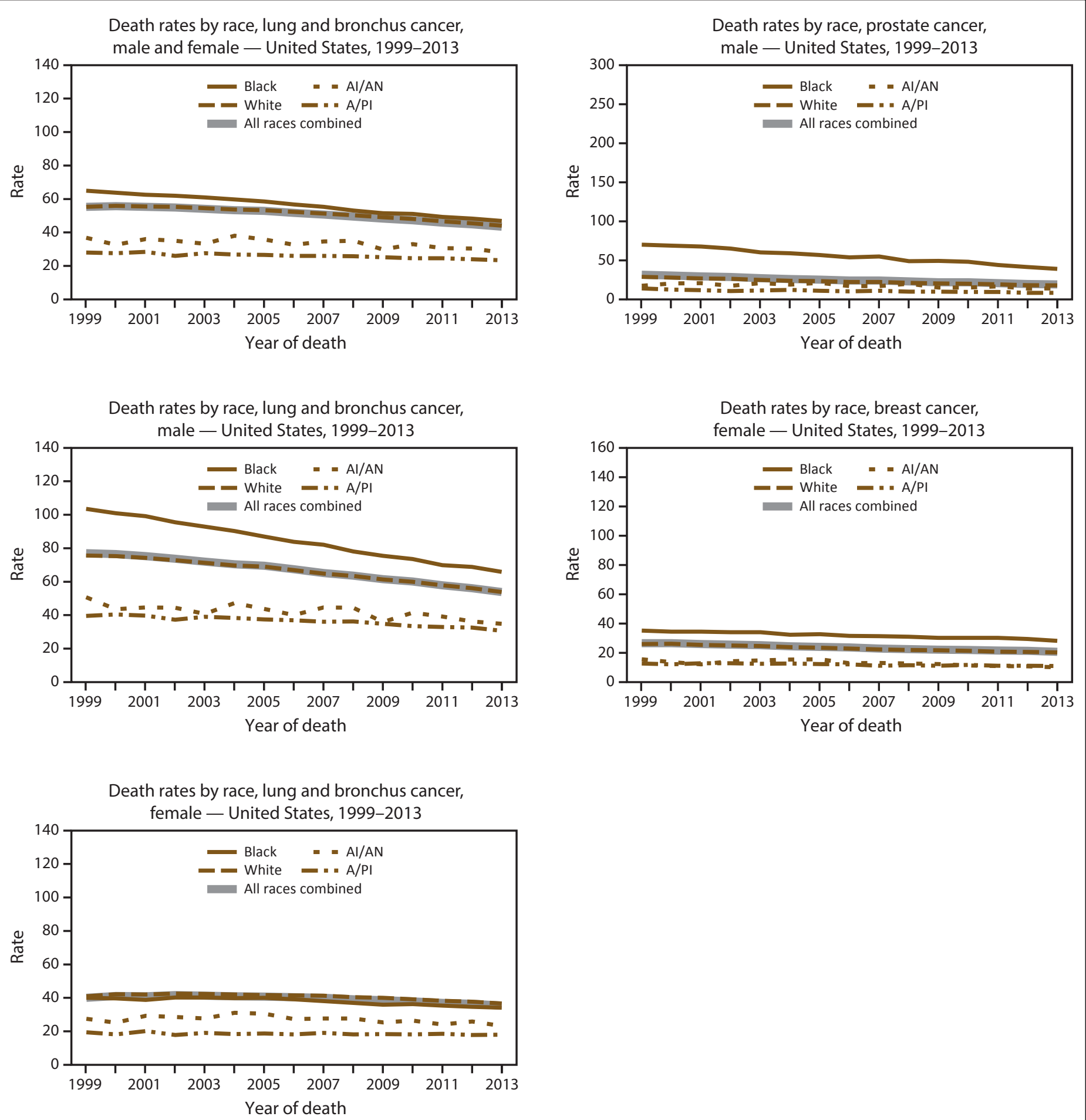

Abbreviations: Al/AN = American Indian/Alaska Native; A/PI = Asian/Pacific Islander.

* Rates are the number of deaths per 100,000 persons and are age-adjusted to the 2000 U.S. standard population (19 age groups - Census P25-1130). For more information, see USCS technical notes (https://www.cdc.gov/cancer/npcr/uscs/pdf/uscs-2013-technical-notes.pdf).

$\dagger$ Rates are not presented for persons of unknown or other race. Data for specified racial populations other than white and black should be interpreted with caution. For more information, see USCS technical notes (https://www.cdc.gov/cancer/npcr/uscs/pdf/uscs-2013-technical-notes.pdf\#nameddest=IntRaceEthnicityData).

$\S$ Data are from the National Vital Statistics System (NVSS). Data for death rates cover $100 \%$ of the U.S. population. Use caution when comparing incidence and death rates because of potential differences in population coverage. 
FIGURE 8. Reported rate* of cancer deaths, by primary cancer site, ethnicity, ${ }^{\dagger}$ and sex — United States, $2013^{\S}$
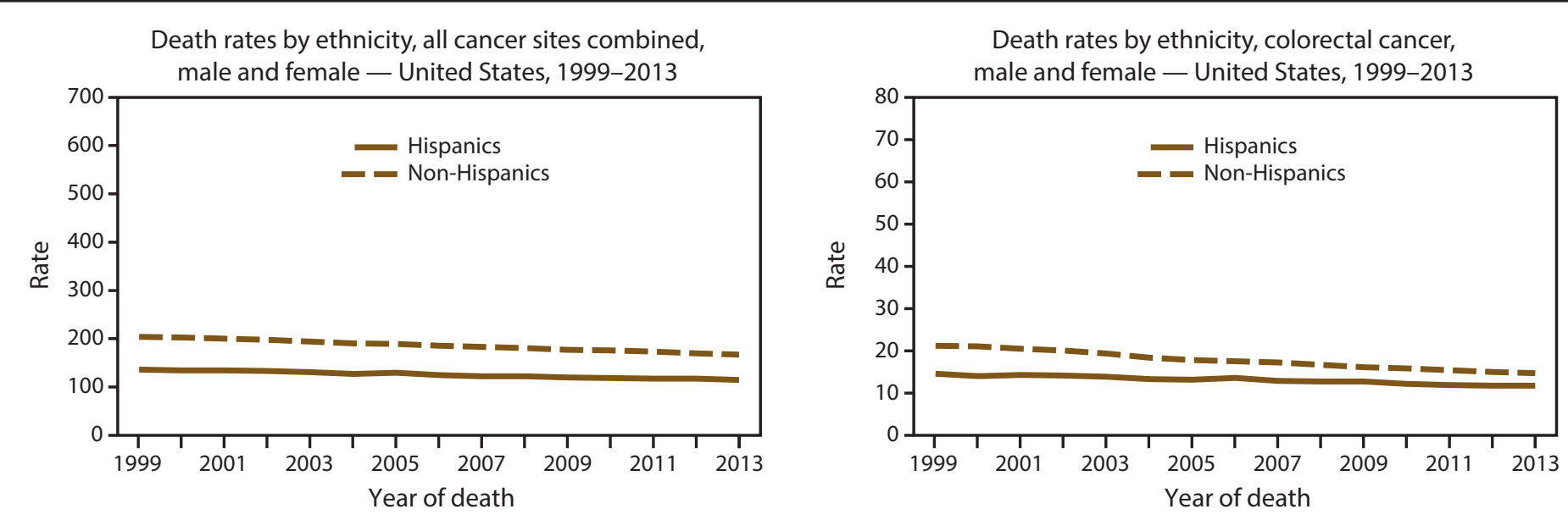

Death rates by ethnicity, all cancer sites combined, male - United States, 1999-2013

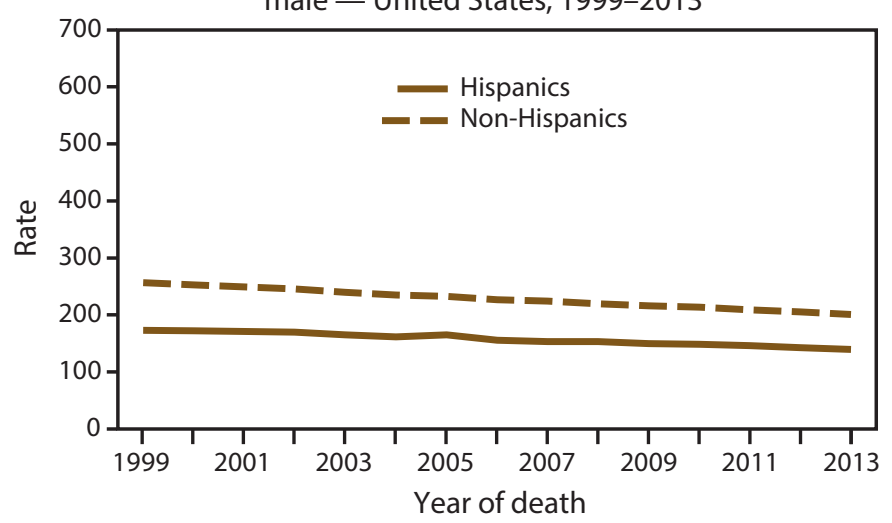

Death rates by ethnicity, colorectal cancer, male - United States, 1999-2013

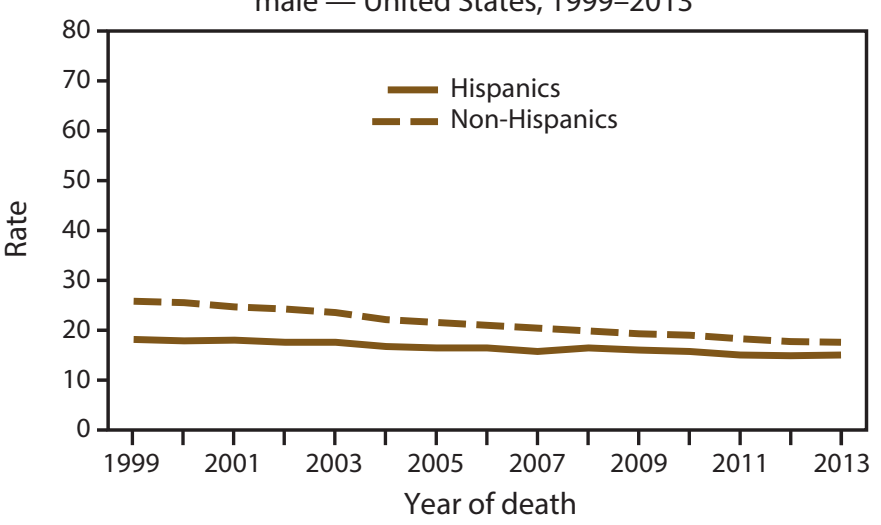

Death rates by ethnicity, all cancer sites combined, female - United States, 1999-2013

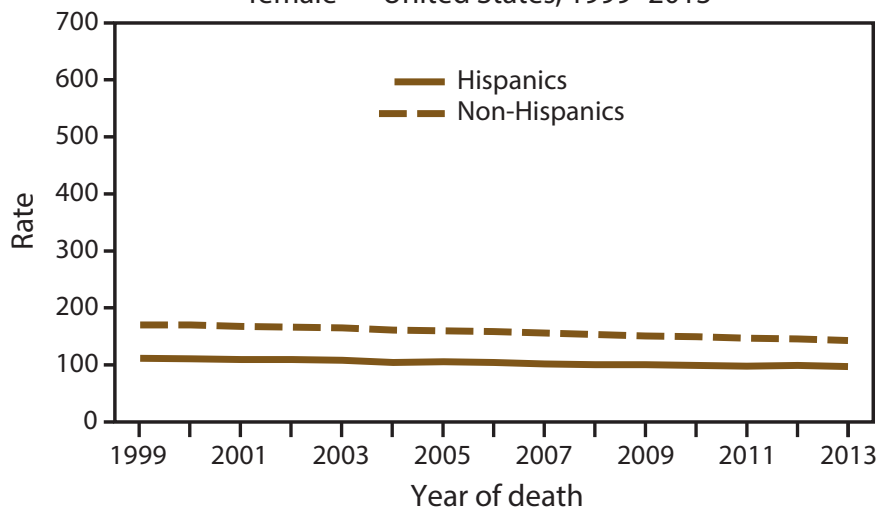

Death rates by ethnicity, colorectal cancer, female - United States, 1999-2013

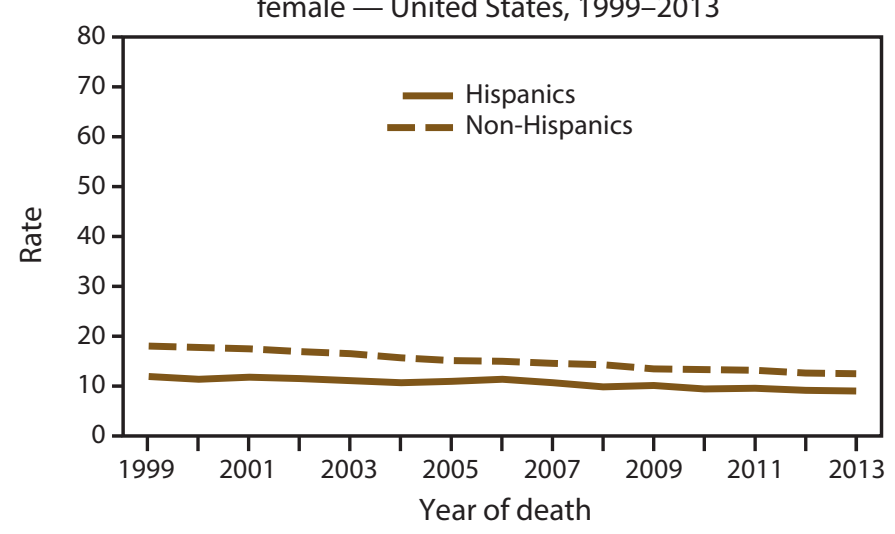

See figure footnotes on the next page. 
FIGURE 8. (Continued) Reported rate* of cancer deaths, by primary cancer site, ethnicity, ${ }^{\dagger}$ and sex — United States, $2013^{\S}$
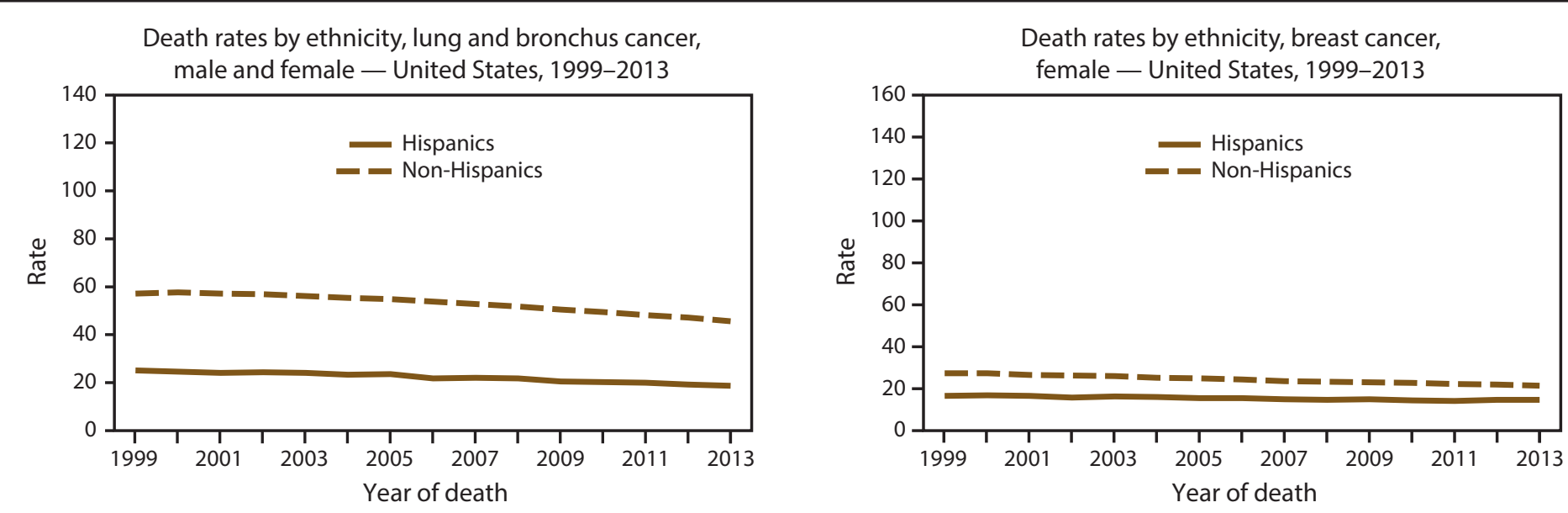

Death rates by ethnicity, lung and bronchus cancer, male — United States, 1999-2013
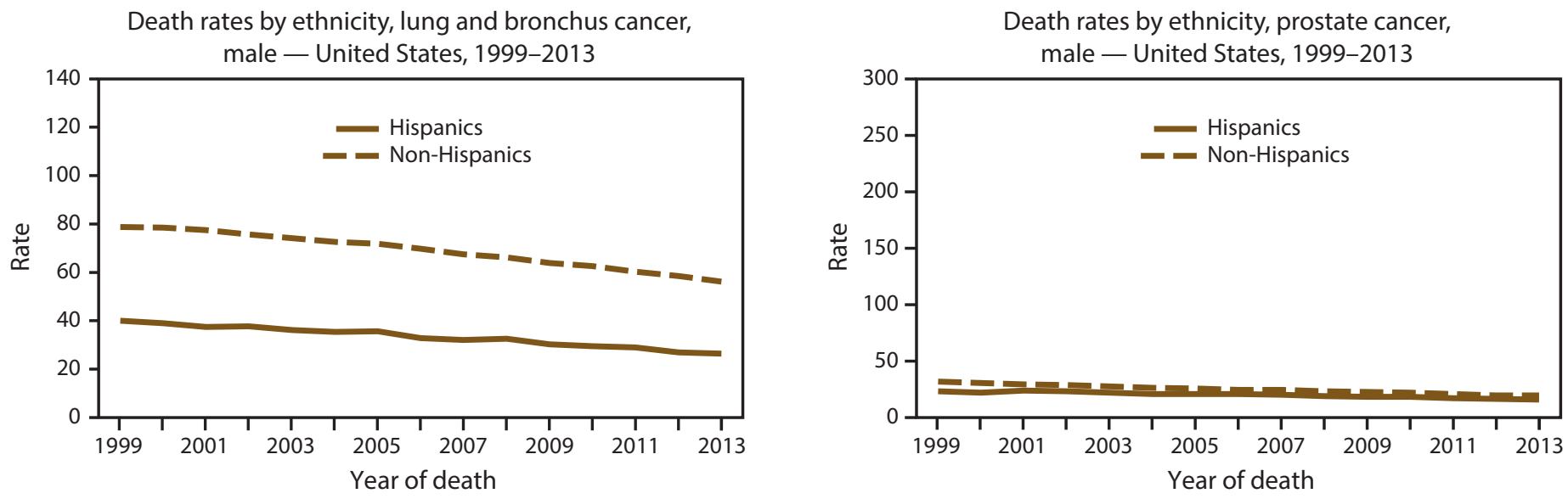

Death rates by ethnicity, lung and bronchus cancer, female - United States, 1999-2013

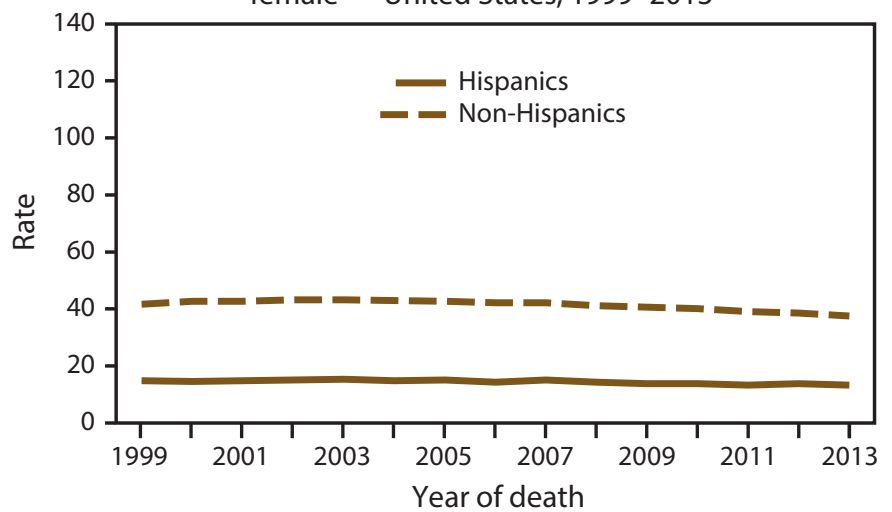

* Rates are the number of deaths per 100,000 persons and are age-adjusted to the 2000 U.S. standard population (19 age groups - Census P25-1130). For more information, see USCS technical notes (https://www.cdc.gov/cancer/npcr/uscs/pdf/uscs-2013-technical-notes.pdf).

† Rates are not presented for persons of unknown ethnicity. Data for specified ethnic populations should be interpreted with caution. For more information, see USCS technical notes (https://www.cdc.gov/cancer/npcr/uscs/pdf/uscs-2013-technical-notes.pdf\#nameddest=IntRaceEthnicityData).

$\S$ Data are from the National Vital Statistics System (NVSS). Data for death rates cover $100 \%$ of the U.S. population. Use caution when comparing incidence and death rates because of potential differences in population coverage. 
TABLE 1. Reported number and rate* of invasive ${ }^{\dagger}$ cancer cases, by primary cancer site and sex — United States, $2013^{\S}$

\begin{tabular}{|c|c|c|c|c|c|c|}
\hline \multirow[b]{2}{*}{ Cancer site } & \multicolumn{2}{|c|}{ Male } & \multicolumn{2}{|c|}{ Female } & \multicolumn{2}{|c|}{ Total } \\
\hline & No. & Rate & No. & Rate & No. & Rate \\
\hline All sites combined & 781,451 & 479.0 & 777,679 & 412.6 & $1,559,130$ & 439.0 \\
\hline Oral cavity and pharynx & 29,693 & 17.4 & 12,024 & 6.3 & 41,717 & 11.5 \\
\hline Lip & 1,399 & 0.9 & 547 & 0.3 & 1,946 & 0.6 \\
\hline Tongue & 9,164 & 5.3 & 3,592 & 1.9 & 12,756 & 3.5 \\
\hline Salivary gland & 2,629 & 1.7 & 1,779 & 1.0 & 4,408 & 1.3 \\
\hline Floor of mouth & 1,368 & 0.8 & 621 & 0.3 & 1,989 & 0.5 \\
\hline Gum and other mouth & 3,054 & 1.9 & 2,392 & 1.2 & 5,446 & 1.5 \\
\hline Nasopharynx & 1,289 & 0.8 & 521 & 0.3 & 1,810 & 0.5 \\
\hline Tonsil & 6,528 & 3.7 & 1,415 & 0.7 & 7,943 & 2.1 \\
\hline Oropharynx & 1,459 & 0.8 & 447 & 0.2 & 1,906 & 0.5 \\
\hline Hypopharynx & 1,893 & 1.1 & 450 & 0.2 & 2,343 & 0.6 \\
\hline Other oral cavity and pharynx & 910 & 0.5 & 260 & 0.1 & 1,170 & 0.3 \\
\hline Digestive system & 155,535 & 95.4 & 124,185 & 63.8 & 279,720 & 78.2 \\
\hline Esophagus & 12,913 & 7.8 & 3,519 & 1.8 & 16,432 & 4.5 \\
\hline Stomach & 14,429 & 9.0 & 8,719 & 4.5 & 23,148 & 6.6 \\
\hline Small intestine & 4,307 & 2.6 & 3,887 & 2.0 & 8,194 & 2.3 \\
\hline Colon and rectum & 71,099 & 44.2 & 65,020 & 33.6 & 136,119 & 38.4 \\
\hline Colon excluding rectum & 48,175 & 30.3 & 48,748 & 25.0 & 96,923 & 27.4 \\
\hline Rectum and rectosigmoid junction & 22,924 & 13.9 & 16,272 & 8.6 & 39,196 & 11.0 \\
\hline Anus, anal canal, and anorectum & 2,441 & 1.5 & 4,136 & 2.1 & 6,577 & 1.8 \\
\hline Liver and intrahepatic bile duct & 21,143 & 12.0 & 8,330 & 4.2 & 29,473 & 7.9 \\
\hline Gallbladder & 1,280 & 0.8 & 2,654 & 1.3 & 3,934 & 1.1 \\
\hline Other biliary & 3,401 & 2.2 & 2,979 & 1.5 & 6,380 & 1.8 \\
\hline Pancreas & 22,787 & 14.1 & 21,590 & 10.9 & 44,377 & 12.4 \\
\hline Retroperitoneum & 623 & 0.4 & 610 & 0.3 & 1,233 & 0.4 \\
\hline Peritoneum, omentum, and mesentery & 170 & 0.1 & 1,804 & 0.9 & 1,974 & 0.6 \\
\hline Other digestive organs & 942 & 0.6 & 937 & 0.5 & 1,879 & 0.5 \\
\hline Respiratory system & 123,760 & 76.9 & 104,348 & 53.4 & 228,108 & 63.6 \\
\hline Nose, nasal cavity, and middle ear & 1,435 & 0.9 & 895 & 0.5 & 2,330 & 0.7 \\
\hline Larynx & 9,923 & 5.9 & 2,519 & 1.3 & 12,442 & 3.4 \\
\hline Lung and bronchus & 111,907 & 69.8 & 100,677 & 51.5 & 212,584 & 59.4 \\
\hline Pleura & 57 & 0 & 48 & 0 & 105 & 0 \\
\hline $\begin{array}{l}\text { Trachea, mediastinum, and other } \\
\text { respiratory organs }\end{array}$ & 438 & 0.3 & 209 & 0.1 & 647 & 0.2 \\
\hline Bones and joints & 1,650 & 1.1 & 1,334 & 0.8 & 2,984 & 0.9 \\
\hline Soft tissue including heart & 6,093 & 3.9 & 4,965 & 2.8 & 11,058 & 3.3 \\
\hline Skin excluding basal and squamous & 45,977 & 29.0 & 31,938 & 17.6 & 77,915 & 22.4 \\
\hline Melanoma of the skin & 42,430 & 26.6 & 29,513 & 16.3 & 71,943 & 20.7 \\
\hline Other nonepithelial skin & 3,547 & 2.4 & 2,425 & 1.3 & 5,972 & 1.7 \\
\hline Male and female breast & NA & NA & NA & NA & 232,924 & 66.3 \\
\hline Female breast & NA & NA & 230,815 & 123.7 & NA & NA \\
\hline Male breast & 2,109 & 1.3 & NA & NA & NA & NA \\
\hline Female genital system & NA & NA & 91,872 & 48.6 & NA & NA \\
\hline Cervix & NA & NA & 11,955 & 7.2 & NA & NA \\
\hline Corpus and uterus, NOS & NA & NA & 50,560 & 25.9 & NA & NA \\
\hline Corpus & NA & NA & 48,937 & 25.0 & NA & NA \\
\hline Uterus, NOS & NA & NA & 1,623 & 0.8 & NA & NA \\
\hline Ovary & NA & NA & 20,927 & 11.2 & NA & NA \\
\hline Vagina & NA & NA & 1,266 & 0.6 & NA & NA \\
\hline Vulva & NA & NA & 4,895 & 2.6 & NA & NA \\
\hline Other female genital organs & NA & NA & 2,269 & 1.2 & NA & NA \\
\hline Male genital system & 186,509 & 108.2 & NA & NA & NA & NA \\
\hline Prostate & 176,450 & 101.6 & NA & NA & NA & NA \\
\hline Testis & 8,351 & 5.5 & NA & NA & NA & NA \\
\hline Penis & 1,334 & 0.9 & NA & NA & NA & NA \\
\hline Other male genital organs & 374 & 0.2 & NA & NA & NA & NA \\
\hline Urinary system & 91,832 & 58.0 & 39,163 & 20.3 & 130,995 & 36.9 \\
\hline Urinary bladder & 53,921 & 34.9 & 17,030 & 8.6 & 70,951 & 20.0 \\
\hline Kidney and renal pelvis & 35,914 & 21.7 & 21,034 & 11.2 & 56,948 & 16.0 \\
\hline Ureter & 1,185 & 0.8 & 722 & 0.4 & 1,907 & 0.5 \\
\hline Other urinary organs & 812 & 0.5 & 377 & 0.2 & 1,189 & 0.3 \\
\hline
\end{tabular}

See table footnotes on next page. 
TABLE 1. (Continued) Reported number and rate* of invasive ${ }^{\dagger}$ cancer cases, by primary cancer site and sex - United States, $2013^{\S}$

\begin{tabular}{|c|c|c|c|c|c|c|}
\hline \multirow[b]{2}{*}{ Cancer site } & \multicolumn{2}{|c|}{ Male } & \multicolumn{2}{|c|}{ Female } & \multicolumn{2}{|c|}{ Total } \\
\hline & No. & Rate & No. & Rate & No. & Rate \\
\hline Eye and orbit & 1,540 & 1.0 & 1,271 & 0.7 & 2,811 & 0.8 \\
\hline Brain and other nervous system & 12,092 & 7.6 & 9,756 & 5.5 & 21,848 & 6.5 \\
\hline Brain & 11,453 & 7.2 & 9,036 & 5.1 & 20,489 & 6.0 \\
\hline Cranial nerves other nervous system & 639 & 0.4 & 720 & 0.4 & 1,359 & 0.4 \\
\hline Endocrine system & 13,052 & 8.1 & 37,033 & 22.2 & 50,085 & 15.3 \\
\hline Thyroid & 11,816 & 7.3 & 35,877 & 21.6 & 47,693 & 14.6 \\
\hline Other endocrine including thymus & 1,236 & 0.8 & 1,156 & 0.7 & 2,392 & 0.7 \\
\hline Lymphomas & 40,056 & 25.3 & 32,899 & 17.6 & 72,955 & 21.1 \\
\hline Hodgkin lymphoma & 4,574 & 2.9 & 3,659 & 2.3 & 8,233 & 2.6 \\
\hline Non-Hodgkin lymphoma & 35,482 & 22.4 & 29,240 & 15.4 & 64,722 & 18.5 \\
\hline Myeloma & 12,556 & 7.8 & 10,006 & 5.1 & 22,562 & 6.3 \\
\hline Leukemias & 26,337 & 16.9 & 19,023 & 10.3 & 45,360 & 13.2 \\
\hline Acute lymphocytic leukemia & 2,599 & 1.7 & 2,052 & 1.3 & 4,651 & 1.5 \\
\hline Chronic lymphocytic leukemia & 9,223 & 5.8 & 5,869 & 3.0 & 15,092 & 4.2 \\
\hline Acute myeloid leukemia & 7,921 & 5.1 & 6,419 & 3.5 & 14,340 & 4.2 \\
\hline Chronic myeloid leukemia & 3,499 & 2.3 & 2,495 & 1.4 & 5,994 & 1.8 \\
\hline Other leukemias & 3,095 & 2.0 & 2,188 & 1.1 & 5,283 & 1.5 \\
\hline Mesothelioma & 2,441 & 1.6 & 766 & 0.4 & 3,207 & 0.9 \\
\hline Kaposi Sarcoma & 985 & 0.7 & 120 & 0.1 & 1,105 & 0.4 \\
\hline Miscellaneous & 29,234 & 19.0 & 26,161 & 13.3 & 55,395 & 15.7 \\
\hline
\end{tabular}

Abbreviations: NA = not applicable; NOS = not otherwise specified.

* Rates are the number of cases per 100,000 persons and are age-adjusted to the 2000 U.S. standard population (19 age groups - Census P25-1130). For more information, see USCS technical notes (https://www.cdc.gov/cancer/npcr/uscs/pdf/uscs-2013-technical-notes.pdf).

+ Invasive cancer excludes basal and squamous cell carcinomas of the skin except when these occur on the skin of the genital organs, and in situ cancers except urinary bladder. Urinary bladder cancer includes invasive and in situ.

$\S$ Data are compiled from cancer registries that meet the data quality criteria for all invasive cancer sites combined (all registries except Nevada, covering approximately $99 \%$ of the U.S. population). 
TABLE 2. Reported number and rate* of cancer deaths, by primary cancer site and sex - United States, $2013^{\dagger}$

\begin{tabular}{|c|c|c|c|c|c|c|}
\hline \multirow[b]{2}{*}{ Cancer site } & \multicolumn{2}{|c|}{ Male } & \multicolumn{2}{|c|}{ Female } & \multicolumn{2}{|c|}{ Total } \\
\hline & No. & Rate & No. & Rate & No. & Rate \\
\hline All sites combined & 307,553 & 196.2 & 277,319 & 139.1 & 584,872 & 163.0 \\
\hline Oral cavity and pharynx & 6,227 & 3.7 & 2,623 & 1.3 & 8,850 & 2.4 \\
\hline Lip & 42 & 0 & 17 & 0 & 59 & 0 \\
\hline Tongue & 1,507 & 0.9 & 701 & 0.4 & 2,208 & 0.6 \\
\hline Salivary gland & 599 & 0.4 & 287 & 0.1 & 886 & 0.2 \\
\hline Floor of mouth & 51 & 0 & 33 & 0 & 84 & 0 \\
\hline Gum and other mouth & 706 & 0.4 & 542 & 0.3 & 1,248 & 0.3 \\
\hline Nasopharynx & 467 & 0.3 & 176 & 0.1 & 643 & 0.2 \\
\hline Tonsil & 657 & 0.4 & 182 & 0.1 & 839 & 0.2 \\
\hline Oropharynx & 663 & 0.4 & 243 & 0.1 & 906 & 0.2 \\
\hline Hypopharynx & 260 & 0.2 & 64 & 0 & 324 & 0.1 \\
\hline Other oral cavity and pharynx & 1,275 & 0.8 & 378 & 0.2 & 1,653 & 0.4 \\
\hline Digestive system & 85,255 & 52.9 & 63,528 & 31.4 & 148,783 & 41.1 \\
\hline Esophagus & 11,731 & 7.1 & 2,958 & 1.5 & 14,689 & 4.0 \\
\hline Stomach & 6,793 & 4.3 & 4,468 & 2.3 & 11,261 & 3.2 \\
\hline Small intestine & 705 & 0.5 & 565 & 0.3 & 1,270 & 0.4 \\
\hline Colon and rectum & 27,230 & 17.3 & 24,583 & 12.1 & 51,813 & 14.5 \\
\hline Colon excluding rectum & 21,494 & 13.8 & 20,469 & 10.1 & 41,963 & 11.7 \\
\hline Rectum and rectosigmoid junction & 5,736 & 3.5 & 4,114 & 2.1 & 9,850 & 2.7 \\
\hline Anus, anal canal, and anorectum & 371 & 0.2 & 529 & 0.3 & 900 & 0.2 \\
\hline Liver and intrahepatic bile duct & 16,300 & 9.5 & 7,732 & 3.8 & 24,032 & 6.5 \\
\hline Gallbladder & 750 & 0.5 & 1,410 & 0.7 & 2,160 & 0.6 \\
\hline Other biliary & 704 & 0.5 & 814 & 0.4 & 1,518 & 0.4 \\
\hline Pancreas & 19,854 & 12.4 & 19,142 & 9.4 & 38,996 & 10.8 \\
\hline Retroperitoneum & 111 & 0.1 & 82 & 0 & 193 & 0.1 \\
\hline Peritoneum, omentum, and mesentery & 71 & 0 & 679 & 0.3 & 750 & 0.2 \\
\hline Other digestive organs & 635 & 0.4 & 566 & 0.3 & 1,201 & 0.3 \\
\hline Respiratory system & 89,108 & 56.0 & 71,536 & 35.9 & 160,644 & 44.6 \\
\hline Nose, nasal cavity, and middle ear & 269 & 0.2 & 174 & 0.1 & 443 & 0.1 \\
\hline Larynx & 2,994 & 1.8 & 735 & 0.4 & 3,729 & 1.0 \\
\hline Lung and bronchus & 85,658 & 53.9 & 70,518 & 35.4 & 156,176 & 43.4 \\
\hline Pleura & 42 & 0 & 24 & 0 & 66 & 0 \\
\hline $\begin{array}{l}\text { Trachea, mediastinum, and other } \\
\text { respiratory organs }\end{array}$ & 145 & 0.1 & 85 & 0 & 230 & 0.1 \\
\hline Bones and joints & 832 & 0.5 & 621 & 0.3 & 1,453 & 0.4 \\
\hline Soft tissue including heart & 2,378 & 1.5 & 2,182 & 1.2 & 4,560 & 1.3 \\
\hline Skin excluding basal and squamous & 8,723 & 5.6 & 4,025 & 2.0 & 12,748 & 3.6 \\
\hline Melanoma of the skin & 6,239 & 4.0 & 3,155 & 1.6 & 9,394 & 2.7 \\
\hline Other nonepithelial skin & 2,484 & 1.6 & 870 & 0.4 & 3,354 & 0.9 \\
\hline Male and female breast & NA & NA & NA & NA & 41,324 & 11.5 \\
\hline Female breast & NA & NA & 40,860 & 20.7 & NA & NA \\
\hline Male breast & 464 & 0.3 & NA & NA & NA & NA \\
\hline Female genital system & NA & NA & 29,828 & 15.2 & NA & NA \\
\hline Cervix & NA & NA & 4,217 & 2.3 & NA & NA \\
\hline Corpus and uterus, NOS & NA & NA & 9,325 & 4.6 & NA & NA \\
\hline Corpus & NA & NA & 3,903 & 1.9 & NA & NA \\
\hline Uterus, NOS & NA & NA & 5,422 & 2.7 & NA & NA \\
\hline Ovary & NA & NA & 14,276 & 7.2 & NA & NA \\
\hline Vagina & NA & NA & 437 & 0.2 & NA & NA \\
\hline Vulva & NA & NA & 1,003 & 0.5 & NA & NA \\
\hline Other female genital organs & NA & NA & 570 & 0.3 & NA & NA \\
\hline Male genital system & 28,390 & 19.7 & NA & NA & NA & NA \\
\hline Prostate & 27,681 & 19.2 & NA & NA & NA & NA \\
\hline Testis & 383 & 0.2 & NA & NA & NA & NA \\
\hline Penis & 270 & 0.2 & NA & NA & NA & NA \\
\hline Other male genital organs & 56 & 0 & NA & NA & NA & NA \\
\hline Urinary system & 20,765 & 13.6 & 9,747 & 4.8 & 30,512 & 8.5 \\
\hline Urinary bladder & 11,294 & 7.7 & 4,463 & 2.1 & 15,757 & 4.4 \\
\hline Kidney and renal pelvis & 8,967 & 5.6 & 4,939 & 2.5 & 13,906 & 3.9 \\
\hline Ureter & 251 & 0.2 & 183 & 0.1 & 434 & 0.1 \\
\hline Other urinary organs & 253 & 0.2 & 162 & 0.1 & 415 & 0.1 \\
\hline
\end{tabular}

See table footnotes on next page. 
TABLE 2. (Continued) Reported number and rate* of cancer deaths, by primary cancer site and sex - United States, $2013^{\dagger}$

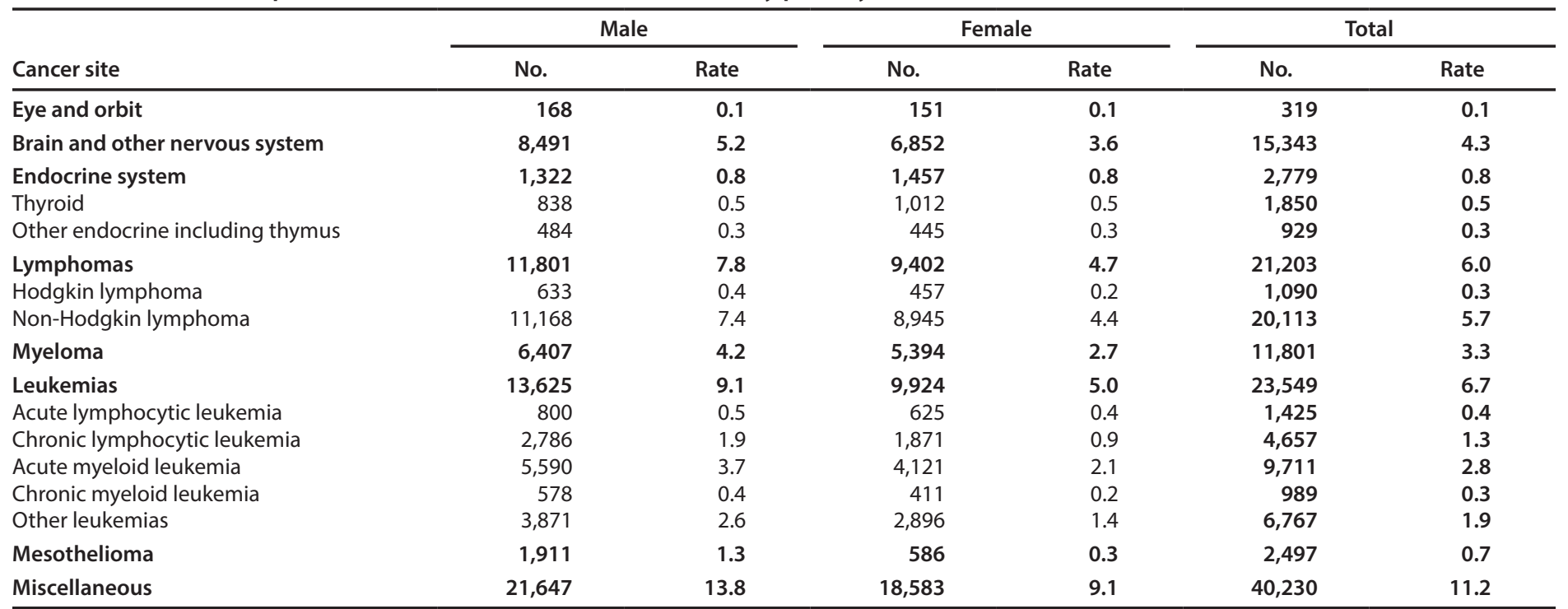

Abbreviations: NA = not applicable; NOS = not otherwise specified.

* Rates are the number of deaths per 100,000 persons and are age-adjusted to the 2000 U.S. standard population (19 age groups - Census P25-1130). For more information, see USCS technical notes (https://www.cdc.gov/cancer/npcr/uscs/pdf/uscs-2013-technical-notes.pdf).

${ }^{\dagger}$ Data are from the National Vital Statistics System (NVSS). 
TABLE 3. Reported number and rate* of invasive ${ }^{\dagger}$ cancer cases, all sites combined, by geographic division and area — United States, $2013^{\S}$

\begin{tabular}{|c|c|c|}
\hline \multirow[b]{2}{*}{ Area/State } & \multicolumn{2}{|c|}{ All races/ethnicities } \\
\hline & No. & Rate \\
\hline Northeast & 319,548 & 478.5 \\
\hline New England & 82,466 & 464.8 \\
\hline Connecticut & 20,510 & 474.2 \\
\hline Maine & 8,366 & 463.8 \\
\hline Massachusetts & 36,097 & 457.5 \\
\hline New Hampshire & 7,886 & 479.2 \\
\hline Rhode Island & 6,097 & 479.4 \\
\hline Vermont & 3,510 & 437.1 \\
\hline Middle Atlantic & 237,082 & 483.5 \\
\hline New Jersey & 49,960 & 483.1 \\
\hline New York & 109,560 & 484.3 \\
\hline Pennsylvania & 77,562 & 483.0 \\
\hline Midwest & 350,820 & 448.1 \\
\hline East North Central & 242,838 & 448.2 \\
\hline Illinois & 64,959 & 454.9 \\
\hline Indiana & 32,372 & 438.8 \\
\hline Michigan & 52,067 & 440.1 \\
\hline Ohio & 62,802 & 452.4 \\
\hline Wisconsin & 30,638 & 451.1 \\
\hline West North Central & 107,982 & 447.7 \\
\hline lowa & 16,911 & 456.1 \\
\hline Kansas & 14,572 & 450.9 \\
\hline Minnesota & 27,770 & 451.8 \\
\hline Missouri & 31,628 & 442.6 \\
\hline Nebraska & 9,176 & 437.6 \\
\hline North Dakota & 3,508 & 433.6 \\
\hline South Dakota & 4,417 & 450.1 \\
\hline South & 578,843 & 433.6 \\
\hline South Atlantic & 316,742 & 432.0 \\
\hline Delaware & 5,681 & 502.0 \\
\hline District of Columbia & 2,780 & 445.2 \\
\hline Florida & 108,216 & 413.0 \\
\hline Georgia & 45,984 & 450.3 \\
\hline Maryland & 29,824 & 451.0 \\
\hline North Carolina & 49,970 & 445.4 \\
\hline South Carolina & 24,809 & 436.9 \\
\hline Virginia & 38,151 & 418.5 \\
\hline West Virginia & 11,327 & 464.0 \\
\hline East South Central & 101,032 & 464.8 \\
\hline Alabama & 25,340 & 444.0 \\
\hline Kentucky & 26,068 & 511.7 \\
\hline Mississippi & 15,482 & 459.9 \\
\hline Tennessee & 34,142 & 450.9 \\
\hline
\end{tabular}

TABLE 3. (Continued) Reported number and rate* of invasive $^{\dagger}$ cancer cases, all sites combined, by geographic division and area United States, $2013^{\S}$

\begin{tabular}{lrr}
\hline & \multicolumn{2}{c}{ All races/ethnicities } \\
\cline { 2 - 3 } Area/State & \multicolumn{1}{c}{ No. } & Rate \\
\hline West South Central & 161,069 & 419.0 \\
Arkansas & 15,879 & 454.0 \\
Louisiana & 24,184 & 476.3 \\
Oklahoma & 19,044 & 440.3 \\
Texas & 101,962 & 399.4 \\
West & - & - \\
Mountain & - & - \\
Arizona & 28,418 & 370.6 \\
Colorado & 21,764 & 396.1 \\
Idaho & 7,358 & 419.5 \\
Montana & 5,610 & 437.0 \\
Nevada & - & - \\
New Mexico & 8,728 & 363.7 \\
Utah & 9,626 & 393.2 \\
Wyoming & 2,517 & 382.0 \\
Pacific & 225,898 & 412.3 \\
Alaska & 2,664 & 410.4 \\
California & 160,911 & 402.8 \\
Hawaii & 7,000 & 419.8 \\
Oregon & 20,458 & 431.5 \\
Washington & 34,865 & 450.3 \\
\hline
\end{tabular}

* Rates are the number of cases per 100,000 persons and are age-adjusted to the 2000 U.S. standard population (19 age groups - Census P25-1130). For more information, see USCS technical notes (https://www.cdc.gov/cancer/ npcr/uscs/pdf/uscs-2013-technical-notes.pdf).

$\dagger$ Invasive cancer excludes basal and squamous cell carcinomas of the skin except when these occur on the skin of the genital organs, and in situ cancers except urinary bladder.

$\S$ Data are compiled from cancer registries that meet the data quality criteria for all invasive cancer sites combined (all registries except Nevada, covering approximately $99 \%$ of the U.S. population).

"Rates and counts are not presented for the West Census Region, the Mountain Census Division, or Nevada because data from Nevada are not included in this analysis. 
TABLE 4. Reported cancer deaths and death rates, ${ }^{*}$ all sites combined, by geographic division and area - United States, $2013^{\dagger}$

\begin{tabular}{|c|c|c|}
\hline \multirow[b]{2}{*}{ Area/State } & \multicolumn{2}{|c|}{ All races/ethnicities } \\
\hline & No. & Rate \\
\hline United States & 584,872 & 163.0 \\
\hline Northeast & 109,494 & 160.1 \\
\hline New England & 28,932 & 159.4 \\
\hline Connecticut & 6,619 & 147.8 \\
\hline Maine & 3,227 & 174.8 \\
\hline Massachusetts & 12,858 & 159.7 \\
\hline New Hampshire & 2,584 & 158.6 \\
\hline Rhode Island & 2,326 & 173.9 \\
\hline Vermont & 1,318 & 164.1 \\
\hline Middle Atlantic & 80,562 & 160.4 \\
\hline New Jersey & 16,315 & 156.0 \\
\hline New York & 35,735 & 155.5 \\
\hline Pennsylvania & 28,512 & 170.0 \\
\hline Midwest & 135,293 & 170.7 \\
\hline East North Central & 94,527 & 173.0 \\
\hline Illinois & 24,491 & 171.7 \\
\hline Indiana & 13,258 & 179.4 \\
\hline Michigan & 20,367 & 170.2 \\
\hline Ohio & 24,986 & 177.4 \\
\hline Wisconsin & 11,425 & 164.6 \\
\hline West North Central & 40,766 & 165.6 \\
\hline lowa & 6,509 & 168.2 \\
\hline Kansas & 5,379 & 162.9 \\
\hline Minnesota & 9,601 & 155.1 \\
\hline Missouri & 12,955 & 179.1 \\
\hline Nebraska & 3,459 & 160.7 \\
\hline North Dakota & 1,286 & 150.8 \\
\hline South Dakota & 1,577 & 154.1 \\
\hline South & 223,673 & 168.4 \\
\hline South Atlantic & 120,225 & 162.8 \\
\hline Delaware & 1,905 & 167.1 \\
\hline District of Columbia & 1,095 & 177.7 \\
\hline Florida & 42,734 & 154.9 \\
\hline Georgia & 16,417 & 168.1 \\
\hline Maryland & 10,608 & 163.0 \\
\hline North Carolina & 18,589 & 167.7 \\
\hline South Carolina & 9,745 & 174.0 \\
\hline Virginia & 14,414 & 162.3 \\
\hline West Virginia & 4,718 & 190.5 \\
\hline
\end{tabular}

TABLE 4. (Continued) Reported cancer deaths and death rates, * all sites combined, by geographic division and area - United States, $2013^{\dagger}$

\begin{tabular}{lrr}
\hline & \multicolumn{2}{c}{ All races/ethnicities } \\
\cline { 2 - 3 } Area/State & \multicolumn{1}{c}{ No. } & Rate \\
\hline East South Central & 40,890 & 189.5 \\
Alabama & 10,328 & 182.1 \\
Kentucky & 10,082 & 199.3 \\
Mississippi & 6,527 & 196.5 \\
Tennessee & 13,953 & 185.4 \\
West South Central & 62,558 & 167.3 \\
Arkansas & 6,688 & 189.6 \\
Louisiana & 9,419 & 188.7 \\
Oklahoma & 8,039 & 185.4 \\
Texas & 38,412 & 156.9 \\
West & 116,412 & 148.3 \\
Mountain & 35,623 & 146.1 \\
Arizona & 11,347 & 146.4 \\
Colorado & 7,357 & 139.2 \\
Idaho & 2,707 & 156.3 \\
Montana & 1,997 & 154.0 \\
Nevada & 4,817 & 164.9 \\
New Mexico & 3,481 & 145.1 \\
Utah & 2,971 & 127.9 \\
Wyoming & 946 & 147.7 \\
Pacific & 80,789 & 149.3 \\
Alaska & 1,016 & 173.1 \\
California & 57,714 & 146.6 \\
Hawaii & 2,332 & 134.9 \\
Oregon & 7,799 & 163.2 \\
Washington & 11,928 & 156.3 \\
\hline
\end{tabular}

* Rates are the number of deaths per 100,000 persons and are age-adjusted to the 2000 U.S. standard population (19 age groups - Census P25-1130). For more information, see USCS technical notes (https://www.cdc.gov/cancer/ npcr/uscs/pdf/uscs-2013-technical-notes.pdf).

† Data are from the National Vital Statistics System (NVSS). 
TABLE 5. Reported number and rate* of invasive ${ }^{\dagger}$ cancer cases, by primary cancer site and age group — United States, $2013^{\S}$

\begin{tabular}{|c|c|c|c|c|c|c|c|c|c|c|c|c|}
\hline \multirow[b]{3}{*}{ Cancer site } & \multicolumn{10}{|c|}{ Age group (yrs) } & & \\
\hline & \multicolumn{2}{|c|}{$<15$} & \multicolumn{2}{|c|}{$15-24$} & \multicolumn{2}{|c|}{ 25-39 } & \multicolumn{2}{|c|}{$40-64$} & \multicolumn{2}{|c|}{$\geq 65$} & \multicolumn{2}{|c|}{ Total (all ages) } \\
\hline & No. & Rate & No. & Rate & No. & Rate & No. & Rate & No. & Rate & No. & Rate (crude) \\
\hline All sites combined & 10,172 & 16.8 & 12,482 & 28.6 & 59,280 & 95.7 & 625,691 & 606.5 & 851,505 & $1,920.3$ & $1,559,130$ & 497.0 \\
\hline Oral cavity and pharynx & 107 & 0.2 & 226 & 0.5 & 1,138 & 1.8 & 21,699 & 21.0 & 18,547 & 41.8 & 41,717 & 13.3 \\
\hline Esophagus & - & - & - & - & 131 & 0.2 & 6,513 & 6.3 & 9,782 & 22.1 & 16,432 & 5.2 \\
\hline Stomach & - & - & 67 & 0.2 & 639 & 1.0 & 8,301 & 8.0 & 14,137 & 31.9 & - & 7.4 \\
\hline Colon and rectum & 48 & 0.1 & 359 & 0.8 & 3,463 & 5.6 & 52,994 & 51.4 & 79,255 & 178.7 & 136,119 & 43.4 \\
\hline Liver and intrahepatic bile duct & 180 & 0.3 & 76 & 0.2 & 307 & 0.5 & 15,104 & 14.6 & 13,806 & 31.1 & 29,473 & 9.4 \\
\hline Pancreas & - & - & 57 & 0.1 & 446 & 0.7 & 14,506 & 14.1 & 29,361 & 66.2 & - & 14.1 \\
\hline Larynx & - & - & - & - & 93 & 0.2 & 5,998 & 5.8 & 6,337 & 14.3 & 12,442 & 4.0 \\
\hline Lung and bronchus & 35 & 0.1 & 101 & 0.2 & 948 & 1.5 & 65,462 & 63.5 & 146,038 & 329.3 & 212,584 & 67.8 \\
\hline Melanomas of the skin & 120 & 0.2 & 912 & 2.1 & 5,477 & 8.8 & 29,698 & 28.8 & 35,736 & 80.6 & 71,943 & 22.9 \\
\hline Female breast & - & - & 189 & 0.9 & 9,965 & 32.3 & 117,033 & 222.1 & 103,622 & 415.9 & - & 144.8 \\
\hline Cervix & - & - & 120 & 0.6 & 2,796 & 9.1 & 6,605 & 12.5 & 2,428 & 9.7 & - & 7.5 \\
\hline Corpus and uterus, NOS & - & - & 62 & 0.3 & 1,607 & 5.2 & 26,844 & 51.0 & 22,044 & 88.5 & - & 31.7 \\
\hline Ovary & 115 & 0.4 & 346 & 1.6 & 1,028 & 3.3 & 9,498 & 18.0 & 9,940 & 39.9 & 20,927 & 13.1 \\
\hline Prostate & - & - & - & - & 94 & 0.3 & 74,866 & 148.3 & 101,478 & 522.4 & 176,450 & 114.3 \\
\hline Testis & 69 & 0.2 & 1,464 & 6.5 & 4,222 & 13.6 & 2,396 & 4.7 & 200 & 1.0 & 8,351 & 5.4 \\
\hline Urinary bladder & 20 & 0 & 55 & 0.1 & 513 & 0.8 & 17,787 & 17.2 & 52,576 & 118.6 & 70,951 & 22.6 \\
\hline Kidney and renal pelvis & 549 & 0.9 & 161 & 0.4 & 2,140 & 3.5 & 25,809 & 25.0 & 28,289 & 63.8 & 56,948 & 18.2 \\
\hline Brain and nervous system & 2,170 & 3.6 & 954 & 2.2 & 2,023 & 3.3 & 8,381 & 8.1 & 8,320 & 18.8 & 21,848 & 7.0 \\
\hline Thyroid & 222 & 0.4 & 1,936 & 4.4 & 9,820 & 15.8 & 25,477 & 24.7 & 10,238 & 23.1 & 47,693 & 15.2 \\
\hline Hodgkin lymphoma & 327 & 0.5 & 1,516 & 3.5 & 2,183 & 3.5 & 2,631 & 2.6 & 1,576 & 3.6 & 8,233 & 2.6 \\
\hline Non-Hodgkin lymphoma & 591 & 1.0 & 923 & 2.1 & 2,909 & 4.7 & 23,046 & 22.3 & 37,253 & 84.0 & 64,722 & 20.6 \\
\hline Myeloma & - & - & - & - & 278 & 0.4 & 7,953 & 7.7 & 14,313 & 32.3 & 22,562 & 7.2 \\
\hline Leukemias & 2,896 & 4.8 & 1,241 & 2.8 & 2,162 & 3.5 & 13,922 & 13.5 & 25,139 & 56.7 & 45,360 & 14.5 \\
\hline Mesothelioma & - & - & - & - & 46 & 0.1 & 676 & 0.7 & 2,478 & 5.6 & 3,207 & 1.0 \\
\hline Kaposi Sarcoma & - & - & 43 & 0.1 & 300 & 0.5 & 460 & 0.4 & 301 & 0.7 & - & 0.4 \\
\hline
\end{tabular}

Abbreviation: NOS = not otherwise specified.

* Rates are the number of cases per 100,000 persons. For more information, see USCS technical notes (https://www.cdc.gov/cancer/npcr/uscs/pdf/uscs-2013-technicalnotes.pdf).

${ }^{\dagger}$ Invasive cancer excludes basal and squamous cell carcinomas of the skin except when these occur on the skin of the genital organs, and in situ cancers except urinary bladder. Urinary bladder cancer includes invasive and in situ.

$\S$ Data are compiled from cancer registries that meet the data quality criteria for all invasive cancer sites combined (all registries except Nevada, covering approximately $99 \%$ of the U.S. population).

" Counts and rates are suppressed if $<16$ cases were reported in a specific category. Some counts and rates are suppressed as complementary cell suppression. 
TABLE 6. Reported number and rate* of cancer deaths, by primary cancer site and age group — United States, $2013^{\dagger}$

\begin{tabular}{|c|c|c|c|c|c|c|c|c|c|c|c|c|}
\hline \multirow[b]{3}{*}{ Cancer site } & \multicolumn{10}{|c|}{ Age group (yrs) } & & \\
\hline & \multicolumn{2}{|c|}{$<15$} & \multicolumn{2}{|c|}{$15-24$} & \multicolumn{2}{|c|}{$25-39$} & \multicolumn{2}{|c|}{$40-64$} & \multicolumn{2}{|c|}{$\geq 65$} & \multicolumn{2}{|c|}{ Total (all ages) } \\
\hline & No. & Rate & No. & Rate & No. & Rate & No. & Rate & No. & Rate & No. & Rate (crude) \\
\hline All sites combined & 1,287 & 2.1 & 1,496 & 3.4 & 7,446 & 11.9 & 167,085 & 160.5 & 407,558 & 911.3 & 584,872 & 184.8 \\
\hline Oral cavity and pharynx & —§ & - & - & - & 114 & 0.2 & 3,608 & 3.5 & 5,111 & 11.4 & 8,850 & 2.8 \\
\hline Esophagus & - & - & - & - & 87 & 0.1 & 5,161 & 5.0 & 9,441 & 21.1 & 14,689 & 4.6 \\
\hline Stomach & - & - & 19 & 0 & 287 & 0.5 & 3,504 & 3.4 & 7,450 & 16.7 & - & 3.6 \\
\hline Colon and rectum & - & - & 46 & 0.1 & 805 & 1.3 & 15,356 & 14.8 & 35,603 & 79.6 & - & 16.4 \\
\hline Liver and intrahepatic bile duct & 33 & 0.1 & 32 & 0.1 & 211 & 0.3 & 10,089 & 9.7 & 13,667 & 30.6 & 24,032 & 7.6 \\
\hline Pancreas & - & - & - & - & 183 & 0.3 & 10,756 & 10.3 & 28,045 & 62.7 & 38,996 & 12.3 \\
\hline Larynx & - & - & - & - & - & - & 1,350 & 1.3 & 2,372 & 5.3 & 3,729 & 1.2 \\
\hline Lung and bronchus & - & - & 22 & 0 & 383 & 0.6 & 42,733 & 41.1 & 113,032 & 252.7 & - & 49.3 \\
\hline Melanomas of the skin & - & - & 26 & 0.1 & 352 & 0.6 & 3,082 & 3.0 & 5,932 & 13.3 & - & 3.0 \\
\hline Female breast & - & - & - & - & 961 & 3.1 & 15,774 & 29.7 & 24,114 & 96.0 & 40,860 & 25.4 \\
\hline Cervix & - & - & - & - & 422 & 1.4 & 2,369 & 4.5 & 1,413 & 5.6 & 4,217 & 2.6 \\
\hline Corpus and uterus, NOS & - & - & - & - & 106 & 0.3 & 3,024 & 5.7 & 6,194 & 24.7 & 9,325 & 5.8 \\
\hline Ovary & - & - & 32 & 0.1 & 170 & 0.5 & 4,614 & 8.7 & 9,458 & 37.7 & - & 8.9 \\
\hline Prostate & - & - & - & - & - & - & 3,033 & 6.0 & 24,638 & 125.7 & 27,681 & 17.8 \\
\hline Testis & - & - & 32 & 0.1 & 130 & 0.4 & 167 & 0.3 & 53 & 0.3 & - & 0.2 \\
\hline Urinary bladder & - & - & - & - & 31 & 0 & 2,450 & 2.4 & 13,275 & 29.7 & 15,757 & 5.0 \\
\hline Kidney and renal pelvis & 40 & 0.1 & 19 & 0 & 138 & 0.2 & 4,256 & 4.1 & 9,453 & 21.1 & 13,906 & 4.4 \\
\hline Brain and nervous system & 437 & 0.7 & 241 & 0.5 & 751 & 1.2 & 6,080 & 5.8 & 7,834 & 17.5 & 15,343 & 4.8 \\
\hline Thyroid & - & - & - & - & 17 & 0 & 473 & 0.5 & 1,357 & 3.0 & 1,850 & 0.6 \\
\hline Hodgkin lymphoma & - & - & 32 & 0.1 & 137 & 0.2 & 334 & 0.3 & 583 & 1.3 & - & 0.3 \\
\hline Non-Hodgkin lymphoma & 29 & 0 & 91 & 0.2 & 344 & 0.5 & 4,089 & 3.9 & 15,560 & 34.8 & 20,113 & 6.4 \\
\hline Myeloma & - & - & - & - & 33 & 0.1 & 2,478 & 2.4 & 9,289 & 20.8 & 11,801 & 3.7 \\
\hline Leukemias & 350 & 0.6 & 345 & 0.8 & 643 & 1.0 & 4,574 & 4.4 & 17,637 & 39.4 & 23,549 & 7.4 \\
\hline Mesothelioma & - & - & - & - & - & - & 443 & 0.4 & 2,045 & 4.6 & 2,497 & 0.8 \\
\hline
\end{tabular}

Abbreviation: NOS $=$ not otherwise specified.

* Rates are the number of deaths per 100,000 persons. For more information, see USCS technical notes (https://www.cdc.gov/cancer/npcr/uscs/pdf/uscs-2013technical-notes.pdf).

${ }^{\dagger}$ Data are from the National Vital Statistics System (NVSS).

$\S$ Counts and rates are suppressed if $<16$ cases were reported in a specific category. Some counts and rates are suppressed as complementary cell suppression. 
TABLE 7. Reported number and rate* of invasive ${ }^{\dagger}$ cancer cases, by primary cancer site and race ${ }^{\S}$ — United States, 2013

\begin{tabular}{|c|c|c|c|c|c|c|c|c|}
\hline \multirow[b]{2}{*}{ Cancer site } & \multicolumn{2}{|c|}{$\mathrm{Al} / \mathrm{AN}$} & \multicolumn{2}{|c|}{$\mathrm{A} / \mathrm{PI}$} & \multicolumn{2}{|c|}{ Black } & \multicolumn{2}{|c|}{ White } \\
\hline & No. & Rate & No. & Rate & No. & Rate & No. & Rate \\
\hline All sites combined & 8,676 & 276.4 & 47,802 & 284.0 & 170,123 & 443.6 & $1,304,263$ & 439.3 \\
\hline Oral cavity and pharynx & 244 & 7.1 & 1,373 & 7.8 & 3,644 & 9.0 & 35,858 & 11.8 \\
\hline Lip & —** & - & 18 & 0.1 & 26 & 0.1 & 1,816 & 0.6 \\
\hline Tongue & 69 & 1.9 & 302 & 1.8 & 813 & 2.0 & 11,402 & 3.7 \\
\hline Salivary gland & 17 & 0.5 & 186 & 1.1 & 423 & 1.1 & 3,710 & 1.3 \\
\hline Floor of mouth & - & - & 36 & 0.2 & 221 & 0.5 & 1,693 & 0.5 \\
\hline Gum and other mouth & 24 & 0.8 & 216 & 1.3 & 502 & 1.3 & 4,590 & 1.5 \\
\hline Nasopharynx & 16 & 0.5 & 411 & 2.2 & 268 & 0.7 & 1,090 & 0.4 \\
\hline Tonsil & 46 & 1.2 & 114 & 0.6 & 632 & 1.5 & 7,073 & 2.3 \\
\hline Oropharynx & 17 & 0.5 & 19 & 0.1 & 267 & 0.6 & 1,590 & 0.5 \\
\hline Hypopharynx & 19 & 0.5 & 60 & 0.4 & 362 & 0.9 & 1,889 & 0.6 \\
\hline Other oral cavity and pharynx & - & - & - & - & 130 & 0.3 & 1,005 & 0.3 \\
\hline Digestive system & 1,919 & 63.3 & 11,416 & 70.1 & 35,835 & 94.9 & 227,267 & 75.5 \\
\hline Esophagus & 93 & 3.2 & 326 & 2.0 & 1,604 & 4.2 & 14,289 & 4.7 \\
\hline Stomach & 202 & 6.9 & 1,694 & 10.7 & 3,563 & 9.9 & 17,338 & 5.8 \\
\hline Small intestine & 33 & 1.0 & 184 & 1.1 & 1,406 & 3.7 & 6,482 & 2.2 \\
\hline Colon and rectum & 905 & 29.9 & 4,921 & 29.6 & 16,843 & 44.9 & 111,623 & 37.5 \\
\hline Colon excluding rectum & 597 & 20.6 & 3,138 & 19.3 & 12,379 & 33.5 & 79,695 & 26.8 \\
\hline Rectum and rectosigmoid junction & 308 & 9.3 & 1,783 & 10.3 & 4,464 & 11.4 & 31,928 & 10.8 \\
\hline Anus, anal canal, and anorectum & 33 & 0.9 & 84 & 0.5 & 729 & 1.8 & 5,661 & 1.9 \\
\hline Liver and intrahepatic bile duct & 312 & 9.3 & 2,037 & 12.3 & 4,422 & 10.4 & 22,350 & 7.1 \\
\hline Gallbladder & 43 & 1.7 & 196 & 1.2 & 626 & 1.8 & 3,019 & 1.0 \\
\hline Other biliary & 36 & 1.3 & 343 & 2.2 & 604 & 1.7 & 5,331 & 1.8 \\
\hline Pancreas & 221 & 7.7 & 1,433 & 9.2 & 5,492 & 15.1 & 36,908 & 12.1 \\
\hline Retroperitoneum & - & - & 59 & 0.3 & 146 & 0.4 & 1,011 & 0.4 \\
\hline Peritoneum, omentum, and mesentery & 17 & 0.5 & 62 & 0.4 & 164 & 0.4 & 1,720 & 0.6 \\
\hline Other digestive organs & 18 & 0.6 & 77 & 0.5 & 236 & 0.7 & 1,535 & 0.5 \\
\hline Respiratory system & 1,251 & 43.8 & 5,756 & 36.8 & 24,488 & 66.2 & 195,297 & 64.4 \\
\hline Nose, nasal cavity, and middle ear & - & - & 94 & 0.6 & 252 & 0.6 & 1,930 & 0.7 \\
\hline Larynx & 58 & 1.8 & 177 & 1.1 & 1,672 & 4.2 & 10,402 & 3.4 \\
\hline Lung and bronchus & 1,175 & 41.5 & 5,446 & 35.0 & 22,489 & 61.2 & 182,352 & 60.1 \\
\hline Pleura & - & - & - & - & - & - & 92 & 0 \\
\hline $\begin{array}{l}\text { Trachea, mediastinum, and other } \\
\text { respiratory organs }\end{array}$ & - & - & 37 & 0.2 & 68 & 0.2 & 521 & 0.2 \\
\hline Bones and joints & 27 & 0.7 & 99 & 0.5 & 333 & 0.8 & 2,466 & 1.0 \\
\hline Soft tissue including heart & 80 & 2.4 & 414 & 2.4 & 1,283 & 3.3 & 9,058 & 3.2 \\
\hline Skin excluding basal and squamous & 192 & 6.1 & 323 & 1.9 & 746 & 2.0 & 72,417 & 25.1 \\
\hline Melanomas of the skin & 161 & 5.0 & 213 & 1.3 & 362 & 1.0 & 67,291 & 23.3 \\
\hline Other nonepithelial skin & 31 & 1.1 & 110 & 0.7 & 384 & 1.0 & 5,126 & 1.8 \\
\hline Male and female breast & 1,279 & 38.6 & 8,946 & 49.9 & 27,160 & 70.1 & 192,817 & 66.0 \\
\hline Female breast & 1,272 & 72.3 & 8,914 & 91.1 & 26,854 & 122.9 & 191,077 & 124.4 \\
\hline Male breast & - & - & 32 & 0.4 & 306 & 1.9 & 1,740 & 1.3 \\
\hline
\end{tabular}

See table footnotes on next page. 
TABLE 7. (Continued) Reported number and rate* of invasive ${ }^{\dagger}$ cancer cases, by primary cancer site and race ${ }^{\S}$ United States, $2013^{\uparrow}$

\begin{tabular}{|c|c|c|c|c|c|c|c|c|}
\hline \multirow[b]{2}{*}{ Cancer site } & \multicolumn{2}{|c|}{$\mathrm{Al} / \mathrm{AN}$} & \multicolumn{2}{|c|}{$\mathrm{A} / \mathrm{PI}$} & \multicolumn{2}{|c|}{ Black } & \multicolumn{2}{|c|}{ White } \\
\hline & No. & Rate & No. & Rate & No. & Rate & No. & Rate \\
\hline Female genital system & 624 & 34.2 & 3,529 & 35.8 & 10,267 & 46.7 & 76,112 & 49.1 \\
\hline Cervix & 118 & 6.3 & 588 & 5.9 & 1,936 & 9.0 & 9,058 & 7.0 \\
\hline Corpus and uterus, NOS & 319 & 17.3 & 1,848 & 18.5 & 5,546 & 24.8 & 42,116 & 26.2 \\
\hline Corpus & 309 & 16.7 & 1,796 & 18.0 & 5,185 & 23.2 & 40,946 & 25.4 \\
\hline Uterus, NOS & - & - & 52 & 0.5 & 361 & 1.6 & 1,170 & 0.7 \\
\hline Ovary & 145 & 8.1 & 887 & 9.2 & 1,969 & 9.1 & 17,688 & 11.4 \\
\hline Vagina & - & - & 40 & 0.4 & 189 & 0.9 & 1,017 & 0.6 \\
\hline Vulva & 25 & 1.6 & 73 & 0.8 & 395 & 1.8 & 4,324 & 2.7 \\
\hline Other female genital organs & - & - & 93 & 0.9 & 232 & 1.1 & 1,909 & 1.2 \\
\hline Male genital system & 855 & 58.3 & 4,079 & 55.0 & 28,677 & 166.9 & 145,637 & 100.1 \\
\hline Prostate & 762 & 54.0 & 3,853 & 52.5 & 28,208 & 164.4 & 136,604 & 92.5 \\
\hline Testis & 80 & 3.3 & 178 & 1.8 & 285 & 1.4 & 7,598 & 6.4 \\
\hline Penis & - & - & 26 & 0.4 & 144 & 0.9 & 1,133 & 0.9 \\
\hline Other male genital organs & - & - & 22 & 0.3 & 40 & 0.2 & 302 & 0.2 \\
\hline Urinary system & 746 & 24.3 & 2,618 & 16.4 & 11,088 & 29.7 & 114,606 & 38.3 \\
\hline Urinary bladder & 232 & 8.7 & 1,247 & 8.3 & 4,040 & 11.6 & 64,236 & 21.3 \\
\hline Kidney and renal pelvis & 500 & 15.0 & 1,274 & 7.5 & 6,864 & 17.6 & 47,630 & 16.1 \\
\hline Ureter & - & - & 65 & 0.4 & 71 & 0.2 & 1,749 & 0.6 \\
\hline Other urinary organs & - & - & 32 & 0.2 & 113 & 0.3 & 991 & 0.3 \\
\hline Eye and orbit & - & - & 56 & 0.3 & 112 & 0.3 & 2,537 & 0.9 \\
\hline Brain and other nervous system & 112 & 3.0 & 622 & 3.6 & 1,639 & 4.0 & 19,211 & 7.0 \\
\hline Brain & 104 & 2.8 & 566 & 3.3 & 1,487 & 3.7 & 18,096 & 6.5 \\
\hline Cranial nerves other nervous system & - & - & 56 & 0.3 & 152 & 0.4 & 1,115 & 0.4 \\
\hline Endocrine system & 315 & 8.3 & 2,944 & 15.7 & 4,140 & 10.2 & 41,563 & 15.8 \\
\hline Thyroid & 298 & 7.8 & 2,796 & 14.9 & 3,759 & 9.3 & 39,758 & 15.1 \\
\hline Other endocrine including thymus & 17 & 0.5 & 148 & 0.9 & 381 & 0.9 & 1,805 & 0.7 \\
\hline Lymphomas & 345 & 10.9 & 2,262 & 13.6 & 6,408 & 16.4 & 62,525 & 21.6 \\
\hline Hodgkin lymphoma & 37 & 1.0 & 216 & 1.1 & 1,109 & 2.6 & 6,688 & 2.6 \\
\hline Non-Hodgkin lymphoma & 308 & 9.9 & 2,046 & 12.4 & 5,299 & 13.8 & 55,837 & 19.0 \\
\hline Myeloma & 124 & 4.3 & 595 & 3.7 & 4,659 & 12.8 & 16,845 & 5.6 \\
\hline Leukemias & 234 & 7.3 & 1,206 & 7.1 & 3,811 & 10.1 & 39,006 & 13.6 \\
\hline Acute lymphocytic leukemia & 41 & 0.9 & 205 & 1.1 & 385 & 0.9 & 3,896 & 1.6 \\
\hline Chronic lymphocytic leukemia & 49 & 1.8 & 144 & 0.9 & 1,115 & 3.1 & 13,229 & 4.3 \\
\hline Acute myeloid leukemia & 80 & 2.6 & 539 & 3.2 & 1,268 & 3.4 & 12,307 & 4.3 \\
\hline Chronic myeloid leukemia & 31 & 0.9 & 183 & 1.0 & 599 & 1.5 & 5,013 & 1.8 \\
\hline Other leukemias & 33 & 1.2 & 135 & 0.8 & 444 & 1.2 & 4,561 & 1.6 \\
\hline Mesothelioma & - & - & 46 & 0.3 & 146 & 0.4 & 2,982 & 1.0 \\
\hline Kaposi Sarcoma & - & - & 29 & 0.2 & 292 & 0.7 & 695 & 0.3 \\
\hline Miscellaneous & 298 & 10.7 & 1,489 & 9.8 & 5,395 & 15.2 & 47,364 & 15.8 \\
\hline
\end{tabular}

Abbreviations: AI/AN = American Indian/Alaska Native; A/PI = Asian/Pacific Islander; NOS = not otherwise specified.

* Rates are the number of cases per 100,000 persons and are age-adjusted to the 2000 U.S. standard population (19 age groups - Census P25-1130). For more

information, see USCS technical notes (https://www.cdc.gov/cancer/npcr/uscs/pdf/uscs-2013-technical-notes.pdf).

+ Invasive cancer excludes basal and squamous cell carcinomas of the skin except when these occur on the skin of the genital organs, and in situ cancers except urinary bladder. Urinary bladder cancer includes invasive and in situ.

$\S$ Rates are not presented for persons of unknown or other race; therefore, categories do not sum to total. Data for specified racial populations other than white and black should be interpreted with caution. For more information, see USCS technical notes (https://www.cdc.gov/cancer/npcr/uscs/pdf/uscs-2013-technical-notes. pdf\#nameddest=IntRaceEthnicityData).

** Counts and rates are suppressed if $<16$ cases were reported. 
TABLE 8. Reported number and rate* of cancer deaths, by primary site and race ${ }^{\dagger} \_$United States, $2013^{\S}$

\begin{tabular}{|c|c|c|c|c|c|c|c|c|}
\hline \multirow[b]{2}{*}{ Cancer site } & \multicolumn{2}{|c|}{$\mathrm{Al} / \mathrm{AN}$} & \multicolumn{2}{|c|}{$\mathrm{A} / \mathrm{PI}$} & \multicolumn{2}{|c|}{ Black } & \multicolumn{2}{|c|}{ White } \\
\hline & No. & Rate & No. & Rate & No. & Rate & No. & Rate \\
\hline All sites combined & 3,109 & 111.2 & 15,703 & 100.0 & 67,952 & 189.5 & 498,108 & 163.3 \\
\hline Oral cavity and pharynx & 32 & 1.0 & 314 & 1.9 & 1,076 & 2.8 & 7,428 & 2.4 \\
\hline Lip & - & - & - & - & - & - & 55 & 0 \\
\hline Tongue & - & - & 53 & 0.3 & 203 & 0.5 & 1,945 & 0.6 \\
\hline Salivary gland & - & - & 22 & 0.1 & 75 & 0.2 & 788 & 0.3 \\
\hline Floor of mouth & - & - & - & - & - & - & 74 & 0 \\
\hline Gum and other mouth & - & - & 46 & 0.3 & 122 & 0.3 & 1,077 & 0.3 \\
\hline Nasopharynx & - & - & 127 & 0.7 & 95 & 0.2 & 416 & 0.1 \\
\hline Tonsil & - & - & - & - & 86 & 0.2 & 736 & 0.2 \\
\hline Oropharynx & - & - & 18 & 0.1 & 139 & 0.4 & 746 & 0.2 \\
\hline Hypopharynx & - & - & - & - & 70 & 0.2 & 246 & 0.1 \\
\hline Other oral cavity and pharynx & - & - & 28 & 0.2 & 275 & 0.7 & 1,345 & 0.4 \\
\hline Digestive system & 1,020 & 35.3 & 5,608 & 35.5 & 19,240 & 53.0 & 122,915 & 40.0 \\
\hline Esophagus & 74 & 2.6 & 271 & 1.7 & 1,308 & 3.5 & 13,036 & 4.2 \\
\hline Stomach & 96 & 3.5 & 808 & 5.1 & 1,964 & 5.6 & 8,393 & 2.8 \\
\hline Small intestine & - & - & 29 & 0.2 & 219 & 0.6 & 1,017 & 0.3 \\
\hline Colon and rectum & 351 & 12.6 & 1,557 & 9.7 & 6,854 & 19.3 & 43,051 & 14.1 \\
\hline Colon excluding rectum & 271 & 10.0 & 1,215 & 7.7 & 5,772 & 16.3 & 34,705 & 11.4 \\
\hline Rectum and rectosigmoid junction & 80 & 2.6 & 342 & 2.1 & 1,082 & 3.0 & 8,346 & 2.7 \\
\hline Anus, anal canal, and anorectum & - & - & 22 & 0.1 & 104 & 0.3 & 769 & 0.3 \\
\hline Liver and intrahepatic bile duct & 256 & 8.0 & 1,542 & 9.5 & 3,385 & 8.4 & 18,849 & 6.0 \\
\hline Gallbladder & 19 & 0.8 & 120 & 0.8 & 329 & 0.9 & 1,692 & 0.6 \\
\hline Other biliary & - & - & 58 & 0.4 & 137 & 0.4 & 1,313 & 0.4 \\
\hline Pancreas & 188 & 6.8 & 1,124 & 7.5 & 4,737 & 13.4 & 32,947 & 10.7 \\
\hline Retroperitoneum & - & - & - & - & 20 & 0.1 & 161 & 0.1 \\
\hline Peritoneum, omentum, and mesentery & - & - & 19 & 0.1 & 48 & 0.1 & 679 & 0.2 \\
\hline Other digestive organs & - & - & 46 & 0.3 & 135 & 0.4 & 1,008 & 0.3 \\
\hline Respiratory system & 777 & 28.8 & 3,622 & 23.8 & 17,584 & 48.8 & 138,661 & 45.3 \\
\hline Nose, nasal cavity, and middle ear & - & - & 20 & 0.1 & 41 & 0.1 & 380 & 0.1 \\
\hline Larynx & 19 & 0.6 & 53 & 0.3 & 599 & 1.6 & 3,058 & 1.0 \\
\hline Lung and bronchus & 754 & 28.0 & 3,539 & 23.3 & 16,906 & 46.9 & 134,977 & 44.1 \\
\hline Pleura & - & - & - & - & - & - & 60 & 0 \\
\hline $\begin{array}{l}\text { Trachea, mediastinum, and other } \\
\text { respiratory organs }\end{array}$ & - & - & - & - & 35 & 0.1 & 186 & 0.1 \\
\hline Bones and joints & - & - & 41 & 0.2 & 164 & 0.4 & 1,238 & 0.4 \\
\hline Soft tissue including heart & 30 & 0.9 & 156 & 0.9 & 552 & 1.4 & 3,822 & 1.3 \\
\hline Skin excluding basal and squamous & 30 & 1.0 & 81 & 0.5 & 306 & 0.8 & 12,331 & 4.1 \\
\hline Melanomas of the skin & 16 & 0.5 & 46 & 0.3 & 141 & 0.4 & 9,191 & 3.1 \\
\hline Other nonepithelial skin & - & - & 35 & 0.2 & 165 & 0.4 & 3,140 & 1.0 \\
\hline Male and female breast & 166 & 5.5 & 1,059 & 6.2 & 6,167 & 16.6 & 33,932 & 11.2 \\
\hline Female breast & 166 & 10.1 & 1,048 & 11.0 & 6,086 & 28.2 & 33,560 & 20.3 \\
\hline Male breast & - & - & - & - & 60 & 0.4 & 340 & 0.3 \\
\hline
\end{tabular}

See table footnotes on next page. 
TABLE 8. (Continued) Reported number and rate* of cancer deaths, by primary site and race ${ }^{\dagger}$ _ United States, $2013^{\S}$

\begin{tabular}{|c|c|c|c|c|c|c|c|c|}
\hline \multirow[b]{2}{*}{ Cancer site } & \multicolumn{2}{|c|}{ Al/AN } & \multicolumn{2}{|c|}{$\mathrm{A} / \mathrm{PI}$} & \multicolumn{2}{|c|}{ Black } & \multicolumn{2}{|c|}{ White } \\
\hline & No. & Rate & No. & Rate & No. & Rate & No. & Rate \\
\hline Female genital system & 148 & 9.0 & 899 & 9.6 & 4,035 & 19.0 & 24,746 & 15.0 \\
\hline Cervix & 30 & 1.7 & 187 & 1.9 & 838 & 3.9 & 3,162 & 2.2 \\
\hline Corpus and uterus, NOS & 37 & 2.2 & 263 & 2.8 & 1,764 & 8.3 & 7,261 & 4.3 \\
\hline Corpus & 16 & 1.0 & 97 & 1.0 & 682 & 3.2 & 3,108 & 1.8 \\
\hline Uterus, NOS & 21 & 1.3 & 166 & 1.8 & 1,082 & 5.1 & 4,153 & 2.5 \\
\hline Ovary & 73 & 4.5 & 416 & 4.5 & 1,254 & 6.0 & 12,533 & 7.5 \\
\hline Vagina & - & - & - & - & 54 & 0.3 & 373 & 0.2 \\
\hline Vulva & - & - & - & - & 64 & 0.3 & 924 & 0.5 \\
\hline Other female genital organs & - & - & - & - & 61 & 0.3 & 493 & 0.3 \\
\hline Male genital system & 138 & 14.5 & 492 & 8.9 & 4,594 & 39.5 & 23,166 & 18.4 \\
\hline Prostate & 131 & 14.2 & 473 & 8.6 & 4,528 & 39.1 & 22,549 & 18.0 \\
\hline Testis & - & - & - & - & - & - & 354 & 0.3 \\
\hline Penis & - & - & - & - & 42 & 0.3 & 218 & 0.2 \\
\hline Other male genital organs & - & - & - & - & - & - & 45 & 0 \\
\hline Urinary system & 167 & 6.1 & 550 & 3.7 & 2,480 & 7.2 & 27,315 & 8.9 \\
\hline Urinary bladder & 48 & 1.7 & 248 & 1.8 & 1,167 & 3.5 & 14,294 & 4.7 \\
\hline Kidney and renal pelvis & 118 & 4.3 & 272 & 1.7 & 1,260 & 3.5 & 12,256 & 4.0 \\
\hline Ureter & - & - & 21 & 0.1 & 18 & 0.1 & 394 & 0.1 \\
\hline Other urinary organs & - & - & - & - & 35 & 0.1 & 371 & 0.1 \\
\hline Eye and orbit & - & - & 一 & - & - & - & 310 & 0.1 \\
\hline Brain and other nervous system & 68 & 2.1 & 376 & 2.2 & 941 & 2.4 & 13,958 & 4.7 \\
\hline Endocrine system & 20 & 0.7 & 141 & 0.9 & 308 & 0.9 & 2,310 & 0.8 \\
\hline Thyroid & 17 & 0.6 & 98 & 0.7 & 182 & 0.5 & 1,553 & 0.5 \\
\hline Other endocrine including thymus & - & - & 43 & 0.2 & 126 & 0.3 & 757 & 0.3 \\
\hline Lymphomas & 91 & 3.5 & 608 & 4.0 & 1,568 & 4.4 & 18,936 & 6.3 \\
\hline Hodgkin lymphoma & - & - & 21 & 0.1 & 108 & 0.3 & 958 & 0.3 \\
\hline Non-Hodgkin lymphoma & 88 & 3.4 & 587 & 3.9 & 1,460 & 4.1 & 17,978 & 5.9 \\
\hline Myeloma & 63 & 2.3 & 214 & 1.4 & 2,157 & 6.4 & 9,367 & 3.1 \\
\hline Leukemias & 104 & 3.7 & 580 & 3.7 & 1,987 & 5.7 & 20,878 & 7.0 \\
\hline Acute lymphocytic leukemia & - & - & 53 & 0.3 & 136 & 0.3 & 1,221 & 0.5 \\
\hline Chronic lymphocytic leukemia & - & - & 33 & 0.2 & 378 & 1.1 & 4,236 & 1.4 \\
\hline Acute myeloid leukemia & 48 & 1.7 & 317 & 2.0 & 778 & 2.2 & 8,568 & 2.9 \\
\hline Chronic myeloid leukemia & - & - & 22 & 0.1 & 99 & 0.3 & 861 & 0.3 \\
\hline Other leukemias & 24 & 1.0 & 155 & 1.0 & 596 & 1.7 & 5,992 & 2.0 \\
\hline Mesothelioma & - & - & 35 & 0.2 & 112 & 0.3 & 2,342 & 0.8 \\
\hline Miscellaneous & 237 & 8.7 & 925 & 6.0 & 4,667 & 13.0 & 34,401 & 11.2 \\
\hline
\end{tabular}

Abbreviations: Al/AN = American Indian/Alaska Native; A/PI = Asian/Pacific Islander; NOS = not otherwise specified.

* Rates are the number of deaths per 100,000 persons and are age-adjusted to the 2000 U.S. standard population (19 age groups - Census P25-1130). For more information, see USCS technical notes (https://www.cdc.gov/cancer/npcr/uscs/pdf/uscs-2013-technical-notes.pdf).

† Data for specified racial populations other than white and black should be interpreted with caution. For more information, see USCS technical notes (https://www. cdc.gov/cancer/npcr/uscs/pdf/uscs-2013-technical-notes.pdf\#nameddest=IntRaceEthnicityData).

$\S$ Data are from the National Vital Statistics System (NVSS).

" Counts and rates are suppressed if $<16$ cases were reported. 
TABLE 9. Reported number and rate* of invasive ${ }^{\dagger}$ cancer cases, by primary cancer site and ethnicity ${ }^{\S}$ United States, 2013

\begin{tabular}{|c|c|c|c|c|}
\hline \multirow[b]{2}{*}{ Cancer site } & \multicolumn{2}{|c|}{ Hispanic } & \multicolumn{2}{|c|}{ Non-Hispanic } \\
\hline & No. & Rate & No. & Rate \\
\hline All sites combined & 117,332 & 343.7 & $1,403,357$ & 450.8 \\
\hline Oral cavity and pharynx & 2,360 & 6.8 & 38,279 & 12.1 \\
\hline Lip & 89 & 0.3 & 1,811 & 0.6 \\
\hline Tongue & 653 & 1.9 & 11,797 & 3.7 \\
\hline Salivary gland & 298 & 0.8 & 3,986 & 1.3 \\
\hline Floor of mouth & 99 & 0.3 & 1,836 & 0.6 \\
\hline Gum and other mouth & 346 & 1.1 & 4,942 & 1.6 \\
\hline Nasopharynx & 152 & 0.4 & 1,607 & 0.5 \\
\hline Tonsil & 438 & 1.2 & 7,317 & 2.3 \\
\hline Oropharynx & 98 & 0.3 & 1,753 & 0.5 \\
\hline Hypopharynx & 134 & 0.4 & 2,133 & 0.7 \\
\hline Other oral cavity and pharynx & 53 & 0.2 & 1,097 & 0.3 \\
\hline Digestive system & 25,401 & 79.0 & 247,673 & 78.5 \\
\hline Esophagus & 800 & 2.6 & 15,228 & 4.7 \\
\hline Stomach & 3,129 & 9.8 & 19,455 & 6.2 \\
\hline Small intestine & 590 & 1.8 & 7,379 & 2.4 \\
\hline Colon and rectum & 10,997 & 33.8 & 121,907 & 39.1 \\
\hline Colon excluding rectum & 7,562 & 23.9 & 87,066 & 27.9 \\
\hline $\begin{array}{l}\text { Rectum and rectosigmoid } \\
\text { junction }\end{array}$ & 3,435 & 10.0 & 34,841 & 11.2 \\
\hline $\begin{array}{l}\text { Anus, anal canal, and } \\
\text { anorectum }\end{array}$ & 440 & 1.3 & 5,977 & 1.9 \\
\hline Liver and intrahepatic bile duct & 4,311 & 12.9 & 24,545 & 7.4 \\
\hline Gallbladder & 586 & 1.9 & 3,244 & 1.0 \\
\hline Other biliary & 735 & 2.5 & 5,524 & 1.7 \\
\hline Pancreas & 3,357 & 11.1 & 39,910 & 12.5 \\
\hline Retroperitoneum & 141 & 0.4 & 1,055 & 0.4 \\
\hline $\begin{array}{l}\text { Peritoneum, omentum, } \\
\text { and mesentery }\end{array}$ & 130 & 0.4 & 1,798 & 0.6 \\
\hline Other digestive organs & 185 & 0.6 & 1,651 & 0.5 \\
\hline Respiratory system & 10,261 & 34.9 & 212,149 & 66.6 \\
\hline $\begin{array}{l}\text { Nose, nasal cavity, and } \\
\text { middle ear }\end{array}$ & 234 & 0.7 & 2,036 & 0.7 \\
\hline Larynx & 809 & 2.5 & 11,310 & 3.5 \\
\hline Lung and bronchus & 9,125 & 31.5 & 198,162 & 62.2 \\
\hline Pleura & —** & - & 88 & 0 \\
\hline $\begin{array}{l}\text { Trachea, mediastinum, and } \\
\text { other respiratory organs }\end{array}$ & 80 & 0.2 & 553 & 0.2 \\
\hline Bones and joints & 424 & 0.9 & 2,487 & 0.9 \\
\hline Soft tissue including heart & 1,210 & 3.0 & 9,571 & 3.3 \\
\hline $\begin{array}{l}\text { Skin excluding basal and } \\
\text { squamous }\end{array}$ & 1,842 & 5.3 & 74,086 & 24.6 \\
\hline Melanomas of the skin & 1,535 & 4.4 & 68,543 & 22.8 \\
\hline Other nonepithelial skin & 307 & 0.9 & 5,543 & 1.8 \\
\hline Male and female breast & 18,155 & 50.1 & 208,425 & 68.3 \\
\hline Female breast & 18,041 & 93.4 & 206,497 & 127.4 \\
\hline Male breast & 114 & 0.8 & 1,928 & 1.3 \\
\hline
\end{tabular}

TABLE 9. (Continued) Reported number and rate* of invasive $^{\dagger}$ cancer cases, by primary cancer site and ethnicity ${ }^{\S}$ — United States, 2013

\begin{tabular}{|c|c|c|c|c|}
\hline \multirow[b]{2}{*}{ Cancer site } & \multicolumn{2}{|c|}{ Hispanic } & \multicolumn{2}{|c|}{ Non-Hispanic } \\
\hline & No. & Rate & No. & Rate \\
\hline Female genital system & 9,034 & 45.4 & 80,637 & 49.0 \\
\hline Cervix & 2,010 & 9.3 & 9,689 & 7.0 \\
\hline Corpus and uterus, NOS & 4,517 & 23.1 & 44,800 & 26.1 \\
\hline Corpus & 4,301 & 21.9 & 43,444 & 25.3 \\
\hline Uterus, NOS & 216 & 1.2 & 1,356 & 0.8 \\
\hline Ovary & 1,912 & 9.7 & 18,507 & 11.3 \\
\hline Vagina & 129 & 0.7 & 1,100 & 0.6 \\
\hline Vulva & 295 & 1.7 & 4,492 & 2.7 \\
\hline Other female genital organs & 171 & 0.9 & 2,049 & 1.2 \\
\hline Male genital system & 14,008 & 93.6 & 167,698 & 110.0 \\
\hline Prostate & 12,403 & 87.5 & 159,452 & 103.2 \\
\hline Testis & 1,400 & 4.7 & 6,782 & 5.7 \\
\hline Penis & 184 & 1.2 & 1,116 & 0.8 \\
\hline Other male genital organs & 21 & 0.1 & 348 & 0.3 \\
\hline Urinary system & 8,926 & 27.7 & 119,098 & 38.0 \\
\hline Urinary bladder & 3,135 & 11.0 & 66,222 & 20.9 \\
\hline Kidney and renal pelvis & 5,634 & 16.1 & 50,006 & 16.1 \\
\hline Ureter & 96 & 0.4 & 1,760 & 0.6 \\
\hline Other urinary organs & 61 & 0.2 & 1,110 & 0.4 \\
\hline Eye and orbit & 216 & 0.5 & 2,548 & 0.9 \\
\hline $\begin{array}{l}\text { Brain and other nervous } \\
\text { system }\end{array}$ & 2,147 & 5.2 & 19,193 & 6.7 \\
\hline Brain & 1,966 & 4.8 & 18,049 & 6.3 \\
\hline $\begin{array}{l}\text { Cranial nerves other } \\
\text { nervous system }\end{array}$ & 181 & 0.4 & 1,144 & 0.4 \\
\hline Endocrine system & 5,965 & 13.8 & 42,877 & 15.7 \\
\hline Thyroid & 5,700 & 13.2 & 40,801 & 14.9 \\
\hline $\begin{array}{l}\text { Other endocrine including } \\
\text { thymus }\end{array}$ & 265 & 0.6 & 2,076 & 0.8 \\
\hline Lymphomas & 6,775 & 19.2 & 64,396 & 21.4 \\
\hline Hodgkin lymphoma & 1,084 & 2.4 & 6,934 & 2.7 \\
\hline Non-Hodgkin lymphoma & 5,691 & 16.9 & 57,462 & 18.7 \\
\hline Myeloma & 1,908 & 6.1 & 20,128 & 6.4 \\
\hline Leukemias & 4,243 & 10.7 & 40,185 & 13.4 \\
\hline Acute lymphocytic leukemia & 1,217 & 2.1 & 3,361 & 1.4 \\
\hline Chronic lymphocytic leukemia & 621 & 2.1 & 14,188 & 4.4 \\
\hline Acute myeloid leukemia & 1,321 & 3.6 & 12,690 & 4.2 \\
\hline Chronic myeloid leukemia & 597 & 1.5 & 5,260 & 1.8 \\
\hline Other leukemias & 487 & 1.4 & 4,686 & 1.6 \\
\hline Mesothelioma & 222 & 0.7 & 2,895 & 0.9 \\
\hline Kaposi Sarcoma & 244 & 0.6 & 844 & 0.3 \\
\hline Miscellaneous & 3,991 & 13.2 & 50,188 & 16.0 \\
\hline
\end{tabular}

Abbreviation: NOS = not otherwise specified.

* Rates are the number of cases per 100,000 persons and are age-adjusted to the 2000 U.S. standard population (19 age groups - Census P25-1130). For more information, see USCS technical notes (https://www.cdc.gov/cancer/ npcr/uscs/pdf/uscs-2013-technical-notes.pdf).

+ Invasive cancer excludes basal and squamous cell carcinomas of the skin except when these occur on the skin of the genital organs, and in situ cancers except urinary bladder. Urinary bladder cancer includes invasive and in situ.

$\S$ Rates and counts are not presented for persons of unknown ethnicity; therefore, categories do not sum to total. Data for specified ethnic populations should be interpreted with caution. For more information, see USCS technical notes (https://www.cdc.gov/cancer/npcr/uscs/pdf/uscs-2013-technicalnotes.pdf\#nameddest=IntRaceEthnicityData).

" Data are compiled from cancer registries that meet the data quality criteria for all invasive cancer sites combined and have information on ethnicity (all registries except Nevada and Virginia, covering approximately $97 \%$ of the U.S. population). Data from Nevada did not meet the data quality criteria and information about ethnicity was missing on $85 \%$ of the cases from Virginia.

** Counts and rates are suppressed if $<16$ cases were reported. Some counts and rates are suppressed as complementary cell suppression. 
TABLE 10. Reported number and rate* of cancer deaths, by primary cancer site and ethnicity ${ }^{\dagger}$ — United States, $2013^{\S}$

\begin{tabular}{|c|c|c|c|c|}
\hline \multirow[b]{2}{*}{ Cancer site } & \multicolumn{2}{|c|}{ Hispanic } & \multicolumn{2}{|c|}{ Non-Hispanic } \\
\hline & No. & Rate & No. & Rate \\
\hline All sites combined & 35,147 & 114.7 & 548,516 & 167.2 \\
\hline Oral cavity and pharynx & 455 & 1.4 & 8,364 & 2.5 \\
\hline Lip & —? & - & 58 & 0 \\
\hline Tongue & 114 & 0.3 & 2,086 & 0.6 \\
\hline Salivary gland & 39 & 0.1 & 845 & 0.3 \\
\hline Floor of mouth & - & - & 81 & 0 \\
\hline Gum and other mouth & 65 & 0.2 & 1,178 & 0.4 \\
\hline Nasopharynx & 37 & 0.1 & 605 & 0.2 \\
\hline Tonsil & 38 & 0.1 & 798 & 0.2 \\
\hline Oropharynx & 58 & 0.2 & 843 & 0.3 \\
\hline Hypopharynx & 23 & 0.1 & 298 & 0.1 \\
\hline Other oral cavity and pharynx & 77 & 0.2 & 1,572 & 0.5 \\
\hline Digestive system & 11,914 & 38.7 & 136,551 & 41.3 \\
\hline Esophagus & 593 & 1.9 & 14,060 & 4.2 \\
\hline Stomach & 1,633 & 5.1 & 9,605 & 3.0 \\
\hline Small intestine & 78 & 0.3 & 1,190 & 0.4 \\
\hline Colon and rectum & 3,568 & 11.7 & 48,133 & 14.7 \\
\hline Colon excluding rectum & 2,902 & 9.6 & 38,973 & 11.9 \\
\hline Rectum and rectosigmoid junction & 666 & 2.0 & 9,160 & 2.8 \\
\hline Anus, anal canal, and anorectum & 50 & 0.1 & 846 & 0.3 \\
\hline Liver and intrahepatic bile duct & 2,994 & 9.3 & 20,974 & 6.2 \\
\hline Gallbladder & 254 & 0.9 & 1,905 & 0.6 \\
\hline Other biliary & 123 & 0.4 & 1,393 & 0.4 \\
\hline Pancreas & 2,473 & 8.4 & 36,458 & 11.0 \\
\hline Retroperitoneum & 19 & 0.1 & 174 & 0.1 \\
\hline Peritoneum, omentum, and mesentery & 40 & 0.1 & 706 & 0.2 \\
\hline Other digestive organs & 89 & 0.3 & 1,107 & 0.3 \\
\hline Respiratory system & 5,629 & 19.7 & 154,680 & 46.8 \\
\hline Nose, nasal cavity, and middle ear & 33 & 0.1 & 408 & 0.1 \\
\hline Larynx & 219 & 0.7 & 3,498 & 1.0 \\
\hline Lung and bronchus & 5,353 & 18.8 & 150,502 & 45.6 \\
\hline Pleura & - & - & 62 & 0 \\
\hline $\begin{array}{l}\text { Trachea, mediastinum, and other } \\
\text { respiratory organs }\end{array}$ & 20 & 0.1 & 210 & 0.1 \\
\hline Bones and joints & 188 & 0.5 & 1,261 & 0.4 \\
\hline Soft tissue including heart & 392 & 1.0 & 4,161 & 1.3 \\
\hline Skin excluding basal and squamous & 357 & 1.2 & 12,372 & 3.8 \\
\hline Melanomas of the skin & 236 & 0.7 & 9,151 & 2.9 \\
\hline Other nonepithelial skin & 121 & 0.4 & 3,221 & 1.0 \\
\hline Male and female breast & 2,695 & 8.0 & 38,540 & 11.8 \\
\hline Female breast & 2,671 & 14.5 & 38,104 & 21.3 \\
\hline Male breast & 24 & 0.2 & 436 & 0.3 \\
\hline
\end{tabular}

TABLE 10. (Continued) Reported number and rate* of cancer deaths, by primary cancer site and ethnicity ${ }^{\dagger}$ — United States, $2013^{\S}$

\begin{tabular}{|c|c|c|c|c|}
\hline \multirow[b]{2}{*}{ Cancer site } & \multicolumn{2}{|c|}{ Hispanic } & \multicolumn{2}{|c|}{ Non-Hispanic } \\
\hline & No. & Rate & No. & Rate \\
\hline Female genital system & 2,280 & 12.6 & 27,492 & 15.4 \\
\hline Cervix & 521 & 2.5 & 3,682 & 2.3 \\
\hline Corpus and uterus, NOS & 679 & 3.8 & 8,629 & 4.7 \\
\hline Corpus & 222 & 1.2 & 3,673 & 2.0 \\
\hline Uterus, NOS & 457 & 2.6 & 4,956 & 2.7 \\
\hline Ovary & 942 & 5.3 & 13,312 & 7.4 \\
\hline Vagina & 39 & 0.2 & 398 & 0.2 \\
\hline Vulva & 63 & 0.4 & 939 & 0.5 \\
\hline Other female genital organs & 36 & 0.2 & 532 & 0.3 \\
\hline Male genital system & 1,758 & 16.3 & 26,567 & 19.9 \\
\hline Prostate & 1,634 & 15.8 & 25,983 & 19.4 \\
\hline Testis & 80 & 0.3 & 302 & 0.2 \\
\hline Penis & 41 & 0.2 & 229 & 0.2 \\
\hline Other male genital organs & - & - & 53 & 0 \\
\hline Urinary system & 1,720 & 5.9 & 28,730 & 8.7 \\
\hline Urinary bladder & 630 & 2.4 & 15,098 & 4.6 \\
\hline Kidney and renal pelvis & 1,053 & 3.4 & 12,820 & 3.9 \\
\hline Ureter & 18 & 0.1 & 416 & 0.1 \\
\hline Other urinary organs & 19 & 0.1 & 396 & 0.1 \\
\hline Eye and orbit & 17 & 0.1 & 302 & 0.1 \\
\hline Brain and other nervous system & 1,046 & 2.9 & 14,279 & 4.5 \\
\hline Endocrine system & 275 & 0.8 & 2,498 & 0.8 \\
\hline Thyroid & 177 & 0.6 & 1,670 & 0.5 \\
\hline Other endocrine including thymus & 98 & 0.2 & 828 & 0.3 \\
\hline Lymphomas & 1,593 & 5.3 & 19,571 & 6.1 \\
\hline Hodgkin lymphoma & 134 & 0.4 & 954 & 0.3 \\
\hline Non-Hodgkin lymphoma & 1,459 & 4.9 & 18,617 & 5.7 \\
\hline Myeloma & 774 & 2.7 & 11,003 & 3.4 \\
\hline Leukemias & 1,677 & 5.1 & 21,833 & 6.8 \\
\hline Acute lymphocytic leukemia & 320 & 0.7 & 1,103 & 0.4 \\
\hline Chronic lymphocytic leukemia & 146 & 0.6 & 4,502 & 1.4 \\
\hline Acute myeloid leukemia & 666 & 2.0 & 9,032 & 2.8 \\
\hline Chronic myeloid leukemia & 70 & 0.2 & 916 & 0.3 \\
\hline Other leukemias & 475 & 1.6 & 6,280 & 2.0 \\
\hline Mesothelioma & 125 & 0.4 & 2,369 & 0.7 \\
\hline Miscellaneous & 2,238 & 7.5 & 37,898 & 11.5 \\
\hline
\end{tabular}

Abbreviation: $\mathrm{NOS}=$ not otherwise specified.

* Rates are the number of deaths per 100,000 persons and are age-adjusted to the 2000 U.S. standard population (19 age groups - Census P25-1130). For more information, see USCS technical notes (https://www.cdc.gov/cancer/ npcr/uscs/pdf/uscs-2013-technical-notes.pdf).

† Data are from the National Vital Statistics System (NVSS).

$\S$ Rates are not presented for persons of unknown ethnicity; therefore, categories do not sum to total. Data for specified ethnic populations should be interpreted with caution. For more information, see USCS technical notes (https://www.cdc. gov/cancer/npcr/uscs/pdf/uscs-2013-technical-notes.pdf\#nameddest=IntRace EthnicityData).

१ Counts and rates are suppressed if $<16$ cases were reported. 
TABLE 11. Reported number of invasive* cancer cases, all cancer sites combined, by state — United States, 2004-2013 ${ }^{\dagger}$

\begin{tabular}{|c|c|c|c|c|c|c|c|c|c|c|}
\hline State & 2004 & 2005 & 2006 & 2007 & 2008 & 2009 & 2010 & 2011 & 2012 & 2013 \\
\hline Alaska & 2,430 & 2,371 & 2,496 & 2,513 & 2,671 & 2,647 & 2,746 & 2,666 & 2,612 & 2,664 \\
\hline Alabama & 22,251 & 22,665 & 23,351 & 24,215 & 25,316 & 25,307 & 25,305 & 25,195 & 25,383 & 25,340 \\
\hline Arkansas & 13,918 & 14,203 & 14,417 & 14,871 & 14,833 & 14,984 & 15,190 & 15,151 & 15,512 & 15,879 \\
\hline Arizona & 24,196 & 24,629 & 25,784 & 27,018 & 26,803 & 28,295 & 27,622 & 28,743 & 28,545 & 28,418 \\
\hline California & 146,314 & 148,143 & 149,651 & 156,072 & 158,341 & 160,282 & 161,351 & 161,217 & 160,817 & 160,911 \\
\hline Colorado & 18,345 & 18,882 & 19,261 & 20,696 & 20,948 & 21,627 & 21,448 & 21,761 & 21,846 & 21,764 \\
\hline Connecticut & 19,474 & 19,775 & 20,534 & 20,587 & 20,692 & 21,069 & 20,773 & 20,665 & 20,592 & 20,510 \\
\hline District of Columbia & 2,742 & 2,765 & 2,751 & 2,972 & 2,728 & 2,807 & 2,939 & 3,135 & 3,003 & 2,780 \\
\hline Delaware & 4,495 & 4,799 & 5,058 & 5,141 & 5,239 & 5,277 & 5,281 & 5,466 & 5,459 & 5,681 \\
\hline Florida & 101,494 & 104,701 & 105,486 & 107,733 & 110,183 & 109,603 & 108,931 & 110,653 & 109,554 & 108,216 \\
\hline Georgia & 36,724 & 37,382 & 39,182 & 42,013 & 42,977 & 43,660 & 43,118 & 44,921 & 46,154 & 45,984 \\
\hline Hawaii & 6,013 & 6,103 & 6,194 & 6,406 & 6,640 & 6,773 & 6,730 & 6,788 & 6,852 & 7,000 \\
\hline Idaho & 6,170 & 6,573 & 6,766 & 7,171 & 7,148 & 7,366 & 7,431 & 7,551 & 7,538 & 7,358 \\
\hline Illinois & 61,518 & 61,898 & 63,773 & 64,956 & 66,301 & 66,557 & 65,198 & 66,369 & 65,130 & 64,959 \\
\hline Indiana & 30,156 & 30,659 & 31,712 & 32,023 & 32,417 & 32,423 & 32,677 & 32,864 & 32,543 & 32,372 \\
\hline lowa & 16,254 & 16,457 & 16,744 & 16,852 & 16,944 & 17,594 & 17,526 & 17,531 & 17,175 & 16,911 \\
\hline Kansas & 13,644 & 13,695 & 14,003 & 14,553 & 14,727 & 14,608 & 14,608 & 14,906 & 14,843 & 14,572 \\
\hline Kentucky & 22,498 & 22,774 & 23,960 & 24,527 & 24,697 & 24,919 & 25,484 & 25,669 & 26,191 & 26,068 \\
\hline Louisiana & 22,071 & 21,076 & 21,575 & 22,431 & 22,906 & 23,560 & 23,661 & 24,150 & 24,198 & 24,184 \\
\hline Massachusetts & 35,459 & 35,919 & 37,105 & 37,201 & 37,736 & 37,478 & 35,711 & 37,198 & 36,481 & 36,097 \\
\hline Maryland & 25,491 & 25,865 & 26,002 & 27,907 & 28,447 & 28,463 & 28,710 & 28,642 & 28,489 & 29,824 \\
\hline Maine & 8,347 & 8,305 & 8,628 & 8,542 & 8,472 & 8,356 & 8,385 & 8,336 & 8,481 & 8,366 \\
\hline Michigan & 52,128 & 52,819 & 53,501 & 55,831 & 53,580 & 54,009 & 55,167 & 55,617 & 53,248 & 52,067 \\
\hline Minnesota & 24,502 & 24,622 & 25,505 & 26,801 & 26,990 & 26,901 & 27,028 & 28,019 & 27,835 & 27,770 \\
\hline Missouri & 28,895 & 30,601 & 30,832 & 31,108 & 31,042 & 31,893 & 31,203 & 31,901 & 32,136 & 31,628 \\
\hline Mississippi & 13,506 & 13,663 & 14,235 & 15,005 & 15,328 & 15,033 & 15,460 & 15,361 & 15,343 & 15,482 \\
\hline Montana & 4,914 & 5,225 & 5,192 & 5,350 & 5,369 & 5,612 & 5,627 & 5,722 & 5,517 & 5,610 \\
\hline North Carolina & 41,513 & 43,778 & 44,991 & 46,870 & 47,706 & 49,465 & 49,546 & 50,395 & 49,248 & 49,970 \\
\hline North Dakota & 3,327 & 3,477 & 3,497 & 3,594 & 3,525 & 3,485 & 3,585 & 3,724 & 3,694 & 3,508 \\
\hline Nebraska & 8,807 & 9,031 & 9,171 & 9,398 & 9,216 & 8,851 & 9,158 & 9,204 & 9,018 & 9,176 \\
\hline Nevada & —§ & - & - & - & - & - & - & - & - & - \\
\hline New Hampshire & 7,002 & 7,233 & 7,280 & 7,448 & 7,714 & 7,618 & 7,742 & 7,971 & 7,745 & 7,886 \\
\hline New Jersey & 46,552 & 46,971 & 48,590 & 49,194 & 49,083 & 49,495 & 48,838 & 49,687 & 49,268 & 49,960 \\
\hline New Mexico & 8,247 & 8,272 & 8,486 & 8,775 & 8,984 & 9,021 & 9,006 & 8,851 & 8,815 & 8,728 \\
\hline New York & 100,219 & 101,660 & 104,618 & 106,397 & 108,138 & 108,711 & 106,341 & 110,138 & 106,911 & 109,560 \\
\hline Ohio & 58,765 & 60,115 & 60,763 & 61,490 & 63,211 & 62,975 & 61,175 & 62,348 & 60,801 & 62,802 \\
\hline Oklahoma & 17,758 & 17,875 & 18,960 & 19,744 & 18,857 & 18,957 & 18,637 & 18,897 & 19,082 & 19,044 \\
\hline Oregon & 18,499 & 18,682 & 19,112 & 19,376 & 20,370 & 19,909 & 19,727 & 20,636 & 20,035 & 20,458 \\
\hline Pennsylvania & 73,045 & 73,803 & 75,923 & 77,186 & 77,243 & 77,601 & 77,931 & 79,562 & 76,689 & 77,562 \\
\hline Rhode Island & 6,289 & 6,001 & 6,270 & 6,358 & 6,269 & 6,239 & 5,762 & 5,898 & 6,168 & 6,097 \\
\hline South Carolina & 21,118 & 21,933 & 22,555 & 23,504 & 23,576 & 23,883 & 24,638 & 24,737 & 25,399 & 24,809 \\
\hline South Dakota & 4,021 & 3,922 & 3,830 & 4,079 & 4,029 & 4,191 & 4,126 & 4,429 & 4,225 & 4,417 \\
\hline Tennessee & 27,702 & 30,218 & 30,998 & 32,100 & 32,957 & 34,014 & 33,854 & 34,374 & 34,363 & 34,142 \\
\hline Texas & 90,532 & 92,394 & 94,362 & 98,911 & 99,603 & 100,782 & 99,386 & 100,351 & 101,919 & 101,962 \\
\hline Utah & 7,763 & 7,920 & 8,309 & 8,517 & 8,859 & 9,108 & 9,496 & 9,712 & 9,681 & 9,626 \\
\hline Virginia & 33,484 & 34,571 & 35,351 & 37,244 & 37,308 & 37,846 & 36,402 & 37,277 & 36,744 & 38,151 \\
\hline Vermont & 3,387 & 3,460 & 3,718 & 3,602 & 3,529 & 3,681 & 3,659 & 3,630 & 3,609 & 3,510 \\
\hline Washington & 30,679 & 31,403 & 31,843 & 31,339 & 33,240 & 34,143 & 34,320 & 34,869 & 34,883 & 34,865 \\
\hline Wisconsin & 27,929 & 27,869 & 28,645 & 29,475 & 29,967 & 30,174 & 30,575 & 31,413 & 30,572 & 30,638 \\
\hline West Virginia & 10,741 & 11,071 & 11,250 & 11,546 & 11,296 & 11,352 & 11,231 & 11,638 & 11,336 & 11,327 \\
\hline
\end{tabular}

* Invasive cancer excludes basal and squamous cell carcinomas of the skin except when these occur on the skin of the genital organs, and in situ cancers except urinary bladder.

${ }^{\dagger}$ Data are compiled from cancer registries that meet the data quality criteria for all invasive cancer sites combined (all registries except Nevada, covering approximately $99 \%$ of the U.S. population). Registry-specific data quality information is available at https://www.cdc.gov/cancer/npcr/uscs/pdf/uscs-2013-technical-notes.pdf\#n ameddest=RegistriesPubCriteria.

$\S$ Counts are not presented for Nevada because data from Nevada did not meet USCS publication criteria for all the years from 2004 to 2013. 
TABLE 12. Reported rate* of invasive ${ }^{\dagger}$ cancer cases, all cancer sites combined, by state - United States, 2004-2013 $\$$

\begin{tabular}{|c|c|c|c|c|c|c|c|c|c|c|}
\hline State & 2004 & 2005 & 2006 & 2007 & 2008 & 2009 & 2010 & 2011 & 2012 & 2013 \\
\hline Alaska & 511.2 & 481.2 & 486.2 & 471.6 & 479.5 & 460.5 & 458.7 & 430.7 & 404.0 & 410.4 \\
\hline Alabama & 460.6 & 461.7 & 464.7 & 473.4 & 485.0 & 477.2 & 466.6 & 457.7 & 453.8 & 444.0 \\
\hline Arkansas & 462.1 & 465.1 & 461.3 & 468.4 & 457.6 & 455.2 & 453.5 & 445.0 & 450.1 & 454.0 \\
\hline Arizona & 418.1 & 408.7 & 413.1 & 419.1 & 405.9 & 415.7 & 394.8 & 399.8 & 384.7 & 370.6 \\
\hline California & 451.6 & 448.1 & 446.1 & 455.5 & 451.0 & 445.6 & 437.2 & 425.6 & 414.0 & 402.8 \\
\hline Colorado & 447.1 & 447.1 & 439.7 & 456.9 & 447.0 & 445.2 & 429.4 & 423.1 & 409.8 & 396.1 \\
\hline Connecticut & 507.5 & 510.0 & 524.5 & 518.6 & 511.4 & 514.1 & 499.7 & 490.4 & 482.3 & 474.2 \\
\hline District of Columbia & 487.4 & 487.0 & 488.7 & 523.8 & 477.2 & 482.2 & 494.6 & 516.6 & 482.4 & 445.2 \\
\hline Delaware & 507.7 & 525.8 & 537.5 & 529.1 & 526.3 & 516.6 & 507.6 & 511.8 & 496.7 & 502.0 \\
\hline Florida & 470.9 & 474.1 & 469.7 & 470.9 & 471.9 & 460.6 & 447.8 & 444.3 & 428.5 & 413.0 \\
\hline Georgia & 476.6 & 468.9 & 473.0 & 490.3 & 485.5 & 480.1 & 459.5 & 468.3 & 465.0 & 450.3 \\
\hline Hawaii & 435.2 & 430.2 & 427.4 & 434.2 & 438.7 & 438.9 & 425.6 & 421.8 & 418.1 & 419.8 \\
\hline Idaho & 463.1 & 478.0 & 473.0 & 484.4 & 467.3 & 467.6 & 458.0 & 454.4 & 442.2 & 419.5 \\
\hline Illinois & 492.8 & 490.0 & 500.1 & 501.6 & 503.5 & 497.8 & 479.9 & 480.8 & 463.8 & 454.9 \\
\hline Indiana & 476.4 & 477.3 & 485.4 & 481.5 & 477.4 & 469.5 & 465.4 & 460.3 & 448.8 & 438.8 \\
\hline lowa & 485.3 & 487.6 & 490.4 & 487.7 & 485.1 & 497.0 & 489.5 & 484.4 & 468.0 & 456.1 \\
\hline Kansas & 481.1 & 477.7 & 481.9 & 493.6 & 492.0 & 479.4 & 473.5 & 477.6 & 467.4 & 450.9 \\
\hline Kentucky & 521.9 & 518.1 & 533.8 & 535.1 & 528.3 & 523.3 & 526.4 & 521.6 & 522.1 & 511.7 \\
\hline Louisiana & 497.0 & 481.1 & 493.8 & 501.1 & 500.3 & 502.0 & 495.4 & 494.5 & 485.8 & 476.3 \\
\hline Massachusetts & 514.3 & 517.0 & 529.8 & 523.3 & 522.0 & 509.5 & 477.9 & 489.3 & 471.9 & 457.5 \\
\hline Maryland & 463.9 & 463.1 & 458.1 & 482.3 & 482.3 & 469.1 & 465.4 & 452.3 & 440.2 & 451.0 \\
\hline Maine & 544.7 & 534.0 & 544.8 & 527.8 & 512.8 & 499.1 & 493.4 & 484.0 & 478.7 & 463.8 \\
\hline Michigan & 504.2 & 504.5 & 504.2 & 517.1 & 489.8 & 485.8 & 489.1 & 485.1 & 456.8 & 440.1 \\
\hline Minnesota & 481.2 & 475.7 & 483.3 & 496.5 & 488.5 & 476.9 & 471.3 & 477.7 & 462.8 & 451.8 \\
\hline Missouri & 470.3 & 490.5 & 485.7 & 481.5 & 471.8 & 476.2 & 458.4 & 462.2 & 457.6 & 442.6 \\
\hline Mississippi & 468.1 & 469.2 & 479.5 & 495.1 & 498.4 & 482.2 & 485.8 & 474.6 & 465.3 & 459.9 \\
\hline Montana & 473.6 & 492.2 & 478.2 & 475.6 & 467.3 & 476.9 & 472.2 & 468.8 & 442.1 & 437.0 \\
\hline North Carolina & 478.1 & 490.3 & 486.6 & 490.2 & 483.8 & 489.3 & 477.6 & 473.3 & 450.8 & 445.4 \\
\hline North Dakota & 462.9 & 479.8 & 475.8 & 485.2 & 467.5 & 458.7 & 462.9 & 470.0 & 464.0 & 433.6 \\
\hline Nebraska & 479.3 & 485.0 & 485.9 & 490.7 & 473.6 & 449.0 & 456.4 & 453.8 & 435.7 & 437.6 \\
\hline Nevada & - & - & - & - & - & - & - & - & - & - \\
\hline New Hampshire & 523.9 & 530.6 & 519.3 & 517.8 & 524.6 & 506.3 & 502.0 & 510.8 & 484.6 & 479.2 \\
\hline New Jersey & 508.9 & 509.4 & 522.0 & 521.7 & 512.8 & 509.6 & 494.6 & 496.9 & 484.4 & 483.1 \\
\hline New Mexico & 431.0 & 420.4 & 416.5 & 419.0 & 418.8 & 409.4 & 397.0 & 381.7 & 374.7 & 363.7 \\
\hline New York & 496.2 & 499.5 & 511.0 & 513.1 & 514.8 & 510.0 & 492.1 & 501.2 & 479.8 & 484.3 \\
\hline Ohio & 479.4 & 485.3 & 484.3 & 482.5 & 488.6 & 480.8 & 459.7 & 463.0 & 444.8 & 452.4 \\
\hline Oklahoma & 477.6 & 475.0 & 494.7 & 505.9 & 474.8 & 467.8 & 452.4 & 451.5 & 449.5 & 440.3 \\
\hline Oregon & 484.8 & 477.6 & 475.0 & 470.6 & 482.3 & 461.5 & 447.5 & 458.1 & 432.5 & 431.5 \\
\hline Pennsylvania & 502.5 & 503.9 & 512.8 & 515.2 & 509.9 & 506.8 & 502.8 & 507.5 & 482.9 & 483.0 \\
\hline Rhode Island & 530.8 & 508.5 & 526.6 & 532.4 & 519.1 & 512.6 & 468.7 & 476.6 & 488.9 & 479.4 \\
\hline South Carolina & 484.2 & 490.4 & 485.8 & 489.0 & 475.0 & 469.2 & 472.1 & 463.4 & 459.8 & 436.9 \\
\hline South Dakota & 476.5 & 459.9 & 440.3 & 460.9 & 448.2 & 459.6 & 443.2 & 467.5 & 439.6 & 450.1 \\
\hline Tennessee & 449.7 & 479.2 & 478.8 & 483.3 & 484.0 & 489.9 & 476.6 & 472.9 & 463.6 & 450.9 \\
\hline Texas & 467.9 & 464.3 & 457.7 & 465.3 & 454.4 & 445.8 & 427.3 & 417.6 & 411.5 & 399.4 \\
\hline Utah & 426.4 & 419.7 & 423.4 & 419.2 & 421.7 & 419.9 & 424.5 & 422.9 & 408.4 & 393.2 \\
\hline Virginia & 455.7 & 458.8 & 458.9 & 471.4 & 462.0 & 457.4 & 428.8 & 429.3 & 414.0 & 418.5 \\
\hline Vermont & 499.5 & 501.2 & 529.0 & 501.3 & 479.1 & 492.8 & 481.0 & 469.9 & 457.0 & 437.1 \\
\hline Washington & 505.3 & 504.3 & 496.9 & 475.4 & 491.6 & 490.1 & 479.6 & 476.3 & 463.3 & 450.3 \\
\hline Wisconsin & 480.8 & 472.5 & 478.5 & 483.4 & 482.4 & 477.8 & 476.5 & 479.3 & 457.7 & 451.1 \\
\hline West Virginia & 491.8 & 501.2 & 503.1 & 507.9 & 491.5 & 488.1 & 477.7 & 489.7 & 470.7 & 464.0 \\
\hline Wyoming & 451.2 & 427.5 & 454.2 & 436.1 & 438.1 & 426.5 & 432.9 & 437.2 & 398.0 & 382.0 \\
\hline
\end{tabular}

* Rates are the number of cases per 100,000 persons and are age-adjusted to the 2000 U.S. standard population (19 age groups - Census P25-1130). For more information, see USCS technical notes (https://www.cdc.gov/cancer/npcr/uscs/pdf/uscs-2013-technical-notes.pdf).

${ }^{\dagger}$ Invasive cancer excludes basal and squamous cell carcinomas of the skin except when these occur on the skin of the genital organs, and in situ cancers except urinary bladder.

$\S$ Data are compiled from cancer registries that meet the data quality criteria for all invasive cancer sites combined (all registries except Nevada, covering approximately $99 \%$ of the U.S. population). Registry-specific data quality information is available at https://www.cdc.gov/cancer/npcr/uscs/pdf/uscs-2013-technical-notes.pdf\#n ameddest=RegistriesPubCriteria.

I Rates are not presented for Nevada because data from Nevada did not meet USCS publication criteria for all the years from 2004 to 2013. 
TABLE 13. Reported number of cancer deaths, all cancer sites combined, by state — United States, 2004-2013*

\begin{tabular}{|c|c|c|c|c|c|c|c|c|c|c|}
\hline State & 2004 & 2005 & 2006 & 2007 & 2008 & 2009 & 2010 & 2011 & 2012 & 2013 \\
\hline Alabama & 9,756 & 9,913 & 9,899 & 10,025 & 10,182 & 10,289 & 10,196 & 10,233 & 10,274 & 10,328 \\
\hline Alaska & 728 & 732 & 790 & 839 & 867 & 895 & 884 & 935 & 925 & 1,016 \\
\hline Arizona & 9,618 & 9,820 & 9,918 & 10,133 & 10,081 & 10,271 & 10,678 & 10,690 & 11,085 & 11,347 \\
\hline Arkansas & 6,304 & 6,361 & 6,177 & 6,388 & 6,526 & 6,513 & 6,475 & 6,497 & 6,540 & 6,688 \\
\hline California & 53,700 & 54,729 & 54,140 & 55,011 & 54,686 & 55,990 & 56,453 & 56,448 & 57,675 & 57,714 \\
\hline Colorado & 6,196 & 6,395 & 6,550 & 6,617 & 6,719 & 6,950 & 7,035 & 7,051 & 7,306 & 7,357 \\
\hline Connecticut & 7,174 & 7,052 & 7,044 & 6,827 & 6,830 & 6,819 & 6,954 & 6,837 & 6,681 & 6,619 \\
\hline Delaware & 1,827 & 1,799 & 1,780 & 1,852 & 1,912 & 1,813 & 1,909 & 1,905 & 1,935 & 1,905 \\
\hline District of Columbia & 1,152 & 1,150 & 1,178 & 1,169 & 1,143 & 1,131 & 1,041 & 1,070 & 1,081 & 1,095 \\
\hline Florida & 39,840 & 40,592 & 40,415 & 40,088 & 40,814 & 40,931 & 41,467 & 41,681 & 42,187 & 42,734 \\
\hline Georgia & 14,313 & 14,358 & 14,474 & 14,983 & 14,621 & 15,139 & 15,435 & 15,602 & 16,020 & 16,417 \\
\hline Hawaii & 2,088 & 2,169 & 2,171 & 2,214 & 2,194 & 2,244 & 2,266 & 2,278 & 2,284 & 2,332 \\
\hline Idaho & 2,227 & 2,368 & 2,306 & 2,405 & 2,511 & 2,458 & 2,530 & 2,573 & 2,572 & 2,707 \\
\hline Illinois & 24,289 & 24,250 & 24,083 & 24,113 & 24,298 & 24,182 & 24,070 & 24,006 & 24,562 & 24,491 \\
\hline Indiana & 12,552 & 12,796 & 12,903 & 12,778 & 13,136 & 13,093 & 13,164 & 13,180 & 13,368 & 13,258 \\
\hline lowa & 6,340 & 6,453 & 6,359 & 6,376 & 6,424 & 6,249 & 6,358 & 6,481 & 6,438 & 6,509 \\
\hline Kansas & 5,312 & 5,428 & 5,343 & 5,406 & 5,294 & 5,319 & 5,377 & 5,440 & 5,429 & 5,379 \\
\hline Kentucky & 9,159 & 9,505 & 9,394 & 9,692 & 9,589 & 9,634 & 9,930 & 9,733 & 10,012 & 10,082 \\
\hline Louisiana & 9,434 & 9,249 & 8,853 & 8,736 & 9,197 & 9,098 & 9,203 & 9,233 & 9,308 & 9,419 \\
\hline Maine & 3,124 & 3,218 & 3,089 & 3,112 & 3,093 & 3,133 & 3,247 & 3,201 & 3,226 & 3,227 \\
\hline Maryland & 10,168 & 10,371 & 10,350 & 10,179 & 10,360 & 10,412 & 10,268 & 10,249 & 10,524 & 10,608 \\
\hline Massachusetts & 13,337 & 13,182 & 13,407 & 13,003 & 13,031 & 13,112 & 12,993 & 12,895 & 12,864 & 12,858 \\
\hline Michigan & 19,653 & 20,094 & 20,192 & 20,087 & 20,211 & 20,257 & 20,620 & 20,420 & 20,496 & 20,367 \\
\hline Minnesota & 9,093 & 8,823 & 9,079 & 9,176 & 9,446 & 9,580 & 9,612 & 9,489 & 9,424 & 9,601 \\
\hline Mississippi & 5,983 & 6,065 & 6,236 & 6,001 & 6,165 & 6,130 & 6,271 & 6,278 & 6,496 & 6,527 \\
\hline Missouri & 12,449 & 12,417 & 12,519 & 12,380 & 12,522 & 12,472 & 12,626 & 12,473 & 12,919 & 12,955 \\
\hline Montana & 1,867 & 1,956 & 1,943 & 1,921 & 1,862 & 1,914 & 1,923 & 2,022 & 1,954 & 1,997 \\
\hline Nebraska & 3,270 & 3,355 & 3,430 & 3,479 & 3,376 & 3,336 & 3,438 & 3,410 & 3,479 & 3,459 \\
\hline Nevada & 4,119 & 4,238 & 4,225 & 4,331 & 4,404 & 4,461 & 4,529 & 4,605 & 4,610 & 4,817 \\
\hline New Hampshire & 2,554 & 2,549 & 2,534 & 2,609 & 2,576 & 2,562 & 2,525 & 2,740 & 2,660 & 2,584 \\
\hline New Jersey & 17,206 & 17,171 & 17,180 & 17,096 & 16,874 & 16,540 & 16,815 & 16,708 & 16,483 & 16,315 \\
\hline New Mexico & 3,035 & 3,141 & 3,147 & 3,236 & 3,355 & 3,202 & 3,358 & 3,328 & 3,461 & 3,481 \\
\hline New York & 36,100 & 35,555 & 35,283 & 35,485 & 35,351 & 35,215 & 35,431 & 35,469 & 35,881 & 35,735 \\
\hline North Carolina & 16,477 & 16,724 & 17,318 & 17,478 & 17,453 & 17,513 & 18,060 & 18,284 & 18,405 & 18,589 \\
\hline North Dakota & 1,265 & 1,302 & 1,387 & 1,264 & 1,354 & 1,243 & 1,269 & 1,321 & 1,253 & 1,286 \\
\hline Ohio & 24,940 & 24,702 & 24,975 & 25,230 & 24,998 & 25,149 & 25,083 & 25,140 & 25,261 & 24,986 \\
\hline Oklahoma & 7,269 & 7,446 & 7,491 & 7,727 & 7,657 & 7,639 & 7,831 & 7,997 & 8,040 & 8,039 \\
\hline Oregon & 7,236 & 7,326 & 7,309 & 7,393 & 7,479 & 7,487 & 7,638 & 7,802 & 7,832 & 7,799 \\
\hline Pennsylvania & 29,422 & 29,615 & 29,170 & 29,013 & 28,963 & 28,879 & 29,055 & 28,895 & 28,907 & 28,512 \\
\hline Rhode Island & 2,418 & 2,291 & 2,250 & 2,213 & 2,227 & 2,220 & 2,266 & 2,170 & 2,148 & 2,326 \\
\hline South Carolina & 8,348 & 8,652 & 8,853 & 8,867 & 9,199 & 9,123 & 9,356 & 9,543 & 9,728 & 9,745 \\
\hline South Dakota & 1,555 & 1,612 & 1,570 & 1,612 & 1,570 & 1,503 & 1,655 & 1,665 & 1,630 & 1,577 \\
\hline Tennessee & 12,586 & 12,995 & 13,051 & 13,161 & 13,162 & 13,482 & 13,593 & 13,562 & 13,765 & 13,953 \\
\hline Texas & 33,937 & 34,291 & 34,938 & 35,074 & 35,712 & 35,591 & 36,717 & 37,351 & 38,142 & 38,412 \\
\hline Utah & 2,445 & 2,520 & 2,615 & 2,572 & 2,492 & 2,555 & 2,810 & 2,746 & 2,876 & 2,971 \\
\hline Vermont & 1,212 & 1,202 & 1,214 & 1,346 & 1,279 & 1,254 & 1,392 & 1,347 & 1,325 & 1,318 \\
\hline Virginia & 13,384 & 13,877 & 13,828 & 14,009 & 13,983 & 14,122 & 14,078 & 14,374 & 14,294 & 14,414 \\
\hline Washington & 10,989 & 11,048 & 11,055 & 11,568 & 11,618 & 11,922 & 11,874 & 12,002 & 11,951 & 11,928 \\
\hline West Virginia & 4,694 & 4,617 & 4,613 & 4,690 & 4,605 & 4,786 & 4,685 & 4,782 & 4,684 & 4,718 \\
\hline Wisconsin & 10,861 & 10,943 & 10,925 & 10,963 & 11,185 & 10,866 & 11,279 & 11,608 & 11,252 & 11,425 \\
\hline Wyoming & 875 & 886 & 927 & 940 & 874 & 936 & 1,016 & 936 & 955 & 946 \\
\hline
\end{tabular}

* Data are from the National Vital Statistics System (NVSS). 
TABLE 14. Reported rate* of cancer deaths, all cancer sites combined, by state - United States, 2004-2013 ${ }^{\dagger}$

\begin{tabular}{|c|c|c|c|c|c|c|c|c|c|c|}
\hline State & 2004 & 2005 & 2006 & 2007 & 2008 & 2009 & 2010 & 2011 & 2012 & 2013 \\
\hline Alabama & 204.6 & 204.7 & 199.8 & 198.5 & 197.3 & 196.3 & 190.7 & 187.4 & 184.8 & 182.1 \\
\hline Alaska & 185.9 & 173.3 & 179.7 & 185.2 & 183.2 & 186.5 & 178.4 & 176.4 & 169.1 & 173.1 \\
\hline Arizona & 167.4 & 164.2 & 160.0 & 158.8 & 153.2 & 152.0 & 152.6 & 148.3 & 148.1 & 146.4 \\
\hline Arkansas & 208.3 & 207.5 & 196.6 & 201.0 & 201.1 & 198.0 & 193.7 & 191.2 & 188.6 & 189.6 \\
\hline California & 169.4 & 169.2 & 164.8 & 163.9 & 158.9 & 158.8 & 155.8 & 151.8 & 150.7 & 146.6 \\
\hline Colorado & 159.9 & 160.5 & 158.4 & 154.7 & 151.2 & 151.9 & 148.8 & 144.2 & 143.7 & 139.2 \\
\hline Connecticut & 182.0 & 176.7 & 175.3 & 167.0 & 164.7 & 162.8 & 162.4 & 158.1 & 152.0 & 147.8 \\
\hline Delaware & 208.0 & 199.1 & 190.6 & 193.3 & 192.7 & 178.0 & 184.4 & 179.8 & 176.2 & 167.1 \\
\hline District of Columbia & 206.2 & 206.2 & 210.8 & 208.8 & 201.8 & 196.9 & 178.4 & 180.8 & 178.4 & 177.7 \\
\hline Florida & 178.9 & 177.9 & 174.2 & 169.3 & 168.8 & 165.9 & 163.8 & 160.0 & 157.6 & 154.9 \\
\hline Georgia & 196.3 & 190.8 & 184.9 & 186.1 & 175.7 & 176.3 & 173.9 & 171.0 & 169.6 & 168.1 \\
\hline Hawaii & 150.2 & 151.4 & 148.2 & 147.5 & 142.0 & 141.3 & 140.5 & 138.6 & 134.4 & 134.9 \\
\hline Idaho & 169.8 & 174.7 & 163.6 & 166.5 & 166.9 & 159.0 & 158.6 & 157.7 & 152.2 & 156.3 \\
\hline Illinois & 194.9 & 192.4 & 188.9 & 186.6 & 185.0 & 181.7 & 177.9 & 174.7 & 175.4 & 171.7 \\
\hline Indiana & 199.2 & 200.0 & 198.0 & 192.9 & 194.4 & 190.4 & 187.6 & 185.2 & 184.2 & 179.4 \\
\hline lowa & 181.8 & 183.1 & 178.6 & 176.5 & 176.4 & 169.6 & 170.7 & 172.4 & 167.9 & 168.2 \\
\hline Kansas & 182.8 & 185.5 & 180.0 & 178.6 & 173.1 & 171.5 & 170.4 & 170.1 & 167.7 & 162.9 \\
\hline Kentucky & 215.8 & 219.5 & 212.5 & 215.0 & 208.0 & 204.8 & 207.4 & 200.9 & 201.2 & 199.3 \\
\hline Louisiana & 216.6 & 215.4 & 206.9 & 199.2 & 205.8 & 198.6 & 196.4 & 193.5 & 190.4 & 188.7 \\
\hline Maine & 202.1 & 204.8 & 192.8 & 189.8 & 184.6 & 185.4 & 186.6 & 181.7 & 179.0 & 174.8 \\
\hline Maryland & 190.9 & 190.7 & 187.4 & 180.9 & 180.6 & 176.7 & 170.2 & 166.0 & 165.9 & 163.0 \\
\hline Massachusetts & 189.8 & 186.0 & 187.3 & 179.2 & 176.9 & 175.3 & 170.0 & 166.7 & 163.3 & 159.7 \\
\hline Michigan & 191.1 & 192.7 & 190.8 & 186.4 & 184.5 & 182.0 & 182.0 & 177.4 & 174.3 & 170.2 \\
\hline Minnesota & 176.8 & 169.1 & 171.0 & 168.4 & 170.3 & 168.7 & 166.1 & 160.5 & 155.6 & 155.1 \\
\hline Mississippi & 210.2 & 211.3 & 213.2 & 201.9 & 202.8 & 199.7 & 200.4 & 196.7 & 200.0 & 196.5 \\
\hline Missouri & 201.0 & 197.9 & 195.9 & 190.9 & 189.5 & 185.4 & 184.7 & 179.4 & 182.0 & 179.1 \\
\hline Montana & 179.2 & 184.3 & 177.9 & 170.9 & 161.2 & 162.8 & 159.9 & 164.6 & 154.2 & 154.0 \\
\hline Nebraska & 173.6 & 175.1 & 176.7 & 176.3 & 169.9 & 164.7 & 166.6 & 164.3 & 164.7 & 160.7 \\
\hline Nevada & 192.5 & 191.7 & 185.5 & 181.3 & 179.8 & 175.6 & 173.5 & 170.3 & 163.7 & 164.9 \\
\hline New Hampshire & 195.5 & 189.9 & 184.3 & 185.1 & 177.6 & 173.3 & 167.7 & 177.9 & 167.9 & 158.6 \\
\hline New Jersey & 186.9 & 185.0 & 183.2 & 179.8 & 175.0 & 168.8 & 168.7 & 165.7 & 160.1 & 156.0 \\
\hline New Mexico & 162.5 & 163.1 & 158.8 & 158.3 & 160.7 & 149.0 & 151.3 & 146.7 & 147.8 & 145.1 \\
\hline New York & 177.7 & 173.5 & 171.1 & 169.7 & 166.6 & 163.9 & 162.1 & 159.6 & 159.4 & 155.5 \\
\hline North Carolina & 194.0 & 191.6 & 191.8 & 187.3 & 181.3 & 177.0 & 177.9 & 174.8 & 170.4 & 167.7 \\
\hline North Dakota & 166.2 & 169.9 & 179.8 & 162.3 & 171.2 & 155.6 & 156.1 & 160.4 & 150.6 & 150.8 \\
\hline Ohio & 202.1 & 198.1 & 197.5 & 196.3 & 191.6 & 190.1 & 186.6 & 184.5 & 182.1 & 177.4 \\
\hline Oklahoma & 196.0 & 198.0 & 195.3 & 198.5 & 193.0 & 189.3 & 190.4 & 191.2 & 189.4 & 185.4 \\
\hline Oregon & 188.8 & 186.8 & 181.4 & 178.7 & 176.8 & 172.5 & 172.8 & 172.4 & 168.2 & 163.2 \\
\hline Pennsylvania & 195.7 & 195.2 & 190.3 & 186.4 & 184.1 & 181.7 & 180.5 & 177.4 & 174.8 & 170.0 \\
\hline Rhode Island & 196.4 & 186.5 & 181.8 & 177.8 & 177.5 & 173.7 & 176.7 & 168.5 & 163.3 & 173.9 \\
\hline South Carolina & 195.9 & 198.3 & 195.0 & 188.4 & 190.3 & 182.8 & 182.6 & 182.3 & 179.1 & 174.0 \\
\hline South Dakota & 177.3 & 181.7 & 172.7 & 174.1 & 167.9 & 158.4 & 169.8 & 168.6 & 162.1 & 154.1 \\
\hline Tennessee & 208.4 & 210.6 & 205.0 & 201.6 & 197.1 & 197.7 & 194.6 & 189.1 & 187.8 & 185.4 \\
\hline Texas & 182.6 & 179.5 & 176.7 & 172.3 & 170.4 & 164.8 & 165.1 & 162.5 & 160.3 & 156.9 \\
\hline Utah & 141.0 & 141.0 & 140.2 & 133.6 & 125.8 & 124.9 & 133.0 & 125.6 & 128.8 & 127.9 \\
\hline Vermont & 180.1 & 176.1 & 173.2 & 188.7 & 176.2 & 169.2 & 182.6 & 175.9 & 164.7 & 164.1 \\
\hline Virginia & 189.0 & 190.6 & 185.8 & 184.1 & 179.4 & 176.4 & 171.7 & 170.8 & 165.2 & 162.3 \\
\hline Washington & 184.9 & 181.4 & 175.9 & 179.4 & 175.9 & 175.1 & 169.7 & 166.9 & 161.8 & 156.3 \\
\hline West Virginia & 212.3 & 207.6 & 204.0 & 204.3 & 197.9 & 203.3 & 196.6 & 199.7 & 191.1 & 190.5 \\
\hline Wisconsin & 184.6 & 182.9 & 180.1 & 177.3 & 177.8 & 169.5 & 173.8 & 174.8 & 166.0 & 164.6 \\
\hline Wyoming & 172.1 & 169.3 & 174.5 & 173.4 & 157.0 & 163.8 & 170.1 & 155.9 & 154.2 & 147.7 \\
\hline
\end{tabular}

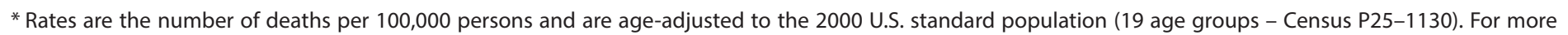
information, see USCS technical notes (https://www.cdc.gov/cancer/npcr/uscs/pdf/uscs-2013-technical-notes.pdf).

† Data are from the National Vital Statistics System (NVSS). 


The Morbidity and Mortality Weekly Report (MMWR) Series is prepared by the Centers for Disease Control and Prevention (CDC) and is available free of charge in electronic format. To receive an electronic copy each week, visit $M M W R$ 's free subscription page at https://www.cdc.gov/mmwr $/ \mathrm{mmwrsubscribe.html}$. Paper copy subscriptions are available through the Superintendent of Documents, U.S. Government Printing Office, Washington, DC 20402; telephone 202-512-1800.

Readers who have difficulty accessing this PDF file may access the HTML file at https://www.cdc.gov/mmwr/volumes/66/ss/ss6604a1.htm?s_cid=ss6604a1_w. Address all inquiries about the $M M W R$ Series, including material to be considered for publication, to Executive Editor, MMWR Series, Mailstop E-90, CDC, 1600 Clifton Rd., N.E., Atlanta, GA 30329-4027 or to mmwrq@cdc.gov.

All material in the MMWR Series is in the public domain and may be used and reprinted without permission; citation as to source, however, is appreciated. Use of trade names and commercial sources is for identification only and does not imply endorsement by the U.S. Department of Health and Human Services.

References to non-CDC sites on the Internet are provided as a service to $M M W R$ readers and do not constitute or imply endorsement of these organizations or their programs by CDC or the U.S. Department of Health and Human Services. CDC is not responsible for the content of these sites. URL addresses listed in $M M W R$ were current as of the date of publication.

ISSN: 1546-0738 (Print) 